\title{
Hans-Joachim Dreyer
}

\section{Petr Veršigora}

\section{"Ljudi s cistoj šovest'ju" \\ Veränderungen eines Partisanenromans unter dem Einfluß der Politik}

Verlag Otto Sagner München · Berlin · Washington D.C.

Digitalisiert im Rahmen der Kooperation mit dem DFG-Projekt „Digi20“

der Bayerischen Staatsbibliothek, München. OCR-Bearbeitung und Erstellung des eBooks durch den Verlag Otto Sagner:

http://verlag.kubon-sagner.de

() bei Verlag Otto Sagner. Eine Verwertung oder Weitergabe der Texte und Abbildungen, insbesondere durch Vervielfältigung, ist ohne vorherige schriftliche Genehmigung des Verlages unzulässig. 
ARBEITEN UND TEXTE ZUR SLAVISTIK · 9 HERAUSGEGEBEN VON WOLFGANG KASACK

Hans-Joachim Dreyer

PETR VERŠIGORA

"LJUDI S ČISTOI SOVESTJU"

Veränderungen eines Partisanenromans unter dem Einfluß der Politik

1976

München Verlag Otto Sagnerin Kommission 


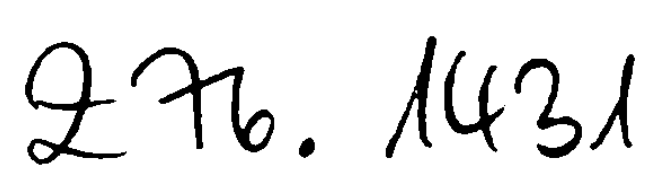

In der slavistik fehlen bisher sowoht Untersuchungen zur sowjetischen Partisanenliteratur als auch zu Petr Versigora.Die vorliegende Analyse, eine iberarbeitete Fassung der Hausarbeit zur Ersten Philologischen Staatsprüfung für das Lehramt am Gymasium, ist ein erster Beitrag, diese Forschungslücke zu füllen. Möge ihre Veröffentlichung der weiteren Erforschung der russischen sowjetischen Literatur und ihrem Verständnis dienen.

Bayerische Staatsbibllothek

Münction

Als Manuskript vervielfätigt

Alle Rechte vorbehalten

ISBN $387690 \quad 1146$

Gesamtherstellung Walter Kleikamp - Koln

7711366 
A Einleitung 1

B Der Autor und sein Werk

1. Petr Petrovid Versigora

2. Die Fartisanendichtung im literarischen Schaffen der Kriegs- und Nachkriegszeit

3. "Ljudi s cistoj sovest'ju" im Spiegel von Presse- und Literaturkritik

C Versigoras Dokumentarroman im Nandel der Sowjetpolitik

1. Beobachtungen zum Zensurmechanismus innerhalb der einzelnen Romanteile

2. Die Folgen der gewandelten Parteimeinung

3. Die Korrektur der organisatorischen Rolle der Partei in Partisanenkampf

a) Zum historischen Forschungsstand

b) Der "Rejd za Dnepr" im Spannungsfeld zweier Parteidoktrinen

c) Der "Karpatskij rejd" in Vergleich mit der Fassung von 1959

4. Die Revision der militärischen Koordinierung zwischen Partisanenbewegung und Roter Armee

a) Historischer Forschungsstand

b) Die Urfassungen von 1945/46 und 1950 in Vergleich mit der Fassung von 1959

5. Die Idealisierung des Partisanenbildes

a) Die Revision der Romentik des Partisanenlebens

b) Die Eliminierung von Disziplinmängeln: Der Partisan als "Wensch mit reinem Gewissen"

c) Die Verschleierung der dem Partisanenkrieg immanenten militärischen Eigengesetzlichkeit

6. Die Revidierung antisowjetischer Fartisanenaktionen

7. Der Rückgriff auf die Tradition des Partisanenkrieges

8. Der Abbau kosmopolitischer Tendenzen 
D Verłigoras "Ljudi s Cistoj sovest'ju" im Zeichen der Entstalinisierung

1. Der Abbau des Personenkultes in Versigoras Dokumentarroman

2. Die ersatzlose Streichung der die Person Stalins verher lichenden Textstellen

3. Die Ergetzung Stalins durch paraphrasierende Begriffe

E Die Reaktion auf die Kampagne gegen den Personenkult und die Aufwertung Stalins

1. Die Auswirkungen der Aufwertung Stalins in Veršigoras "Ljudi s Xistoj sovest'ju"

2. Die ersten Anzeichen eines neuen Fuihrerkultes

$F$ Die Feindbildverschiebung als Ergebnis des Wandels von Innen- und AuBenpolitik

1. Statistische Analyse

2. Die historischen Ursachen

3. Einige Anmerkungen zur ideologischen Komponente der Feindbildverschiebung

G Ausblick

Abkürzungsverzeichnis

Originalitate der Primärliteratur

Bibliographie 
Ber Versuch, die EinfluBnahme der Sowjetpolitik auf die literarische Darstellung der Partisanentätigkeit im Zweiten Weltkrieg aus den einzelnen Fassungen von Verłigoras "Ljudl s distoj sovest'ju" herauszulesen, erwies sich als ergebnisreich, obwohl von den insgessmt neun erschienenen Ausgaben nur drei einsehbar waren.' $\mathrm{Da}$ sich aus diesem Grunde eine Reihe von gravierenden Textvariationen zeitlich nicht genau fixieren lieben, muBten punktuell die Ergebnisse der historischen Forschung zum Partisanenkrieg herangezogen werden. Leider vermittelten jedoch die bisher erstellten Studien ein nur wenis objektives, auf den gröBeren politischen Zusammenhang hinweisendes Bild von den Geschehnissen an der sonjetischen Partisanenfront des 2 weiten Weltkrieges. Während sich in den Ergebnissen von deutscher Selte auf Grund des besonderen Themenkreises eine gewisse Zurückhaltung manifestiert, benutzt die historische wissenschaft der Sowjetunion, die keine wertungsfreie Betrachtungsweise kennt, den Partisanenkrieg, um die Festigkelt des von der kommunistischen Ideologie getragenen Staatswesens zu propagieren. Bedenkt man in diesem Zusammenhang, daB selbst Erich Hesse in seiner Dissertation "Der sowjetrussische Partisanenkrieg 1941 bis 1944 in Spiegel deutscher Kampranweisungen und Befeh$1 e^{\prime 2}$ die Dokumentarromane von Versigora, Kovpak, Fedorov und Ignatov (alle verwendeten Ausgaben stammen aus den spëten füfíger Jahren) zur Beweisfuhrung heranzieht, ohne zu überprüfen, ob es $81 \mathrm{ch}$ um revidierte Fassungen handelt, so wird ersichtlich, wie erforderlich eine detaillierte Ontersuchung unter dem Aspekt des gewählten Themas ist. Zwar bemängelt der Historiker John A.Armstrong die bestehende Forschungslücke, unternimmt selbst jedoch nichts, um diese aufuarbeitens

"It is evident that the publication of documents, memoirs, and histories on partisan activity has been closely related to shifts in the 'general line' of Communist propaganda and to power rivolries in the Soviet regime. A detalled investigation of these relationships would require close examination, employing the tools of content analysis, of the themes treated in books appearing at various times. Such an in-

1 Bei den nicht erheltlichen Ausgaben handelt es sich un die Fassungen von 1946, 1947, 1950, 1951, 1953 und 1955.

2 E.Hesse, Der sowjetrussische Partisanenkrieg 1941 bis 1944 im Splegel deutscher Kampfanwelsungen und Befehle (1969). 
vestigation would also include careful comparisons of the textua: variations, small but often significant, in successive editions of the same book. In the absence of such a detailed investigation, the observations presented in the following paragraphs are necessariliy impressionistic."1

Die vorliegende Arbeit versucht, dieses Versäumnis wenigstens zum Teill anhand von Veršigoras "Ljudi s Eistoj sovest'ju" zu beseitigen."

Der anschließenden Untersuchung liegen folgende Textauggaben von Versigoras Partisanenroman zugrunde:

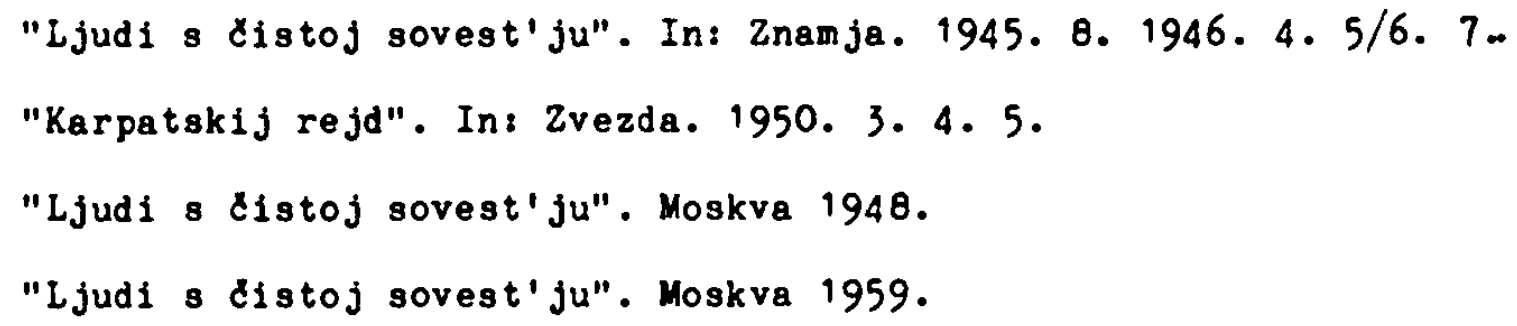

Die im Text verwendeten Siglen sind dem Abkürzungsverzeichnis auf S. S3 zu entnehmen.

J.A.Armstrong, Soviet Partisans in World War II (1964).

2 Hinweise auf die Uberarbeitungsprinzipien der Zensur geben J.Rühle iin "Literatur und Revolution. Die Schriftsteller und der Kommunismus" (Köln/Berlin 1960) sowie W.Kasack im Nachwort zu Kavering "Das Endee ei. ner Bande" (ins Russische Ubertragen von M.Wiebe; Frankf./N. 1973). Weiteren AufschluB liefern in diesem Zusammenhang Kuznecovs "Babij jar" (ins Russische übertragen von A.Kaempfe; München/Zürich/Wien 1970) und die vom Possev-Verlag herausgegebene Fassung von Bulgakovs "Master if Margarita" (Frankf./M 1969), in der die in der "Moskva"-Ausgabe vorm Zensor gestrichenen Passagen durch Kursivdruck abgehoben sind. 


\section{Petr Petrovid Verzigora}

"In den ersten zwei Teilen 'Der Menschen mit reinem Gewissen' wurde die Rolle der bolschewistischen Partei bei der Organisation der Partisanenbewepung ungenizgend herausgestellt, besonders in der Anfangsphase des Krieges. Die Handlungen der Partisanen wurden im Hinblick auf die Operationen der sowjetischen Armee als isolierte Aktivitäten dargestellt."

"In der neuen Ausgabe seiner Aufzeichnungen gelang es Verfifora gut zu zeigen, daß der Kampf der Partisanen, der unter der Fuihrung der Partel die Form einer allgemeinen Volksbewegung angenommen hatte, nach grobartigen Mabstäben geführt sowie gewaltig und erhaben im Ziel, Bestandteil einer historischen Schlacht des Volksriesen für die Ehre und die Freiheit seines sozialistischen Strates, für eine helle Zukunft aller unterjochten Völker nar."2

Ifese beiden Wertungen der Literaturkritik, die sich auf verschiedene Passungen von "Ljudi s cistoj sovest'ju" beziehen, lassen die Vieite des Unformungsprozesses erahnen, dem das Renannte lierk unterzogen wurde. Auf eben diesem Roman begründet sich der Erfolg von Verłigora, dessen ungewöhnlicher Lebenslauf hier skizzlert werden soll. Vergifora wird am 3.5.1905 in der Moldauischen SSR als Sohn eines Dorflehrers geboren. Er besucht eine Agrarschule (ohne sie zu beenden), arbeitet einife Zeit in der Landwirtschaft als Vorsitzender des Komnezam (Komitet nezamozennych seljan) und als Sekretër des Bauern-Sowjet. 1925 geht er als Freiwilliger zur Roten Armee, in der er in einem Musikkorps dient. In Odessa tritt er 1927 in ein Konservatorium ein und läbt sich als Schauspieler und Regisseur ausbilden. Er leitet mehrere Jahre zwei Theater ("Vsedoneck1j teatr rabotej molodezi" und "Izevskij teatr rabocej molodezi"), bevor er die Kino-Akademie besucht und nach ihrer Absolvierung eine Stellung als Repisseur in den Kiever Kinostudios erhölt.

Zu Beginn des Krieges wird er zur Armee eingezoren und nach der Teilnahme an den ersten Kampfhandlungen in die Politabtellung (Frontberichterstatterbrigade) der 40.Armee beordert. 1942 erhält er ir. der Kaderabteilung von Orel eine Fallschirmspringerausbildung und wird am 13.Juni 1942 im Gebiet von Brjansk abgesetzt, wo er zu einer Partisanenahtellune

\footnotetext{
I.Trofimenko, Novoe izdanie choroßej knigi. In: Novyj mir 1952. 7. S. 273 .
}

2 a80. S. 276 . 
stöBt. Unter dem später legendären Partisanenführer Kovpak wird er zum Kommandeur der Aufklärungsabteilung ernannt und nimmt in dieser Furktion am "Rejd 2a Dnepr" und am "Karpatskij rejd" teil. Nach der Ablösune Kovpaks - inzwischen ist er auch Mitglied der KPdSU (1943) - übernimat er das Kommando der 1. Ukrainischen Partisanendivision. Unter seiner leitunf werden der "Rejd v Pol'su" und der "Nemanskij rejd" durchgeführt. Eei Kriegsende bekleidet er den Rang eines Generalmajors und trägt den Titel "Geroj Sovetskoro Sojuza" (verliehen am 8.8.1944), zmel Lenin-Order, den Rot-Banner-Orden, den Bogdan-Chmel'nickij-Orden sowie sieben Medaillen.

Nach Kriegsende erscheint sein Dokumentarromen "Ljudi s cistoj sovest'ju" (abgedruckt 1945/46 in der Zeitschrift "Znamja"), filr den er 1946 einen Stalinpreis der zweiten Klasse erhält. Bedingt durch die massive Kritik, die 1948 an seinem Werk geübt wird, legt er eine überarbeitete Fassung vor, die 195', erweitert durch den ebenfalls in Dokumentarstil geschriebenen Teil "Karpatskij rejd", veröffentlicht wird.

In den Jahren 1947 - 1954 ist Verłigora an der Akademie des Generalstabes tätig und publiziert, nachdem 1947 unter seiner Mitwirkung "Ljudi s Cistc sovest' ju" an mehreren Bühnen als Theaterstück aufgeführt wird, eine Rei. he von Artikeln zu Fragen des Partisanenkampfes. Er stirbt am 27.3.1963 in Moskau.

Aufsehen erregt auBer "Ljudi s distoj sovest'ju" sein historischer AbriB "Brat'ja po oruziju. O narodnych formach vooruzennoj bor'by russkogo 1 ukrainskogo narodov", der in der Zeitschrift "Oktjabr"" erscheint und scharfe Reaktionen des Schriftstellerverbandes hervorruft, in deren Folg der Chefredakteur F.I. Panferov von seinem Posten enthoben wird.

In diesem Artikel schreibt Ver\$igors unter anderem:"Aber wïhrend ei. nige unserer Historiker - Scheibstubengelehrte - richtig die schädliche, gegen das Volk gerichtete konterrevolutionäre und nationalistische Theorie der Grusevskijs uber die Klassenlosigkeit und die nichtbourgeoise Herkunft des ukrainischen Volkes kritisieren und en larven, schmälern sie die Bedeutung des Kosekentums als patriotisch freiheitsliebende Grundlage in der Geschichte des russischen und de: ukrainischen Volkes herab."1

AnstoB zur Kritik gibt in erster Linie jedoch die zu diesem Satz ge hörende FuBnote, in der es lautet:"So zum Beispiel, ist in der stromlintenförmigen 'Geschichte der Ukraine' (AN USSR, Kiev, 1953),

P.P.Verłigora, Brat'ja po oruziju. O narodnych formach vooruzennoj bor'by russkogo i ukrainskopo narodov. In: Oktjabr' 1954. 4. S. 118. 
der, nach unserer Ansicht, unbrauchbare Versuch gemecht worden, eine Geschichte ohne Geschichte darzustellen, d.h. die Entwicklung des Volkes ohne die besonders ausgeprëgte Selte seines früheren Lebens zu zeigen, in der das Schaffen der Volksmassen verkörpert war, in erster Linie das der werktätifen Bauernschaft, die ihren Patriotismus im kasachischen Partisanenkrieg bekundete. Dieses Buch ist eín prägnantes Beispiel, unwürdis der Nachahmung, des Beamten-Ruickversicherertums, das nicht einmal den Hauptkern der historischen Forschung besitzt - den Patriotismus."1

Aus der Feder Verłigoras stammen weiterhin, wobei nur die wichtigsten Schriften genannt werten, der "oterk" "Voennoe trorkestro narodnych mass" (1961), die Erzählungen "Partizanskij komissar" (1946), "Geroj partizanskich rejdov" (1947), "Gerolzeskij syn Cechoslovackogo naroda" (1953), "Ivan Geroj" (1960) und "Dom rodnoj" (1962), ein weiterer Dokumentarroman mit dem Titel "Rejd na San 1 Vislu" (1959) sowie eine Reihe von Kritiken, von denen nur die erwähnt werden sollen, die den Neuerscheinungen auf dem Sektor der Partisanenliteratur gewidwet sind: "O prostom 1 geroiteskom" (1948), "Novye knifi podvigach sovetskich partizan" (1954) und "žizn' v bor'be" (1957).

Ehe die inhaltlich stark voneinander abweichenden Fassungen des Hauptwerks von Verłigora analysiert werden, soll im folgenden kapitel kurz der Stellenwert der Partisanenliteratur umrissen werden.

\section{Die Partisanendichtung in literarischen Schaffen der Kriegs- und}

\section{Nachkriegszeit}

Innerhalb des Literaturschaffens der Kriegszeit, dessen dokumentarisch propagandistischer Wert klar vor dem ästhetischen rangiert, wobei in der ersten Phase des Krieges besonders die Publizistik eine führende Stellung einnimt, ist das Thema der Partisanenbewegung, abgesehen von einigen wenigen Essays und Skizzen, erstaunlicherweise uberhaupt nicht vertreten. ${ }^{2}$ In Erscheinung tritt die Partisanenliteratur erst in der Phase der Nachkriegszeit, in der dann auch literarisch anspruchsvolle Werke

1 P.P.Ver\$1gora, a80. S. 118. DaB das Ausscheiden von Verzigora aus der Akademie des Generalstabes im Jahre 1954 mit den Vorgängen um seinen Artikel "Brat'ja po oruziju" von 1954 zusammenhängt, kann nur vermutet werden, da diesbezüglich keine angaben zu finden waren.

2 Die elnzigen bekannteren Werke, die den Partisanenkrieg punktuell berühren, sind Gorbatovs "Nepokorennye" (1943) sowle Leonovs "Nałestvie" (1942) und "Lenuska" (1943). 
über die Ereignisse des Großen Vaterländischen Krieges erscheinen. Weder die westlich noch die östlich orientierte Literaturgeschichtsschreibung geht den Orsachen für das Fehlen literarischer Werke über die Partisanenbewegung nach.

Während C.Struve überhaupt keine Angaben $z$ diesem Sachverhalt racht erwähnt M.Slonim nur befläufig:" [...] aber viele Berichte uber die Partisanen werden erst nach 1945 veröffentlicht."1 Die sowjetische Litereturwissenschaft schweigt sich zu diesem Tatbestanc ebenfalls aus.

Nach eirgehender Prufung lassen sich jedoch durchaus Gründe finden, die dieses Phänomen erhellen.

1. Von den sich im Einsatz befindlichen Kriegskorrespondenten gehen die meisten an der repulären front ihrer Tätigkeit nach, während ein nur verschwindend geringer Prozentsatz an der Partisanenfront aktiv ist.

2. Im Gegensatz zu den "Soldaten der Feder" in den Kampfrerbänden der Roten Armee, die ihre Eindrücke relativ problemios in der Etapre oder im nicht besetzten Teil der UdSSR auswerten können, müssen die wenifen Berichterstatter in den Partisanenpebieten un. ter erschwerten konsnirativen Bedineungen arbeiten. ${ }^{2}$

3. Der Widerstand in den durch deutsche Truppen besetzten Gebieten entwickelt sich erst spiter und in geringerem Umfanke als von de: sonjetischen Kriegsgeschichtsschreibunp heute darkestellt. Damit spielt die Partisanenbewegung, da inre Lage von 1941 bis Mitte 1943 durch Desorganisation und Isolation gekennzeichnet ist, im Gesamtkonzept der Verteidigungsstrategie nur eine untergeondnete Rolle. Pür das Fehlen der Literatur dieses Genres dürfte dies de: Hauptrrund sein.

Aus diesen Griinden greifen erst kurz vor bzw. nach Kriegsende ehemalige Partisanen selbst zur Feder (Veršigora, Kovçak, Korobov, Medvedev, Igna-

1 M.Slonim, Die Sorjetliteratur (1972) S. 321.

2 So ist vorstellbar, das, selbst wenn Werke über den Partisanenkrieg noch währond des Krieres erschienen wären, aus Gründen der Geheimhaltung weder die echten Namen der Partisanen und ihre Einsatzorte, noch ihre militärtechnischen und taktischen Praktiken hätten genamnt, werden dürfen - ein Unstand, der den dokumentarischen kert der Ber: : erheblich gemindert hätte. Vgl. dazu: P.Ponomarenko, Partizanskoe dvi¿enie v Velikoj Otełestrennoj vojne. In: Bol'łevik 1943. 13. S. 16 29. 
:ov, Fedorov ${ }^{1}$ oder werten nicht am Partisanenkrieg beteilifte die inzwischen vorhandenen Quellen aus (Fadeev, Kataev, Kozlov). Zwar geschieht dies unter den Anzeichen einer gesteuerten Liberalität, doch schon in der folgenden Zdanovära werden die meisten Werke kurz nach ihrem Erscheinen einer starken Kritik unterzogen.

Zu den nach Kriegsende erscheinenden Werken zum Partisanenkrieg gehören P.Ignatovs "Dnevnik partizana" (1945), S.Kovpaks "Ot Putivlja do Karpat" (1945), P.Versigoras "Ljudi s Cistoj sovest'ju" (1946), A.Fadeevs "Molodaja Gvardija" (1946), J.Kozlovs "V krymskom podpol'e" (1947), A.Fedorovs "Podpolnyj obkom dejstruet" (1947), L.Korobovs "Malaja zemlja" (1948), D.Medvedevs "Éto bylo pod Rovno" (1948) und "Otrjad idet na zapad" (1948) sowie V.Kataevs "Za vlast' Sovetov" (1949). Damit ist fast ein Drittel der Beiträge dem legendären Raid Kovpaks gewidmet: "Ot Putivlja do Karpat" vom Führer des Verbandes, Kovpak selbst, "Ljudi s Eistoj sovest'ju" von Versigora, dem Leiter der Aufklärungsabteilung der Einheit und späteren Nachfolger Kovpaks und Korobovs "Malaja zemlja", der dem Verband im letzten Kriegsjahr als Korrespondent der "Pravda" angehört.

Bedingt durch die Rückkehr der Partei zum ahsoluten Führungsanspruch werden 1946/47 eine Reihe der genannten Nerke heftig angegriffen, da sie angeblich dem Dogma der Parteilichkeit nicht entsprechen. Als einer der ersten Verfasser der Partisanenliteratur - er wird damit Opfer der von inm selbst betriebenen Literaturpolitik - muB sich A.Fadeev, der Generalsekretär des Schriftstellerverbandes, der Kritik beugen. Obwohl er für sei-

1 Bei den oben genannten Schriftstellern handelt es sich fast ausschlieblich un hochdekorierte Einheits- oder Verbandsführer:

Yovpak: Generalmajor, zweimaliger Held der SU, 4 Leninorden, SuvorovOrden, Bogdan-Chmel'nickij-Orden, Orden der CSSR und PNR, 10 Medaillen, Mitglied der Partei.

Medvedev: Führer der Partisanenbewegung "Pobediteli", Held der SU, 3 Lenin-Orden, Rotbanner-Orden, Mitglied der Partei.

Ignatov: Füher der Partisanenbewegung im Kuban'-Partisanenstab, LeninOrden, Mitglied der Partei.

Fedorov: Puhrer der Partisanenbewegung im Mittelabschnitt, Held der SU $(2 x)$, Leninorden, Mitglied der Partei.

Veržigora: siehe S. 4 der Arbeit. 
nen 1946 erschienenen und begeistert aufgenommenen Roman "Molodaja gvardija" 1947 einen Stalinpreis erhält, wird er am 3.Dezember 1947 Gegenstand heftifer Angriffe durch die "Pravda". "Ihm wird vorkeworfen, die spontane Auflehnung seiner Helden gegen die deutschen Okkupanten in der Grubenstadt Krasnodon überschätzt- und die führende Rolle der Partei im antifaschistischen Widerstand urterbewertet $z u$ haben. 1951 erscheint nach vierjähriger Umarbeitungszeit eine neue Fassung, die, da sie nach dem Grundsatz umgearbeitet wird: "Geschichte ist auf die Vergangenheit angewandte Politik; historische Ereignisse müssen in Beziehung zur derzeitigen Parteipolitik gesetzt und danach bewertet werden" ${ }^{2}$, nun den Gefallen der Partei findet.

Für die Tatsache, daB Fadeevs Werk "Molodaja guardija" in seiner Urfassung auf authentischen Fakten beruht und trotzdem umgeschrieben werden muB, wählt das Verfasserkollegium von "Russische Sowjetische Literatur im tberblick", um die offersichtliche Fälschung historischer Fakten in der revidierten Ausgabe zu verschlelern, folgende, der offiziellen Begründung verpflichtete Formulierung: "Der Roman wurde 1945 beendet; er fand sofort groBen Anklang. Nach dem Kriege aber wurden neue Dokumente aufgedeckt, die u.a. den illegalen Kampf der Partel und ihre Unterstützung für die Junpgardisten Renauer beleuchteten; Fadeev arbeitete daraufhin im Jahre 1951 seinen Roman um." 3 Die zweite Version von Fadeevs Roman findet dann volle Anerkennung: "Diese Junggardisten standen im ungleichen Kampf nicht allein. Ihre Aktionen waren ein Teil des von der Partei gelenkten Volkskampfes. In lebensochten Szenen [...J schildert Fadeer die illegale Arbeit der Partei, des klugen Ratgebers der Junggardisten."4

Neben Fadeev, dessen Schicksal deutlich werden läBt, daB die Kritik selbst vor hochpestellten linientreuen Gefolgsleuten nicht hal tmacht, greift man auch Kataev wegen seines 1949 erschienenen Romans "Za vlast" Sovetov" an. Initiator der Kampagne ist M.Bebennov, der Kataev vorwirft, die Rolle der Fartei beim Kampf der Partisanen gegen die Deutschen ge-

1 Offene Kritik an "Molodaja grerdija" ubt als erste Zeitung "Kul'tura 1 zizn'" am 30.11.1947, nachdem zuvor schon die "Pravda" am 11.3.1946 im Rahmen einer Rezension in gemäBigter Form die mangelnde Parteilichkeit moniert hat te.

2it. nach M.Slonim, 880. S. 347 .

3 Russigche Somjetische Literatur im tberblick (1970) S. 347. 4 880. S. 264 . 
schmälert und verzerrt zu haben. "Das Plenum der Leitung des Sowjetischen Schriftstellerverbandes bezeichnet den Roman als 'politischen Fehler', und wie schon [Fadeev] ist auch Kataev genötigt, den Roman neu zu fassen." 1 Ein weiteres Beispiel für die Eingriffe der Partei gibt das Werk des hochdekorierten Partisanenfuhrers D.Medvedev "Ėto bylo pod Rovno", das nach entsprechender Umarbeitung 1951 unter dem Titel "Sil 'nye duchom" erneut erscheint. In änlicher Weise wie Medvedev, Kataev und Fadeev ergeht es auch P.Versigora. Sein Werk wird bei Erscheinen von der Literaturkritik, wie schon Padeevs "Molodaja grardija", anerkennend beurteilt, doch auch or muB sich schlieblich der Kritik beugen und seinen Romen überarbeiten. Nach welchen Kriterien dies im einzelnen geschieht, soll im Hauptteil der Arbeit, uber die Zeit der Zdanovära hinaus, in einer genauen Analyse exemplarisch belegt werien.

3. "Ljudi a Cistoj sovest'ju" in Spiegel von Presse- und Literaturkritik

Im Zeitraum von 1946 - 1974 erscheinen insgesamt ca. sechzig Rezensionen zu Versicoras Hauptwerk, von denen besonders die kurz nach der Veröffentlichung publizierten Stimmen den Partisanenroman einhellig positiv aufnehmen. So schreibt V.Dmitrevskij 1946 in "Ogonek":

"Die Wahrhaftigkeit, die heiße Liebe zu den nichtfiktiven Helden, die Ausdruckskraft und die Schlichtheit der Sprache machen das Buch Versigores zu einer bedeutenden Erscheinung in unserer Literatur."2

Konkret werden im einzelnen die Parteilichkeit der Darstellung in bezug auf die Zentralfiguren Rudnev ${ }^{3}$ und Kovpak, die Sichtbarmachung der Verbindung zwischen Partisanenbewegung ${ }^{4}$ und Roter Armee und die entsprechende Betonung von Stalins Fürungsrolle ${ }^{5}$ gewirdigt. Daneben wird von A. Ta-

G.Struve, aa0. S. 460 .

2

V.Dultrevskij, Petro 1 ego kniga. In: Ogonek 1946. 12. S. 25.

3 S.Volkov, Ljudi s Cistoj sovest'ju. In: Voennyj vestnik 1946. 15. S. 63. Vgl. dazu: 1. Tarasenko, 0 nekotorych proizvedenijach sovetskoj voennoj prozy. In: Propagandist i agitator 1948. 5. S. 60.

4 s.Volkov, aaO. S. 61: "Diese Beweguna war eingereiht in den allgemeinen strategischen Plan des Krieges, die Handlingen der Partisaner zielten auf die entscheidendsten Abschnitte der sowjetibch-deutschen Front, koordiniert mit den Operationen der Roten Armee."

5 K. Bogoljubov, M.Rjakin, Ljudi s Xistoj sovest'ju. In: Literatura v Jkole 1947. 4. S. 67. VGl. dazu auch: A.Kosticyn, Memuary geroev narodnoJ vojny. In: Pogranitnik 1946. 23/24. 0. S. 
rasenko die Tatsache als erfreulich betont, daB Ver\$igora die Partisanenbewegung von ihrem romantischen Mythos entkleide, eine Feststellung (1947 !), die bei den Ergebnissen der Arbeit (Kap. C 5 a) ebenso uberrascht wie die Bemerkung von E.Usevid, der Autor dementiere die veraltete Vorstellung von der Disziplinlosigkeit in den Partisaneneinheiten (Kap. C 5 b).

"Unter den Menschen, die wenig mit dem Wesen des sow jetischen Part1sanenkrieges vertraut sind, sind bis heute noch nicht ganz die Vorstellungen von einer rebellischen, halbanarchischen, ausgelassenen Bruderschaft uberwunden, die auch, gemäB den naiven Vorstellungen einifer wenifer, die reizvolle Romantik des Partisanenlebens beinhaltet. Verłigora entkleidet diesen Mythos und macht thn lëcherlich. [...] Der romantische Charakter der Helden des Buches von Versigora besteht darin, daB diese Leute auch in besonders schweren Minuten, an besonders firsteren Tagen ihres Kampfes in der Lage sind, auf den morgigen Tag zu schaven."1

"Mit dem Partisanenkrieg, 'einer unorganisierten Tätigkeit' ist häufig die Vorstellung von Heldentaten verbunden, aber gleichzeitig auch von wlder Zügellosigkeit, von Disziplinmängeln, von Aktionen nach dem Motto 'jeder wie er Lust und Laune hat'. Das Buch von P. Versigora dementiert mit aller Deutlichkeit diese veralteten und in vielem falschen Vorstellungen."

Kritisch äuBern sich als erste, obwohl der Stalinpreis an Verłigora mit folgenden Argumenten verliehen wurde: "Die Erzählung begeistert durch inre Lebendigke1t, Wahrhaftigkeit und Glaubwürdigkeit.C...JP.Vergigora erzählt über tatsächliche Begebenheiten, indem er dle Wahrheit der Dokumente mit der Wahrheit schöpferischer Verallgemeinerung verbindet" ${ }^{3}$, K.Bogol jubov und M.Rjakin, indem sie inm vorwerfen:

"Das Buch ist nicht frei von Fehlern. Der Autor, der über die Partisanenabteilungen erzählt, überschätzt ihre Bedeutung in bezug auf die Handlungen der repulären Telle der Sowjetarmee. In Buch sind sowohl grobe sprachliche wie stilistische Fehler enthalten. Dessen ungeachtet ist das Buch im ganzen eine bedeutende Erscheinung in unserer Literatur." 4

1 A.Tarasenko, Ljudi a distoj sovest'ju. In: Družba narodov 1947. 16. S. 230 .

2

E. Osevid, Ljudi s distoj sovest'ju. In: Znamja 1947. 1. S. 153.

3 Laureatury Stalinskich premij 281946 god. In: Znamja 1947. 8. S. 183.

4 K.Bogol jubov, M.Rajkin, aao. S. 70. 
Die endgültige Fende in der Beurteilung durch Presse- und Literaturkritik setzt oit A.Cakovskij $j^{\prime}$ ein, der im Gegensatz zu A.Tarasenko die sich im Terk äuBernde Romantik bemängelt, ehe A.Prochodov ${ }^{2}$ die angeblich fehlende Parteilichkeit beanstandet. Vorgeworfen werden Verłigora im einzelnen:

1. Die nangelnde Darstellung der Fuhrungsrolle der Partei bei der Organisation und Entwicklung der Partisanenberegur.g. 3

2. Die fehlende Betonung der Koordination 2 wischen den Aktionen der Partisanenberegung und den Kampfhandlungen der Roten Armee. 4

3. Die unzureichende Beschreibung der militäriachen Verbindung zwischen den beweglichen Partisanenverbänden und den bodenständigen Partisanengruppen.5

1950/51 erscheinen in kurzen Abständen die Telle 3 und 4 des Partisanenronans unter dem Titel "Karpatskij rejd" sowie die revidierte Fassung der Teile 1 und 2 . Beide werden positiv aufgenommen, da Veršigora die an "Ljudi s Cistoj sovest'ju" 1948 geäuBerte Kritik hinsichtlich aller vier Teile beherzigt. So schreibt P.Savel'ev zwar, "C...J immerhin stellen wir fest, daB der 'Karpatskij rejd' vom Standpunkt der Meisterschaft her unzweifelhaft bedeutend höher steht als das erste Buch des Partisanenschriftstellers" ${ }^{6}$, doch vermerkt er zugleich anerkennend:

"Die Fehler und MiBgriffe, die von der Parteikritik nach der ersten Ausgabe des Buches hervorgehoben wurden, hat der Autor in der zwe1ten ausgemerzt.[...] Der wichtigste Erfolg des Autors besteht darin, dab es ihm an vielen treffenden Beispielen gelang zu zeigen, dab Genosse Stalin persönlich ständig den Kampf der Partisanen im Hinterland des Feindes lenkte und ihn - diesen Kampf - in seine allgemeinen strategischen Pläne der Vernichtung der Okkupanten einkalkulierte." 7

A.Cakorskij, Obidnaja snischoditel'nost'. In: Novyj mir 1948. 5. S. 205.

2 A.Prochodor, Počemu ne ustranjajutsja nedostatki knigi pri ee pereizdani jach. In: Kul'tura 1 zizn' 1948.11.0.S.

3 Bol'saja sovjetskaja énciklopedija v 74 tomach. Band VII (1951) s. v. Verłigora. S. 541 .

4 880. S. 541 .

5 A.Karavaeva, Kniga o Karpatskom rejde. Ins Literaturnaja gazeta 1951. 7. S. 3 .

6 P.Savel'ev, Ljudi s tistoj sovest'ju. In: Novyj mir 1951. 4. S. 198.

7 880. S. $198-199$. 
In diese Richtung geht auch die Beurteilung von A.Sinickij:

"P.Versigora, nicht nur ein ehemaliger Augenzeuge, sondern auch ein unmittelbarer Tellnehmer der von ihn beschriebenen Ereignisse, vermochte gut ein Bild des Karpatskij rejd der Partisanen zu zeichnen. [...] In Werk ist die Rolle der Partei der Bolscheniken bei der Organisation und Leitung in der Partisanenbewegung ausgezeichnet aufgezeigt."1

Im Zeltraum von 1952 bis 1963 ist es still um "Ljudi s Cistoj sovest'ju" und seinen Autor, abgesehen von der Tatsache, dab Versigora durch den von Ihm publizierten AbriB "Brat'ja po oruziju", nachdem das nach dem Partisanenroman erscheinende gleichnamige Theaterstück ein MiBerfolg ist ${ }^{2}$, für kurze Zeit ins Rampenlicht der Offentlichkeit tritt.

Eine neue Dimension des Schaffens von Versigora, uber den literarischen Bereich hinaus, eröffnet sich erst nach dem Tode des Autors durch den in

"Novyj mir" erscheinenden Nekrolog von P.Voron'ko, in dem es heist:

"Petr Petrovil war ein wahrhafter und furchtloser Freund. In den ersten Nachkriegsjahren, als viele ehemalige Partisanen schweren Beschuldigungen ausgesetzt waren und manchmal auch Repressalien, tat er alles, was in seiner Macht stand, um die Wahrheit wiederherzustellen und die Ehre der unschuldigen Menschen zu retten." 3

A.Sinickij, Soldaty armil mira. In: Komsomol'akaja pravda 1950. 52. S. 3 .

2 Siehe dazu: I.Al'tman, Dramaturgi ja $v 1947$ godu. In: Oktjabr' 1948. 3. S. 182 und V.Kommissarzevskij, Celovek na scene. Zametki rezissera. In: Novyj mir 1952. 10. S. 212.

3 p.Voron'ko (polkovnik), Celovek s Cistoj sovest'ju. In: Novyj mir 1963. 4. S. 288. - Erst in diesem Zusamrenhang wird der von A.Sinickij (a80. S. 3) zu Papier gebrachte Satz verständich, der die in der Abteilung Kovpaks Kämpfenden indirekt zu rehabilitieren veroucht: "Viele KovpakLeute fuhren auf die gigantiachen Neubauten des Kommunismus. Die ehemaligen Partisanen, die mit der Waffe in den Händen gegen die faschistischen Okkupanten in den Jahren des Großen Vaterländischen Krieges gekämpft hatten, kämpfen jetzt an der Arbeitsfront für einen sicheren und daverhaften Frieden, der mit Blut im Kampf erobert wurde. Diesen Frieden werden sie niemals und niemandem opfern."

Versigora, der sich nach der Aussage von P.Voron'ko selbatlos für seine Mitkämpfer eingesetzt hat, scheint in dieser Hinsicht in die Nähe von A.Zdanov zu rücken, von dem John A.Armstrong behauptet: "The emphasis on the close association between partisans and Party was closely related to the prestige of A.A.Zhdanov, whose Leningrad partisan operation had been especially successful. Toward the beginning of 1948, hoever, Zhdanov appeared to be losing his influence; in August he died. There are even some indications that Zhdanov's patronage of ex-partisans may have been involved in his decline." (aa0. S. 67). 
1. Beobachtungen zum Zensurmechanismus innerhalb der einzelnen Romenteile

Vergleicht man die verschiedenen Fassuneen von "Ljudi s listoj sovest'ju", so besteht kein Zweifel, daB das Werk mehr als einmal über den Tisch eines Zensors gegangen ist. Trotzdem fällt es schwer, uber den Mechanismus der Zensur und ihre Praktiken genaue Angaben zu machen, obwohl bekannt ist, daB die Bandbreite ihrer Wirksamkeit "von der Eliminierung eines Gedankens, die der Autor beim Abfassen eines Textes selbst vornimmt, bis zur Eliminierung des Autors selbst aus der Gesellschaft" ${ }^{1}$ reicht. Wie das Wissen um die Praktiken der Zensur schon bei der Niederschrift eines Werkes den Schriftsteller beeinfluBt, zeigt der Vergleich der Urfassung Teil $1 / 2(1945 / 46)$ mit der von Teil 3/4 (1950). Wenn Versigora auch nicht zu einer vorurteilsfreien Darstellung der Wirklichkeit vorstöBt, so beweisen ca. 250 Streichungen innerhalb des Teiles $1 / 2$ durch den Zensor, $d a B$ er ihr immerhin recht nahe gekommen sein muB. In Teil $3 / 4$ seines Romans - zieht man die Textstellen ab, die der Entstalinisierung zum Opfer fallen - scheint der Autor der Kritik von 1948 an Teil $1 / 2$ bei Konzipierung von Teil $3 / 4$ im voraus Rechnung zu tragen. So ist der 1950 erschienene "Karpatskij rejd" wesentlich parteilicher und damit stärker ideologisch verbrämt als der "Kejd za Dnepr" von 1945/46. Die Zahl der von der Zensur monierten Stellen reduziert sich im Vergleich zur Fassung von 1959 dadurch auf ein Minimum (ca. 40 Änderungen).

Folgende Zensurmethodik kommt beim Vergleich zutage:

1. Die beanstandete Textstelle wird punktuell durch Umschreibung leicht verändert.

2. Die monierte Textpassage wird entfernt und durch eine neu konzipierte ersetzt.

3. Die kritisierte Passage wird ersatzlos gestrichen.

Im Hinblick auf die der Arbeit zugrunde liegenden Fassungen (UF, F48, P59) lassen sich eine Reihe von Spielarten an Abweichungen formal festhalten, die die Kompliziertheit der Methodik deutlich machen.

1. Die in der $F 48$ gegenüber der UF vorgenommene Anderung ist auch in

1 P.Hubner, Zensur in der UdSSR I (1971) S. 3. 
der F59 enthalten (UF \& F48; F48 = F59).

2. D1e in der $F 48$ gegenulber der UF feststellbare Anderung ist in der F59 nicht beibehalten worden, sondern entspricht wieder der UF (UF \& F48; F59 = UF).

3. Die F $\triangle 8$ ist, gemessen an der UF, nicht verändert, dafür jedoch die 559 (UF $=F 48 ; F 48 \neq F 59$ ).

4. Die in der $F 48$ gegenuber der UF vorgenommene Revidierung, ist in der 859 nochmals einer Neukonzipierung zum Opfer gefallen (UF $\neq$ F48; F48 \& F59).

An zmei Beispielen läBt sich exemplarisch aufzeigen, in welchem Rahmen, vom Umfang her gesehen, die Eingriffe durch die Zensur wirksam werden. Auf der einen Seite steht die Beanstandung und die damit verbundene Revidierung nur eines einzigen Fortes (UF46, 4, S. 44: "Die Faschisten erreichten oft ihr Ziel." - F59, S. 195: "Die Paschisten erreichten manchmal ihr Ziel."), auf der anderen die Streichung von insgesamt 2 mei Seiten (UF50, 3, S. 22f.) und ein ersatzweiser Einschub von zrei neu konzipierten Kapiteln (F59, S. 385 - 397).

\section{Die Folgen der gewandelten Parteimeinung}

Die Tatsache, daB gegen die Schriftsteller der Partisanenliteratur, in ihrer Mehrzahl langjëhrige Mitglieder der Kommunistischen Partel und hochdekorierte Partisanenführer, plötzlich der Vorwurf erhoben wird, den Grundsatz der Parteilichkeit zu verletzen, ist nicht in einer Abweichung von diesem Dogma seitens der Literaten zu suchen. Vielmehr revidiert die Fihrungsspitze der Fartei im nachherein ihre Auffassung von der ihr eigentlich zustehenden historischen Rolle innerhalb der Partisanenbewegung und macht mit der Kritik an den Schriftstellern dieses Genres deutlich, daB sich am Prinzip der Parteilichkeit selbst, trotz des in den Kriegsjahren liberaler gehandhabten Regelkanons, nichts geändert hat.

Die Verschiebung deutet sich schon am 24 . Mai 1945 beim Empfang der Generalität der Roten Armee im Kreml an. Während Stalin in seinem Trinkspruch einerseits den Patriotismus als tragende Kraft des Fiderstandes hervorhebt, betont er andererseits gleichzeitig die Rolle der Partei "als Inspirator und Organisator des allgemeinen Volkskampfes." Diese These wird zum allgemeingültigen Dogma und gilt seit 1946/47, offensichtlich durch den Rückgriff auf die in folgenden zitierte Konzeption Lenins von 1906: "Die Partisanenkampfaktio-

1 G. von Rauch, Geschichte der Sowjetunion (1969) S. 440. 
nen müssen unter Kontrolle der Partei durchgeführt werden [... J" ${ }^{1}$, auch fir den Partisanenkrieg. 1947/48 schlägt sich diese These dann in der Literaturkritik nieder.

Die Sichtbarmachung und der Vollzug des Kurswechsels gehen nach auBen ohne Gesichtgrerlust für die Partei vor sich. Durch die Kritik an einigen Schriftstellern entsteht der Eindruck, daB nicht die Partei den Kurs wechselt, sondern nur einige Abweichler zur Rechenschaft zu ziehen sind, weil sie die Parteilinie verlassen haben.

3. Die Korrektur der organisatorischen Rolle der Partei im Partisanenkampf

a)_Zum_historisischen Forschungss

"Die Geschichte der russischen Partisanenbewegung von 1941 - 1944 ist eines der kompliziertesten und an wenigsten erhellten Kapitel des sowjetisch-deutschen Krieges." 2

Beim Studium der vorhandenen Quellen und Untersuchungen zum Partisanenkrieg bestätigt sich der von A.Werth konstatierte Sachverhalt in vollem Unfange, wobei die herstellung eines objektiven Gesamtbildes durch die stark differierende Bewertung von Einzelphänomenen innerhalb der Partisanenbewegung erschwert wird. Durch den vorhandenen Ost-West-Schnitt in der Beurteilung sind dabei folgende Fragen besonders umstritten:

1. Von welchem Zeitpunkt an darf von einer Partisanenbewegung gesprochen werden?

2. Welche Rolle spielt dabei die Kommunistische Partei als Initiator und Organisator?

3. Welches sind die den Partisanenkrieg auslösenden Momente?

4. In welchem Umfang kann die Partisanenbewegung als ein militärisch bedeutsamer Faktor im Gesamtkonzept der sowjetischen Verteidigungs- und Angriffsstrategie angesehen werden?

Ein einheitliches Konzept ist in den historischen Darstellungen des östlichen Lagers aus der Zeit nach $1948 / 49$ zu finden. Allen voran nimmt die

\footnotetext{
2it. nach Sowjetsystem und Demokratische Gesellschaft. Band II (1968) 8. v. Guerillakrieg. Spalte 1128. AufschluB uber diesen Sachverhalt gibt auch die Darstellung der "Istorija Velikoj Otecestvennoj vojny Sovetskogo Sojuza", in der es heiBt: "[...]die Partei stützte sich auf die Instruktionen $V$.l.Lenins, daB die Partisanenaktionen unter inrer Kontrolle durchgeführt werden mússen." (Band IV, 1962, S. 532).

A. Werth, RuBland im Krieg 1941 - 1945. Band II (1965) S. 526.
}

2 
"Istorija Velikoj Otexestvennoj vojny Sovetskogo Sojuza" auf insgesamt 135 Selten offiziell Stellur.g, wobei in erster Linie die Fragen nach dem Beginn des Partisanenkrieges und der organisatorischen Rolle der Partei eindeutig beantwortet werden:

"Der heldenhafte Kampf des sowjetischen Volkes im Hinterland der deutsch-faschistischen Armee hatte schon in den allerersten Tagen des Groben Vaterländischen Krieges begonnen. [...] Inspirator und Organisator des heldenhaften Kampfes im Rücken des Feirdes war die Kommunistische Partei." 1

Diese beiden Thesen werden auch in allen anderen sowjetischen Publikationen (Telpuchovskij $j^{2}, K r a v \not ̌ e n k o^{3}, B y{ }^{2} k v^{4}$ ) unisono vertreten.

Ahnliche Positionen beziehen fast einheitlich die Vertreter der DDR-Histo. rik, an deren Sọtze Kühnrich mit seiner umfangreichen Darstellung "Der Partisanenkrieg in Europa 1939 - 1945" steht. Von dem von Kühnrich ${ }^{5}$ abgesteckten Rahmen weicht nur P.Kolmsee ab,der zwar ebenfalls den Beginn der sowjetischen Partisanenaktionen mit Kriegsausbruch datiert ("Die sowjetische Partisanenbewegung entstand gleich in den ersten Tagen der faschisti. schen Aggression." ${ }^{6}$ ), an anderer Stelle jedoch sein Urteil durch eine ver. klausulierte Formulierung revidiert:

"Viele einfache Sowjetbürger erkannten nicht sofort, daB Millionen

Istorija. Band II (1961) S. 119. Annliche Formulierungen lassen sich auch in den jeweiligen Kapiteln der Bände III, IV und VI finden.

2 B.S.Telfuchovskij, Die sowjetische Geschichte des GroBen Vaterländisches Krieges 1941 - 1945 (1961) S. 271.

3 I.S.Kravæenko, Sovetskie partizany (1961) S. 314.

4 L.N.Byckov, Partizanskoe dvizenie $v$ gody Velikoj OteXestrennoj vojne 1941 - 1945 (1965) S. 22.

5 H.Kijhnrich, Der Partisanenkrieg in Europa 1939 - 1945 (1968). Kühnrich beklagt sich hinsichtlich der Ergebnisse westlicher Untersuchungen:"Kennzelchnend für die imperialistische Literatur über die Partisanenbewegung ist das Bestreben, die sowjetische Partisanenberegung und die Rolle der Kommunisten in ihr dadurch zu diskriminieren, dab man behauptet, der Partisanenkrieg sei spontan entstanden und die Kommunisten hätten sich dieser Bewegung später nur vorangestellt." (S. 105).

6

P.Kolmsee, Der Partisanenkampf in der Sowjetunion (1963) S. 43. 
deutscher Arbeiter nicht mehr vom Geist Bebels und Thëlmanns beseelt waren, sondern die Aggressionsplëne der Krupp, Thyssen und Hitler -illig in die Tat umsetzten. Sie muBten erst lernen, die Söldner des deutschen Faschismus zu hassen. Mit dem Hak wuchs auch der Wille, selbst aktiv am Kampf gegen die Eindringlinge teilzunehmen."1

Der sich bei P.Kolmsee andeutende Sachverhalt, daB die in den sowjetischen Untersuchungen dargestellten Verhältnisse nicht den historischen Tatsachen entsprechen, wird durch einen Artikel von P.Ponomarenko, dem Leiter des Zentralstabes der Partisanenbenegung, aus dem Jahre 1943 indirekt bestätigt. Obrohl sein tberblick über die Partisanentätifkeit alle bis zu diesem Zeitpunkt nennenswerten Ereignisse erfaBt, erwähnt er an keiner Stelle 1rgendeine Organigation durch die Partei. Er gibt lediglich zu verstehen, daB "Menschen aus dem Volk den bewaffneten Kampf pegen die Okkupanten führen, bis zuletzt der Partei Lenins und Stalins ergeben." 2 Zieht man westliche Unterguchungen heran, so zeigen sich die geboten Fakten wesentlich stichhaltiger, obwohl hier gelegentlich eine simplifizierung zu bemängeln ist. Am ehesten trifft, nach bisheriger Einschätzung der Gesamtlage, O.Heilbrunn den tatä̈chlcihen Sachverhalt, wenn er schreibts

"Als die Sowjetunion 1941 angegriffen wurde, hatte sie nur wenig getan, um einen Partisanenkrieg zur Unterstützung der Roten Armee in vorbereiteter Weise zu führen. Es gab keinen Partisanengeneralstab, Befehlsordnung und Struktur der Partisanen waren nicht geregelt, es fehlten das Organisationsgerippe und klare Vorstellungen über die Zusammenarbelt mit der Roten Armee; offen war auch die Frage, ob Militärs oder Zivilisten die Einheiten kommandieren sollten, und ausserdem war die Partisanenbewegung ohne nachrichtendienstliche Verbindung. Partisanendoktrin und -konzeption waren in vieler Hinsicht nicht auf der Höhe der Zeit."

Hinsichtlich der Frage nach dem Beginn des Partiganenkampfes widerlegen die westlichen Untersuchungen eindeutig die Behauptung der sowjetischen Historiker, die Partisanenberegung sel sofort bei Kriegsausbruch durch die Führung der Kommunistischen Partei zustandegekommen. Da einerseits

1 P.Kolmsee, aaO. S. 46 .

2 P.Ponomarenko, Partizanskoe dvizenie v Velikoj Otecestrennoj vojne. In: Bol'sevik 1943. 13. S. 18.

3 Sorjetsystem und demokratische Gesellschaft. Band II (1968) s. v. Guerlllakrieg. Spalte $1152 f$. 
die Bevölkerung der zuerst besetzten Gebiete (WeiBruBland, Ukraine) den Deutschen freundich gesinnt und nur durch die nachfolgende Besatzungspolitik aktiviert wird ${ }^{1}$, andererseits eine weitsichtige Planung auf dem Sektor der Partisanenkriegführung fehlt ${ }^{2}$, beschränkt sich die Tätigkeit der Partisanen in den Kriegsjahren 1941/42, wie auch Verłigoras "Ljudi 8 cistoj sovest'ju" zeigt, in erster Linie auf spontane und sporadische Unternehmungen.

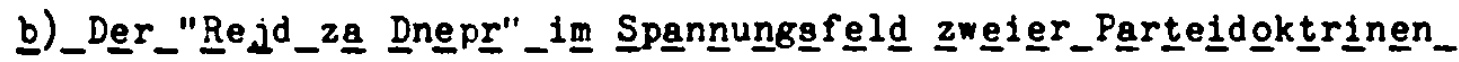

Da die Fassung von 1948 der gewandelten politischen Situation erstaunlicherweise noch nicht entspricht, obwohl mit der "Pravda"-Kritik an Fadeev "Molodaja gvard1ja" der richtungweisende Eingriff schon 1947 erfolgt, kör nen die Eingriffe der Zensur nur an der vorliegenden Ausgabe von 1959 sichtbar gemacht werien.

Verłigora wird am 13.Juni 1942, zwei Monate nach Bildung des Zentralstabe der Partisanenbewegung (30.Mai 1942), mit Fallschirm im Partisanengebiet von Brjansk abgesetzt. Schon seine ersten Eindrücke vom zentralen Hauptquartier zeigen an, daB zu diesem Zeitpunkt von einem hohen Organisations grad nicht gesprochen werden kann. Da sich zudem weder eine kräftemäBige Schwerpunktbildung noch eine durchdachte Besetzung mit im Partisanenkampf geschulten Fuhrern aus seinen Zeilen herauslesen läBt ("Es ergab sich für mich die Gelegenheit, mit Partisanenfürern zusammenzutreffen, die sich einbildeten, groBe Strategen zu sein, aber in Wirklichkeit hatte sie einfach das Schicksal und die Geographie des Krieges in einen Abschnitt gestellt, wo die Kräfte der Deutschen nicht ausreichten, um ihn zu besetzen." ; UF45, 8, S. 42), wird diese Textstelle, ebenso wie die nachfolgend zitierte, von der Zensur gestrichen.

1 Siehe dazus G. von Rauch, aa0. S. 385ff. und: W.Görlitz, Der Zmeite Weltkrieg 1939 - 1945 (1952) S. $101 \mathrm{ff}$.

2 Zu diesem Sachverhalt äuBert sich A.Werth, aa0. Band II. S. 526 wie folgt:"Tatsache ist, daB sich in den auf die Invasion folgenden turbulenten Monaten des Jahres 1941 in den riesizen, von den Deutschen eben erst besetzten Gebieten alles in chaotischem Zustand befand und daB vor sonjetischer Seite im voraus praktisch nichts getan worden war, um im Falle einer Besetzung in diesem Tell des Landes eine Partisanenbewegune organisieren zu können. Es war [...] keine 'materielle Basis' für den Partisanenkrieg vorhanden $[\ldots . .$. " 
"Der Stab des Kommandos bestand im Grunde genommen nur aus einem eigentümlichen Sammelpunkt von Meldungen, eirem Ort, durch den mit Hilfe einer einzigen Funkstation alle Aktivitäten der Partisanenabtellungen zur 'GroBen Erde' gemeldet wurden. Und die 'GroBe Erde' half den Partisanen, soweit möglich, mit einer Kiste Patronen, durch eine frische Zeitung, durch einen Satz Verpflegung. Aber im übrigen handelten alle nach dem Prinzip:'Jeder wie er Lust und Laune hat'." (UF45, 8, S. 42)

Ein neukonzipiertes Textstück, dessen Intention es ist, den ursprünglichen Sachverhalt ins genaue Gegenteil zu verkehren, wird dafür eingeschoben. In der Fassung von 1959 berichtet Versigora nun von einer Einsatzbesprechung der Partisanenfuhrer, die den Eindruck einer breit angelegten und gut organisierten Tätigkeit vermitteln soll.

"In den ersten Tagen des Aufenthaltes im Partisanengebiet war es mir möglich, bei einer der Beratungen der Kommandeure von Gebietsvereinieungen anwesend zu sein, aber noch vor Beginn der Besprechung erfuhr ich von Veteraner des Partisanenbezirks, das die Wälder von Brjansk schon im Winter 1941-1942 allen rechtschaffenden sowjetischen Menschen zur Basis geworden waren. Sie waren zurückgeblieben oder wurden speziell auf dem vom Feind besetzten Gebiet eingesetzt. [... Auf GeheiB der Partei blieben in den Wëldern Untergrundgruppen und Organisationen zurück. Kommunisten, Komsomolzen, fortschrittiiche Arbeiter und Kolchosbauern, die schaffende Intelligenz unseres Gebietes, wie auch das ganze sowjetische Volk, stellten gemäB dem Aufruf der Partei Anträge zur Aufnahme in Partisanenabteilungen." (F59, S. 30)

Im Gegensatz zur Urfassung, aus der eindeutig hervorgeht, daB die Partisanenbewegung erst Mitte 1942 ins Leben gerufen wird, stellt sie Verkigora in der Fassung von 1959 als eine allkemeine Volksbewegung dar, deren Wirkung er wie folgt beschreibt:

"In einigen Bezirken nahm die Partisanenbewegung den Charakter eines Volksaufstandes gegen die faschistischen Eroberer an und versetzte die faschistischen Rädelsfuhrer und ihre Schützlinge in angst und Schrecken. Unsere Kampfaktionen beunruhigen nicht nur die deutschen Soldaten und Gendarmen. Wie sie sehen, ist durch unsere Erfolge auch die hitlersche Führungsspitze beunruhigt." (F59, S. 32)

Angesichts der Diskrepanz zwischen beiden Fassungen, versucht Verłigora, die Glaubwürdigkeit der eigenen Darstellune zu stützen, indem er einen Kommissar der vereinikten Partisanenverbände namens Bondarenko einführt und inm auf einer Einsatzbesprechung ein Referat halten läBt, das Aufschlub uber die bisherigen Erfolge der Partisanenbewegung geben soll. Ob diese Einsatzbesprechung, die in der UF45/46 mit keinem Wort erwähnt wird, eine reine Fiktion Verbigoras ist, entzieht sich der tberprüfung, 
doch erweist sich eine Reihe von Fakten derart dubios, daB der Verdacht einer Pälschung nahe liegt. ' Sieht man den aus dem Kontext zu erschlieBenden Zejtraum der Tagung als authentisch an ("An dem ungluckseligen Datum, 13.Juli 1942, verabschledete ich mich auf dem Flughafen von meiner Frau."; "In den ersten Tagen meines Aufenthaltes ir Partisanengebiet hatte ich Gelegenheit, einer Zusammenkunft der Fuhrer der Kreisverbände beizuwohnen." ${ }^{3}$ ), so fält neben der starken Indoktrinierung von Bondarenkos Lageeinschätzung (Betonung des Antefls der Kommunistischen Partei bei der Organisation und Lenkung des Partisanenkrieges) besonders die Nennung der bis zu diesem Zeltpunkt erzielten Erfolge auf. Rekapituliert man anhand der UF45/46 und den Darstellungen der Literatur des westlichen lagers die in Juli 1942 tatsächlich bestehende Situation an der Partisanenfront, so wird deutlich, daB eine detalliferte Aufstellung der Verluste des Gegners in dieser Form uberhaupt nicht existiert haben kann. AuBerdem sind die ge. nannten Zahlen viel zu hoch gegriffen.

"Bis zum 1.Mai 1942 töteten die Partisanen dieses Gebietes nach unvollständigen Angaben [...] 19845 feindliche Soldaten, 237 Offiziere. 1 General sowie 2090 Polizisten und Verräter. 74 offiziere und 172 Soldaten wurden gefangengenommen. tber den Gegner und seine Truppenbewegungen war umfangreiches Material gesammelt worden, das an die Befehlshaber der einzelnen Frontabschnitte weitergeleitet wurde. 44 Feindflugzeuge wurden abgeschossen oder bel tberfällen auf Transportzüge und Flugplätze vernichtet, 32 feindliche Eisenbahnzüge die Böschungen hinabgestürzt, darunter 5 Eisenbahnzüge mit Kriegsmaterial - Panzer, Flugzeuge - und 2 Panzerzüge. 205 Kilometer El senbahngleise wurden zerstört, 41 Eisenbahnbrücken und 84 StraBenbricken ge sprengt, 9 Kommandostäbe und 8 Polizeiverwaltungen ausgeräuchert. Gesprengt und verbrannt wurden 42 Panzer und Panzerspähwagen, 418 Kraftfahrzeuge, 6 Brennst of flager, 9 Raupenschlepper, 21 Kleiderkammern und ein Vorratslager mit Verpflepung und vunition.

An Kriegsbeute wurden eingebracht: 10 Panzer und Panzerspähwagen, 14 Geschütze, 154 Kaschinengewehre, 400 Gewehre, 14 Kraftwagen, 135 Pferde, 146 Fahrzeuge und efnfge Hundert Stück Nutzvieh. [...J

$\overline{1}$

Auffällig in diesem Zusammenhang ist die Passage, in der Versigora, offensichtlich zur Rechtfertigung für die "fehlerhafte" Darstellung in de Urfassung, folgendes ausführt:"Die Besprechung kam mir sehr zugute. Da ich mich erst einige Tage im Partisanengebiet aufhielt, konnte ich mir noch keine klare Vorstellung von der Organisation dieser groBen Volksbewegung machen." (F59, S. 30)

UF 45,8, S. 41 .

3 F59, S. 30. 
Die Deutschen und ihre Helfershelfer wurden aus 346 Ortschaften mit einer Bevölkerung von 170000 Personen von den Partisanen vertrieben." (F59, S. 31)

Noch unglaubwürdiger wird Ver\$igoras Darstellung, abgesehen von der Vorspiegelung der Erfolgsstatistik, durch das Zitieren zweier deutscher Tagesbefehle und einer Anweisung des Generalstabschefs des Hauptquartieres der deutschen Armee, Generalfeldmarschalls von Brauchitsch. Da Ver\$igora im AnschluB an die oben wiedergegebene Statistik Bondarenko behaupten läBt, daB die Erfolge der Partisanenbewepung sogar das Oberkommando der Hitlerschen Wehrmacht beunruhigen, wird die Intention des Verfahrens allzu deutlich: Die teilweise wörtliche fiederpabe der drei deutschen Dorumente soll den geschilderten Sachverhalt zusätzlich stützen und damit glaubwürdiger erscheinen lassen. Dies gelingt auf den ersten Blick, zumindest die Tagesbefehle von General Blotzmann ("Befehl No. 1 vom 15. Februar 1942") und General v. Gridus ("Befehl vom 1.Juli 1941") betreffend, da hier die Möglichkeit besteht, daB es sich um Beutedokumente handelt. Bedenkt man in diesem Zusammenhang jedoch, daB die Tagesbefehle nur einen winzigen Ausschnitt aus der Gesamtfrontlage spiegeln, ist ihre Beweiskraft für die von Verß̌igora gegebene Einschätzung der Lage von geringem Stellenwert (Beunruhigung des deutschen OKW). AuBerdem muB vermutet werden - vergegenwärtigt man sich generell Diktion und Inhalt deutscher Tagesbefehle - daB der Autor von "Ljudi s cistoj sovest'ju" diese beiden Dokumente punktuell so verändert hat, daB sie die offizielle sowjetische Version vom Partisanenkrieg bekrüfigen.

"General Blotzmann, der mit seinen Soldaten den Kampf gegen die Partisanen führte, schrieb in seinem Tagesbefehl $\mathrm{Nr}$. 1 vom 15.Februar 1942:'Durch unsere Abwehr ist das Vorhandensein einer groBen Anzahl von Partisanen festgestellt worden. Die Partisanen sind gut beschuht und gekleidet, besitzen gute Pferde und Schlitten und genuigend Schneeschuhe und Tarnmäntel. Die Einwohnerschaft der russischen Dörfer sympathisiert wit ihnen und unterstützt sie. In den Gemeinden gibt es keine Polizei und keine Dorfältesten. Wenn die Truppen Ruhestellung beziehen, legen sich über die Hälfte der Soldaten nicht mehr schlafen.' [...]

General von Gridus schrieb in seinem Tagesbefehl vom 1.Juli 1941: 'Die Partisanen schieben besser und wählen ihre Verteidigungs- und Angriffsstellungen besser als die ungarischen Soldaten. Von Moskau aus werden die Partisanen durch Flugzeuge mit Geschützen und Ausrüstungsgegenständen versorgt... ... Bittet ein Bauer sich ein Gewehr aus, so ist ihm keinesfalls eins zu geben - er könnte es gegen euch wenden. ... Ihr dürft euch in den Hásern nicht unterhalten - alles wird den Partisanen hinterbracht." (F59, S. 32) 
Zieht man das von Verßigora zitierte Dokument des Oberkommandos der Heeres heran, so ergeben sich weitere, noch gravierendere Unstimmigkeiten:

"Der Generalstabschef des Hauptquartiers der deutschen Armee, General von Brauchitsch, schrieb in seireer Anleitung 'Zur Bekämpfung der Partisanen': 'Die russischen Partisanen fügen nicht nur kleineren Einheiten und Verbänden der Kampftruppe erheblichen Schaden zu, sondern behindern auch die Versorgung des Heeres und zerstören militärische Anlagen in den rückwärtigen Gebieten." (F59, S. 32)

Während die beiden unbedeutenden Tagesbefehle in der 559 in ihrer genauen zeitlichen Datierung vorliegen, wird im oben zitierten Dokument auf eine Zeitangabe generell verzichtet. Der Grund, der Vergigora zu diesem Verfahren greifen läBt, ist relativ leicht einsichtig: Da der Wortlaut der Tagesbefehle auch für einen Militärhistoriker kaum nachprüfbar sein dürfte - aus diesem Grunde das Mitzitieren von Tag, Monat und Jahr - liegt die therprüfung eines Aktenstückes des Oberkommandos der Hehrmacht, bel Vorhandensein von genauen Zeitangaben, durchaus im Bereich des Möglichen.

Der Versuch, die von Veršigora zitierten Richtlinien "Zur Bekämpfung der Partisenen" mit dem Oripinalschriftstück zu vergleichen, ertrachte folgendes Ergebnis: Bei den einzigen, in der einschlägigen Militärliteratur und den erreichbaren Dokumentensammlingen des Zweiten Weltkrieges vorhandenen Leitsätzen zur Partisanenbekämpfung aus der Feder des Generalstabschef des Hauptquartiers $v$. Brauchitsch, handelt es sich es um den "Geheimen ErlaB des OKH/Gen. z.b.V. OBdH vom 13.9.1941, 'Kämpfe hinter der Front". Dieser Erlab gibt jedoch nicht, wie Veršigora glaubhaft machen will, eine Einschätzung der Bedrohung durch russische Partisanen, sondern versucht, die komplizierte Rechtslage hinsichtlich der Behandlung der zerstreuten Reste der sowjetischen Streitkräfte, die auf eigene Faust hinter der deutschen Front operieren, zu klären.' Uber die Tatsache hinaus, dab das von Versigora zitierte Dokument mit dem Origiralschriftstück des OKH nicht identisch ist, muB sterk bezweifelt werden, daB es dem Kommisar der vereiniften Partisanenverhände zum Zeitpunkt der Einsatzbesprechung im Jul 1 1942 bekannt gewesen ist. MiBt man an den vorherigen Einschüben die Textstelle der Irfassung, die den tatsächlichen Status der Partisanerbewegung

Eine Fotokopie des genannten Originalschriftstücks, das unter der Chiffre NOKW 1167 in der Dokumentensammlung "Der ProzeB gegen die Hauptkriegsverbrecher" (Nürnberg) enthalten ist, befindet sich in Anhang der Arbeit. 
it Jahre 1942 wiedergibt, so wird verständlich, warum sie im Zuge der tborarbeitung weichen muB.

"Die Partisanenbewegung - das ist eine Armee ohne Intendantur, eine Armee, die weder feste Gesetze hat, noch Ordnungshuter, weder Tribunale, noch eine Miliz. Deshalb besteht hier auch die Gefahr zum Eanditentum, zum Einsatz der Waffe für ein einfaches, ungebundenes und sattes Leben." (UF45, 8, S. 49)

In gleicher Weise verfährt der Zensor mit der Passage, die, im Cegensatz zur offiziellen sowjetischen Diktion, nach der alle Partisaneneinheiten in Funkverbindung zum Zentralstab stehen und von ihm gelenkt werden, das genaue Gegenteil bekundet.

"Keiner wuBte, daB auch dort Partisanenabteilungen handeln. Diese Abteilungen waren 'wilde', daB heiBt, sie handelten auf eigenes $R 1-$ siko und Gefahr. Sie besaßen keine Verbindung mit der 'Großen Erde' keine Vollmachten, keine von Instanzen bestätigten Direktiven. Die einzige Richtlinie war die Rede des Cenossen Stalin vom $3 . J u l i$ des Jahres 1941. Und diese leitete sie den ganzen Krieg. Wie nach einer Magnetnadel, die dem Schiff den Weg zeigt, hielten sie Kurs auf die erbarmungslose Zerstörung des Feindes." (UF46, 4, S. 21)

Zwar müBte der Hinweis auf die Rundfunkrede Stalins - sie wird in allen sowjetischen Quellen, die vor dem Tode des Diktators entstehen, als Beweis für den Beginn des Partisanenkampfes gleich nach Einmarsch der deutschen Truppen herangezogen - genügen, um die Forderung nach verstärkter Parteilichkeit zu erfüllen, doch da im Zuge der Entstalinisierung fast alle Textpassagen, in denen Stalin erwähnt wird (siehe Kapitel D 2) von der Zensur entfernt werden, fällt folglich die gesamte Stelle dem Rotstift zum Opfer.

In krassem Widerspruch steht schlieblich auch die Textpassage der Urfassung, aus der hervorgeht, daB sich die Einheit Verłigoras aus Freiwilligen aller Schattierungen zusammensetzt ("Unter die Partisanen gingen Freiwillige, darunter Romantiker ${ }^{1}$ und solche, die zufällig zu den Partisanen stieBen C...."; UF45, 8, S. 49), zum Einschub in der F59, der die hohe Zahl von Mitgliedern der Kommunistischen Partel hervorheben soll. "Sie waren belde [Kovpak i Rudnev] als Führer der vom Kreisparteikomitee für den illegalen Kampf bestimmten Kommunistengruppen eingesetzt worden. Die Mehrzahl der ersten Partisanen stamme aus dem Parteiaktiv." (F59, S. 43f.)

\footnotetext{
1 "Romentiker" wurde aus der Urfassung ersatzlos gestrichen; vergleiche hierzu Kapitel C 5 a der Arbeit.
} 
Nach dem Muster der schon erwännten Umarbeitungen breitet Versigora das in der Urfassung $45 / 46$ mehr beiläufig erwähnte Treffen von Partisanenfuhrern mit Stalin im Kreml am 31.August 1942, allerdings unter weitestgehender Vermeidung des Namen Stalins, 1959 ausfühlich aus. Die Vorstellung der Teilnehmer, die in der Urfassung keine wesentliche Rolle spielt ("Saburov, Emljutin, Duka, Prokovskij und andere"; UF45, 8, S. 53), schwillt 1959 durch die Nennung der Abteilungen und Einsatzorte zu einer umfangreichen Namensliste an.

Der Bericht Kovpaks vom Treffen im Kreml, dies muB at Rande kurz erwähnt werden, zeigt bei seinen Zuhörern an der Front - so jedenfalls Verłigora - hohe Wirkung: "Die Partisanen und Partisanenführer des Brjansker Gebiets und der ukrainischen Verbände, die die Berichte Kovpaks und der anderen Teilnehmer der denkwürdigen Beratung gehört hatten, handelten jetzt noch uberlepter, waren politisch und moralisch reifer geworden." (ỉ59, S. 46î.)

Dazu pibt Versigora ausschnittweise zwei Befehle Stalins wieder, die vom Einheitsfihrer Matveev von der Einsatzbesprechung im Kreml mit an die Front gebracht werden (F59, S. 48). Diese Befehle, von denen der Leser annehmen muB, daB sie von Stalin anläBlich der Besprechung erlassen wurden, bestärken jedoch eher den geringen Stellenwert der Partisanenbewegung im strategischen Cesamtkonzept, als daB sie die Wichtigkeit der ille. galen Tätigkeit betonen. Der zuerst zitierte Text beschiofigt sich nur mit der allgemeinen Lage an der regularen Front und den aus ihr erwachsenen Möglichkeiten für die Rote Armee (F59, S. 48), während der zweite Text die Gleichstellung von Partisanenberegung und Roter Armee zeigen soll, in Wirklichkeit jedoch von den fünf Anweisungen des obersten Befehlshabers nur die letzte der Partisanenkriegführung gewidmet ist (F59, S. 4Af.). AuBerdem, und hier wird der Leser bewuBt fehlgeleitet, stammen die zitierte Rede sovie der angefühte Befehl nicht vom 31.August 1942, sondern vom 6.. Vovemter 1941 (Vortrag Stalins auf der Festsitzung des Moskauer Sonjets der Deputierten der Herktätigen mit den Partei- und gesellschaftlichen Organisationen Moskaus aus AnlaB des 24 . Jahrestages der GroBen Sozialistischen Oktoberrevolution ${ }^{1}$ ) und vom 1. Mai 1942 (Refehl des

Diese Tatsache ergab sich aus dem Verpleich 2wischen dem Text der F59 und den Reden Stalins. Vergleiche dazu: Stalin spricht. Die Kriegsreden vom 3.Juli 1941 bis zum 9.Mai 1945. Stockholm 1945. S. 18. 
Volkskommisgeriats für Verteidigungswesen Nr. 130 ). Die SchluBfolgerung - nur um diese zu ermöglichen wurde der umfangreiche Einschub installiert - die Verśigora zieht, verwundert nach den bisher aufgezeigten Manipulationen kaum noch:

"Der Pa:tisanenkrieg war zu einem Bestandteil des allgemeinen Planes zur Vernichtung des Gegners geworden." (F59, S. 49) 2

Der sich an die Stalinzitate anschliebende Satz Verbigoras - "Nach diesen Befehlen wurde unser Kampf wie nach einem uns von der Fartei der Bolschewiki in tie Hand gegebenen KompaB ausgerichtet" (F59, S. 49) - soll das Bild vom historischen Anteil der Partei bei der Lenkung des Partisanenkampfes abrunden.

Eine Filschung scheint offensichtlich auch im Zusammenheng mit der Konferenz im Kreml und der Erwähnung von Voroşilov vorzuliegen. Wie aus einer zweiten Textstelle der Urfassung hervorgeht (UF46, 4, S. 63f.) - Kovpak berichtet seinen Kämpfern auf ihr Bitten hin angeblich erneut vom $2 u-$ sammentreffen mit Stalin in Moskau (im Zuge der Entstalinisierunf wird die Stelle ersatzlos gestrichen) - sind laut Kovpak an hochgestellten Persönlichkeiten aus der Führungsspitze Stalin und Molotov anwesend. In der Fassung von 1959 heibt es jedoch:

"Kovpak erhielt von Stalin und Vorošilov die militärische Aufgabe, ein neues Unternehmen durchzuführen." (F59, S. 49)

Hier, am Austausch von Molotov gegen Vorosilov, ist erkennhar, wie entscheidend die jeweilige personelle Besetzung des Regierungskaders den Stand punkt der Parteilichkeit bis ins Literaturgchaffen hinein prägt.

Molotov, dessen Anwesenheit im Kreml als ein eng Vertrauter Stalins durchaus glaubhaft ist (er wird in der Urfassung dreimal penannt), wird im Juni 1956 von seinem AuBenministerposten enthoben und im Ju11 1957, neben Kalenkov, Kaganovic und Sepilov aus dem $2 K$ entfernt. Damit ist er, als ein in Ungnade Gefallener, für die Fassung von 1959 offensichtlich nicht mehr tragbar. Die ersatzweise Einführung

Stalin spricht. 880 . S. $47 f f$.

2

Mit diesen Satz folgt Versigora der offiziellen Linie, die auch von Tel puchovskij (aa0. S. 275) vertreten wird:"Anfang September 1942 fand eine Besprechung der Kommandeure der gröBten Partisaneneinheiten im Kreml statt, die für die weitere Entwicklung und Organisation der Partisanentewegung eine bedeutende Rolle spielte und bei der auf Grund der Kampferfahrungen 'allgemeine Grundsbize für den Kampf im Rücken des Feindes' auggearbeitet wurden." 
von Voroßilov, dem damaligen Oberbefehlshaber der Partisanenbewegung und spëteren Vorzitzenden des Obersten Sowjets $(1953-1960)$, ist unte zwel Gesichtspunkten zu sehen: Einerseits fullt er die durch die Aus merzung Molotovs entstandene Lücke, andererseits wird durch seine Nernung in einem Atemzuge mit Stalin die militärische Entscheldungsbefugnis geteilt, und damit die Position Stalins in nachherein geschwächt.

Um seinen Kritikern gerecht zu werden, schiebt Versigore in die Fassung von 1959, über die schon erwähnten Neukonzipierungen hinaus, eine weitere Textstelle ein, die den hohen Grad an Verbundenheit zwischen Partisanenbewegung und Zentralstab dokumentieren s011, wobei eine ganze Reihe von "fehlerhaften" Passagen von ihm eliminiert werden. Während in der Urfassung 1945/46 der Funkspruch mit einer Anweisung Vorołilovs für die Durchführung eines neuen Kampfauftrages nur beiläufig erwährit wird (UP45, 8 , S. 73), zitiert Verłigora inn 1959 in voller Länge, um anschliebend zu versichern:

"Schon zu Beginn des Streifzuges, [...] im Brjansker Partisanengebiet das die Basis vieler Partisanenabteilungen werden sollte, hatten wir uns von der regen Tätigkeit des Zentralen Stabes der Partisanenbewegung überzeugen können." (F59, S. 73)

Ar der folgenden Behauptung: "Verbindungsoffiziere des Stabes gab es in fast sämtlichen Partisanenabteilungen, so auch bei Kovpak" (F59, S. 73), lassen sich tbertreibung und Widerspruch gleichzeitig ablesen. Erstens zeigt die Streichung von Textstellen, die die Isolierung und Desorganisstion von Partisanengruppen nachweisen ', daB die tatsëchliche Lage eher dem Gegenteil entspricht; zweitens bleibt unverständlich, wie ein Partisan vom Range Verłigoras ${ }^{2}$ bel Vorhandensein von Verbindungsoffizieren kei ne Kenntnis von den Operationsplänen haben 8011 :

"In meiner damaligen Dienststellung konnte ich nlcht über sämtliche Einzelheiten des Angriffsplanes unterrichtet sein, doch war er viele Truppenfiihrern in großen Zügen bekannt." (859, S. 73)

$1 V_{G}$. In diesem Zusammenhang folgende von der Zensur eliminierte Textstellen: UF45,8,S.49; UF45,8,S.104; UF46,4,S.15f. ; UF46,4,S.21; UF $46,4, S .57$; UF $46,5 / 6,5.33$; UF $46,7,5.10$ und UF $46,7,5.30$.

2 Die Bedeutung des von Kovpak, Rudnev und Verßigora geführten Verbandes, dem zeltweilig 1500 Partisanen angehören, wird in allen sowjetischen Darstellungen hervorgehoben, wobei man besondere Anerkennung seinen Befehlshabern zollt. So werden in der "Istorija" Kovpak 19mal, Rudnev $7 \mathrm{mal}$ und Versigora $5 \mathrm{mal}$ namentlich genannt. 
Refloktiert man in diesem Zusammenhang die 1948 an seinem Roman geübte Kritik, so wird auch an dieser Stelle der Rechtfertigungscharakter in Bezug auf die "Versäumnisse" der Urfassung von $1945 / 46$ deutlich.

Ein HöchstmaB an Indoktrinierung zeigt schlieBlich das in die F59 eingeschobene Kapitel, in dem die gelungene Beschaffung eines Funkgerätes durch den persönlichen Einsatz Chruševo breit ausgewalzt ist. Wie schon vorher beobachtet, soll auch bei dieser Konjektur der Schlussatz zur Stärkung des ideologischen Bewubtseins der Leserschaft beitragen:

\begin{abstract}
"Nach dem Kriege, als ich mit Partisanen aus dem Leninfrader und Brajnsker Gebiet, aus BeloruBland und der Krim zusammentraf und deren Tagebuicher und Aufzelchnungen studierte, uberzeligte ich mich immer weder davon, dab sich die Partei von Anfang an um die Bildung der Partisanenabteilungen, aus denen spëter die allgemeine fijderstandsberegung des Volkes hervorping, bemiihte und sie ständig unterstutzte. [...] Im Rücker des Feindes handelten die Partisanenabteilungen als ein untrennbarer Tell der bewaffneten Kräfte, unter der Lenkung des Oberkommandos auf dem whren keg zu Sieg."(F59, S. 111)
\end{abstract}

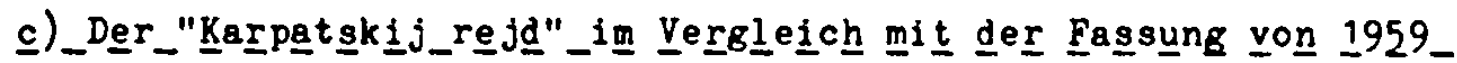
Können in der Orfassung von 1945/46 (Teil 1/2; "Rejd za Dnepr") in bezug auf die Frage nach der Rolle der Partei beim Partisanenkrieg noch vierzehn Streichungen und sieben Neukonzipierurgen registriert werden, so eliminiert der Zensor in der Urfassurg von 1950 (Teil 3/4; "Karpatskij rejd") keine einzige Textstelle, und nur vier neue kommen hinzu. Die Gründe für diese unterschiedliche Reaktion seitens der Zensurbehörde lassen sich leicht erschlieben.

Versigora schreibt den "Rejd $2 a$ Dnepr" unter politischen Bedingungen, die, bringt der Verfasser seine patriotisch-vaterländische Gesinnung zum Ausdruck, gewisse Tellwahrheiten zulassen. Da das vom Autor der Zensur eingereichte Manuskript nicht vorlięt, können zwar keine Rückschlüsse auf eventuelle Beanstandungen gezogen werden, doch ist mit Sicherheit anzunehmen, daB der dann in "Znamja" erfolgte Erstabdruck den Stempel "Razrešatsja $\nabla$ svet" trägt. Gewarnt durch die an thm geübte Kritik sowie die in groBem Stil erfolgte MaBregelung Fadeevs, scheint Versigora bei der Niederschrift des "Karpatskij rejd" vorsichtig geworden $2 u$ sein. Durch die offensichtliche Zurückhaltung, eine Art "Selbstzensur", sind die Zensoren mit dem vom Autor im "Karpatskij rejd" glaubhaft gemachten Führungeanteil der Partei innerhalb der Partisarenbewegung einverstanden: 
nicht eine einzige Passage, das zeigt der Vergleich mit der Fassung von 1959, tritt in diesem Zusammenhang in revidierter Form zutage. Trotzdem lassen vier kleinere Einschübe das Frinzip erkennen, daB allein die Ausklammerung der tätsächlichen historischen Fakten nicht genügt. Neben der Behauptung, daB die Partisanenbewegung sofort bel Kriegsende entstanden ist (F59, S. 414), legt Versigora den Schwerpunkt auf folgende Feststellung:

"In der Abteilung eab es achthundert Kommunisten. Etwa vierhundert davon sind gefallen. [...] Sür die Gefallenen traten immer wieder neue Kommunisten in unsere Reihen ein. Aus dem Volk empfingen wr stets neue Kraft." (F59, S. 529)

Im Schlußkapitel des "Karpatskij rejd" wird schließlich der Fartei, über die organisatorische Rolle im Krieg hinaus, ein weiterer Fihrurgsanteil zuges prochen.

"Ich dachte im Augenblick noch an Patronen und Maschinengewehre und wie ich alles durch die Frontlinie schleusen könnte. Aber die Partei ist bereits um den Frieden besorgt und macht sich Gedanken, wie man den Frieden sichern und unser Vaterland mit Bauwerken und Gartenanlagen verschönern kann. Sie sorgt sich um den Wohlstand des Volkes und dessen schöpferisches friedliches Leben."(F59, S. 670)

Der SchluBsatz, in dem der Erfolg der Partisanenbewefung in erster Linie den von der Partei eingesetzten Führern Dem'jan, Strokac und Rudnev zugesprochen wird (UF50, 5, S. 66) und der damit durchaus der Forderung nach Parteilichkeit entspricht, scheint dem Zensor in diesem speziellen Zuschnitt nicht zu gefallen. Eingedenk des Grundsatzes, dab die Partei zu jeder Zeit und an allen Fronten MaBgebliches peleistet hat, werden die Namen der Einheitsführer gestrichen, so daB nur noch die Partel als Institution schlechthin für sich in Anspruch nehmen kann, die Erfolge im Kampf errungen zu haben:

"Sie alle wissen [die Kovpakleute], daB wir unsere Erfolge im Kampf mit dem Gegner nur erringen konnten, weil die Partei das ganze groBe Sowjetrolk zusammengeschweiBt hat. (F59, S. 675)

1 Vergleicht man die von Versigora vorfenommene Konjektur mit der Darstel lung der "Istorija", so wird deutlich, daB diese Variante der Parteilichkeit zum Dogma gehört:"Aber die sowjetische sozialistische Gesellschaft, inspiriert und gelenkt durch die Kommunistische Partel, brachte genug Kraft guf, um noch während des Krjeges den wirtschaftlichen und kulturellen Wiederaufbau in den befreiten Gebieten zu beginnen. Partei und Regierung entsandten dorthin die erfahrensten Partei- und Wirtschaftskader." (Band V, 1963, S. 401) 


\section{Die Revision der militärischen Koordinierung zwischen Partisanenbere-}

gung und Eoter Armee

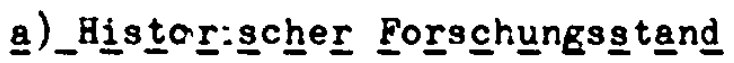

Wie schon aus Kaditel C 3 b der Arbeit hervorpeht, sind die meisten Partisaneneinheiten in den Kriegsjahren 1941/42 auf sich allein gestellt und handeln weitgehend auf eigene Faust. Eine hnderung tritt erst mit Bildung des Zentralstabes der Partisanenbewegurg im Mai 1942 ein. Ehe die dort beschlossenen Operationspläne jedoch zur Realisierung gelangen, vergeht geraume Zeit, zumel ein erfolgreicher Einsatz von Partisanen in Verbindung mit den Streitkräften der Roten Armee eine stabile Frontlage unentbehrlich macht. Die strategische Einplanung von Partisanenverbänden in die militärischen Operationen der repularen sowjetischen Streitkräfte ist demit erst nach dem Fall Stalingrads in der russischen Sommeroffensive von 1943 erkennbar sowie bei den Angriffsoperationen 1944 .

"Erst 1944 legte die Sonjetunion entwurfsweise eine Doktrin der Partisanenkriegfuhrung vor. Die Felddienstordnunf enthëlt (Kap. XVII) die wesentlichen Kampfaufträge und die Taktik der Partisanen, sufklärungsanweisungen und Techniken für Uberfälle und tberraschungsangriffe. [...] Die sowjetische Partisanendoktrin von 1944 befaBte sich, wie es die Felddienstordnung ausdrückte, mit 'dem bewaffneten Kampf der Volksmassen [...] Regen den ausländischen Eindringling, [...] zum $\mathrm{Zwecke}$ des gemeinsamen Vorpehens mit der Roten Armee'."

Im Vergleich mit westlich orientierten Quellen, dit den oben kurz umrissenen Sachverhalt einheitlich bestätigen ${ }^{2}$, erreben sich zu kommunistischen Darstellungen zwar Widersprüche, doch sind sie, Remessen an den in Kapitel C 3 a konstatierten Unstimmigkeiten, weniger prägnant.

In fast allen sowjetischen Darstellungen dienen im Hinblick auf die Jahre 1941/42 zur Charakterisierung der Beziehungen von Partisanenbewegung und

1 Sowjetsystem und demokratische Gesellschaft. Band II (1968) s. v. Guerillakrieg. Spalte $1153 \mathrm{f}$.

2

A.Werth, aa0. S. 531 schreibt dazu:"Die offizielle sonjetische These ist die, dab $\nabla$ or allem seit Herbst 1942 eine straffe Zusammenarbeit $z w i s c h e n$ Moskau [...] und den Partisanen [...] bestanden habe. Die Partisanen hätten nach einem Generalplan Rearbeitet, dessen Grundzüge in Hoskau festgeleg: worden seien. Bis zu einen fewissen Punkt trifft das zu. [...] Die Version allerdings, die aus den Partisanen eine Art zweiter Roter Armee machen will, die im Rücken des peindes kämpfte, vereirfacht die menschlicken Aspekte des Partisanendramas zu sehr." 
Roter Armee, die als Ergebnis einer vorausschauenden Planung de facto gar nicht existierte, Begriffe wie "Zusammenwirkung, "Hilfe" und "Unterstützung"; die Bozeichnung "militërische Koordination" wird jedoch bewubt vermieden. Allerdings versuchen die Historiker der östlichen Hemisphäre durch Formulierlingen globaler Art, unter Vermeidung einer genauen Datierung, den Eindruck zu erwecken, daB die Aktionen der Partisanenbewegung nur als Bestandteil einer schon seit Kriegsbeginn existierenden Planung betrachtet werden dürfen, zu der auch eine enge Zusamrenarbeit mit der Roten Armee gehört:

"Eine Besonderheit der sowjetischen Partisanenbewegung war ihre enge Zusammenarbeit mit der foten Armee, und ihre feste Einordnung in die Resamte sowjetische Kriegführung."

Trotz dieses Versuches, historische Fakten umzuwerten, damit sie ins ideologische Konzept passen, muB die These von der Unterstützung der Roten Armee durch die Fartisanenbewepung, wenn auch nicht in den ersten Kriegsjahron von Moskau geplant, so doch als indirektes Erfebnis bestätift werden. Die Resultate des passiven Widerstandes (Arbeite-lanfsam-Methode, Nichtbefolgung von Anmeisungen der Besatzungsmacht, Sabotage der Produktion u.a.m.) und der aktiven Gegenwehr (Beunruhifung des Gegners, Vernichtung kleirerer Objektschutzeinhejten, Sprenqung von Brücken, Bahnkörpern und Roljbahnen) kommen der Roten hrmee bei ihren Operationen häufig zugute. Hirsichtlich der militïrischen Koordinierung zwischen Partisanenbewequng und Roter Armee ist die Datierung auf das Jahr 1942 durch die sowjetische Geschichtsachreibung rach heutiger Quellenlage sicherlich um zwölf Monate zu früh arpesetzt. ${ }^{2}$

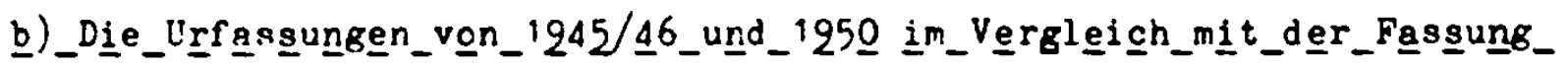
von 1959-

Entsprechend dem schon in Kapitel C 4 a vorgezeichneten Bild freift die Zensur auch hinsichtlich der Frape nach der Koordination bei den Kampf-

H.Kühnrich, 8a0. S. 366 .

2 Stellvertretend aus der Fülle an Darstellungen soll die füberung von H.Görlitz, Der Zweite Keltkrieg 1939-1945. Band II (1952) S. 121 stehen:"Ende 1942/Anferg 1943 wurde das Auftreten gröBerer Partisanenbar:den [...] charakteristisch. Sie arbeiteten mit den angreifenden roten Armeen zusammen." 
handlungen von Partisanenbewegung und Roter Armee korrigierend ein. Ver$\$$ igora, der auf insfesamt vier Seiten in der UF45/46 die geglückte Sprengung des Eisenbahnknotenpunktes "Sarnsk1j krest"" schildert, beendet die Episode mit dem Setz:

"Es war in der Nacht von 4. auf den 5. Dezember des Jahres 1942. In dieser Nacht, 1500 Kilometer im Osten von uns, vollendeten die Truppen der Roten Armee in der Nähe von Stalingrad die Einkreisung der Armee von Paulus." (UF45, 8, S. 93)

In der Fassung von 1959 dagegen ist die Beschreibung dieser Aktion auf den dreifachen Umfang angewachsen (verstärkte Betonung der organisatorischen Leistung des Kovpakverbandes ${ }^{1}$ ), zudem ist an den oben zjtierten Satz eine Passage angefügt, die keires weiteren Kommentares bedarf: "Und das 'Sarnskij krest"' - das war die Hilfeleistung der Partisanen von Kovpak für die heldenhafte Rote Armee, die nunmehr den Wendepunkt zu ihren großen Siegen errelcht hatte." (F59, S. 130)

Eine weitere Textstelle, die von Versigora in die 559 eingeführt wird, um die organisatorische Rolle der Partel zu betonen (siehe S. 19 der Arbeit), wird auch gleich genutzt, um die von der Zenaur gewünchte Betonung vom Zusammenwirken von Partisaneneinheiten und Truppenteilen der Roten Armee zu stützen.

"Der Auftrag, den Matveev von der Regierung erhalten hatte und den er den Kommandeuren der Brjansker Partisanenabteilungen übermitteln sollte - das Gebiet um jeden Preis als Basis für weitere VorstöBe und später als stabiles Aufmarschgebiet für die vorrückenden Truppenteile der Roten Armee zu halten - muBte erfült werden. [...] Dieses Gebiet sollte nicht nur zur Basis der militärischen Aufklärung werden, von hier aus versetzte auch die siegreiche Rote Armee gemeinsam mit den Partisanen dem Gegner wuchtige Schläge." (F59, S. 47)

tber die oben darpestellte Revision im Sinne einer nachträglichen Aufpolierung der de facto nicht vorhandenen strategischen Konzeption hinaus werden von der Zensur eine Reihe von Textstellen eliminiert, die in irgendeiner Form Mängel oder MiBerfolge der hoten Armee dokumentieren.

"Geradeheraus gesagt: bis zur Schlacht um Stalingrad hatten wir alle mit der Roten Armee abgerechnet. Viele bittere Worte waren gesagt-, viele bittere Gedanken gedacht worden. Wir hatten die Deutschen im Hinterland verstreut und rickten vor, aber dort wich man

1 Die Sprengung des "Sarnskij krest"" wird auch von Telpuchovskij als Beweis für die Koordination von Partisanenbewegung und Roter Armee dargestellt, da die Zerstörung zufällig zur gleichen zeit erfolgt wie die Einschließung Stalingrads durch Truppen der Roten Armee. 
bis zu jener Zeit nur zurück. Diese bitteren Gedanken brachte irgendwie auch unser Dichter Platon Voron'ko ${ }^{1}$ zum Ausdruck: ... Der Partisan wiuscht keine Schonung / und um Hilfe ruft er nicht. / Er ruft nicht. den fernen Freund, / der an der Front tausend Verst entfernt kämpft, / von jenseits des Don und des blauen Bug / kommt niemand zur Ablösung... Sie gaben Städte, Dörfer und Flüsse auf, vielleicht wit schweren Gefühlen, aber trotzdem lag dahinter ein Land, immer mehr vom Stalinschen *illen zum Sieg erfüllt, und sie fïhlten es. Sic hatten ein Hinterland, ein mïchtiges sow jetisches Hinterland. Aber wir, eine irmee ohne Hinterland und Flanken, wir sahen fast nur die bitteren Resultate des Rulckzuges. Wir sahen das zu Asche fewordene Belorubland, die ausgequetschte, blutbespritzte Ukraine. Und wir kan. ten auch den Sinn und die schmerzlichen Forte eines gewissen Tagesbe. fehls, und mehr als jeder andere hatten wir, die Zivilisten, Lehrer, Buchhalter, Kollektivbauern und Musiker, die zu den kaffen gegriffen hatten, das Recht, den Männern, die sich nach Osten zurückzogen, Vor. würfe nachzuschleudern. Wenn auch nicht alle, so dachten doch viele von uns, daB wir diese Teilerfolge nicht durch unsere Tapferkeit oder durch unser besonders militärisches Geschick erreicht hat ten, sondern nur deshalb, weil sehr scrwache Truppen des Feindes gegen uns kämpften, da Hitler alle seine besten Kräfte und Reserven der Roten Armee entgepenwarf." (UF46, 4, S. 60f.)

Davon ist auch das Einfestürdnis Veráigoras betroffen, der seine Kampfeinirücke als Fihrer eines Zuges der Roten Armee aus den ersten Monaten des Krieges wiedergibt:

"Hier geriet ich in proBe Verwirrung, die aus irgendeinem Grunde vom Kommandostab der Division und sogar vom Oberkommando als herausragen. des Ereignis beurteilt worden war, als Heldentat oder etwas in diese: Richtung. Hätten der Kommandeur des Korps und die Führer des Politka. ders, die uns einen Tag nach diesem Vorfall auszeichneten, in Wirklichkeit veretanden, was sich ereignet hatte, wäre ihnen klar geworden, daB ein in mitilärischen Dingen unerfahrener Mann das Batallion befehligte, der in seiner Hilflosigkeit eine Dummeit begangen hatte die einen zeitweiligen Erfole brachte.[...] Vielleicht, daB dort ein ebenso unfähiger offizier wie ich die Befehlsgewalt hatte[...]" (UF45, 8, S. 25f.)

Im Textabschnitt, der an die Stelle des gestrichenen von Verßigora in die Fassung von 1959 ersatzweise eingeschohen wird, fehlt jetzt die kritische Selbsteinschätzung, dafür ist jefoch die Unfähigkeit der Deutschen, trotz der damit verbundenen Gefahr, daß sich der unvoreingenommene Leser fragen muB, warum uberhaupt so ungeheure Anstrenkungen und Opfer bei der Verteidigung des Landes notwendig waren, stärker herausgehoben.

"Mir, wie auch vielen Soldaten, die damals nicht über eine genügende Kampferfahrung verfügten und den Feind schlecht einschätzten, war dieser Zug der bornierten deutschen Taktik noch unverständlich. Nach einem halben Jahr hatten wir erkannt, daB '... die Deutschen bei ihren Operationen puinktlich und genau sind, wenn die Lage es gestattet den Vorderungen der Dienstvorschrift nachzukommen. Darin liegt ihre

Vgl. in diesem Zusammenhang Kapitel B 3 S. 12 der Arbeit. 
Stärke. Die Deutschen werden hilflos, sobald die Lage kompliziert wird und in diesem oder jenem Paragraphen der Dienstvorschrift 'nicht mehr entspricht, sondern einen selbständigen EntschluB erfordert, der in der Dienstvorschrift nicht vorgesehen ist. Darin liegt ihre Hauptschwäche." (F59, S. 11)

Stehen schon die kritische Beleuchtung der Koten Armee und ihrer militärischen Führung auf der Liste der unerwünschten Themen, so verwundert es nicht mehr, daß auch die Tätigkeit der Politkommissare ${ }^{2}$, die aus dem Hin-

In diesem Zusammenhang muB darauf hinpewiesen werden, daB ein Teil der angeführten Textstelle (von "die Deutschen" bis "Hauptschwäche") von Verłigora als Zitat kenntlich gemacht ist, ohne daB dem ieser Klarheit uber die Herkunft gegeben wird. Wie die tberprüfung der Passage ergab, handelt es sich um einen Auszug aus den "inweisungen des obersten Befehlshabers", Nr.95, Moskau, 23.Februar 1943 (vgl. J.Stalin, "Uber den Großen Vaterländischen Krieg der Sow jetunion" 1946, S. 97f.). Vermutlich liegen zwei Gründe vor, die das Verschweigen der quelle durch den Autor bedingen:

1. Mit Vollzug der Entstalinisierung sind der Name Stalins und damit auch seine offiziellen Verlautbarungen grc̈Btenteils tabu.

2. Stalins huBerung vom Februar 1943, die offensichtlich im Zusammenhang. mit der Kapitulation der deutschen Truppen in Stalingrad am 2.Februar 1943 steht, kann kaum für den Zejtraum Ende 1941/Anfang 1942 geltend gemacht werden. Die von Verßicora geschilderten Kampfeindrücke, an die das Stalinzitat anschlieBt, stammen eindeutif aus dem August des Jahrea 1941. Rechnet man ein halbes Jahr hinzu ("Nach einem Jahr hatten wir erkannt, daB..."), so ergibt sich als Zeitpunkt für die von Versigora Flaubhaft gemachte Erkenntnis das Frühjahr 1942, eine Etapre im Kriegsverlauf, die derartige Schlüsse uberhaupt nicht zuläBt. Durch das Verschweigen der mit dem $Z$ itat verbundener. Jahreszahl wird diese Diskrepanz weitgehend beseitigt, bzw. ist auf den ersten Blick nicht mehr erkennbar.

Die Institution der Politischen Kommissare wird für die Rote Armee 1918 eingeführt, um einerseits die aus der Zarenarmee notwendiferweise übernommenen Truppenkommandeure, die als poljtisch unzuverlässiff gelten, zu uberwachen, andererseits um die politisch-ideologische Festigunf der Frontsoldaten zu gewährleisten. Dariiber hinaus hat der Komrissar Vorbild für die kämpfende Truppe zu sein und muB in bezug auf Tapferkeit und Opferbereitschaft vorangehen.

Im Oktober 1942 wird auf ErlaB des Obersten Sowjet das Kommissarwesen in der Roten Armee abgeschafft, in den Partisaneneinhelten jedoch für die gesamte Dauer des Krieges beihehalten. Der Grund für diese MaBnahme, neben rein militärischen Erwäpungen, ist der Zweifel Stalins und seiner Fuhrungskader an der politischen Zuverlässigkeit der Partisanen, da sich die bei ihnen äuBernde konspirative Gesinnung schwerlich mit sozialiatischen Ordnungsprinzipien vereinbaren läBt. Aus diesem Crunde werden nach Befreiung der Partisanengebiete durch reguläre Einheiten nur wenige Partisanenformationen den Verbänden der Roten Armee angegliadert. 
terland eingeflogen werden, um gröBere Partisaneneinheiten militärisch und politisch zu schulen, nur positiv erwähnt werden darf. 2war macht Verłigora keine negativen Anmerkungen zum militärischen Führungsstil der Politkommissare - die durchweg positive Gestaltung von Rudnev bexeist dies - doch scheint ihm die von ihnen betriebene Propaganda-Arbeit ein Dorn im Auge zu sein. So fehlt denn die Textstelle in der Fassung von 1959, in der der Autor von "Ljudi s distoj sovest'ju" die Effektivität dieser Leute kritisch beurteilt:

"[...] die kleingeistigen Kommandeure, die für die Propaganda-Arbeit Zuständigen. fielen uns unangenehm auf und saben uns wie ein spitzer Stachel im Herzen, obwohl ihr Prozentsatz nicht hoch war [...]" (UF $46,4,5.61$ )

Aus der Urfassung "Rejd za Dnepr" mub auch die Textstelle weichen, in der Versigora indirekt Kritik an der militärischen Planung seines unmittelbaren Vorgesetzten äuBert, obwohl die in seiner Einheit herrschenden Umgangsformen diese, wie dem Kontext zu entnehmen ist, durchaus zulassen.

"Vielleicht deshalb, wiederhole ich, weil es an 'strategischer Kühnheit' mangelte, oder, weil sich auch bei der Durchführung von Partisanenaktionen, warum ist nicht ersichtlich, Lokalpatriotismus und Praktizismus eingenistet hatten. Nirgendwo wirkt sich der Praktizismus so schädlich aus wie in der Landwirtschaft und im Partisanenkrieg." (UF46, 7, S. 54)

Ebenso wie die oben zitierte kritische Anmerkung Ver\$igoras, die auf den Führer des Verbandes, den Bürgerkriegstellnehmer, den zweifachen Helden der SU und das langjährige Parteimitglied Kovpak gemünzt ist, sind schlieblich auch negative AuBerungen des Autors über die personellen Eingriffe übergeordneter Kommandostäbe innerhalb der kampferprobten Führung der Partisaneneinheiten unerwinscht. 1

"Noch eine andere Uberlegunp ginf mir durch den Kopf. Möglich, daB die hergesandten Genossen bei dem Versuch, die Partisanenstäbe zu

1 Diese Textpassage muBte, abgesehen von der Aufdeckung der Nachteile, die aus der Koordinierung von Partisanenbewegung und Roter Armee für einzelne Partisanenverbände entstehen, aus Gründen weichen, die in $\mathrm{Zu-}$ sammenhang mit der neueingefügten Textstelle der Fassung von 1959 stehen. War Versigora gezwungen, die taktischen Unzulänglichkeiten der Roten Armee auszumerzen urd dafür die starre Befolgung der Dienstvorschriften durch den Gegner einzuschieben, so zeigt sich anhand der durc die Zensur gestrichenen Passage (UF46, 7, S. 54), daB genau das Gegenteil der Fall ist (vgl. dazu die zitierte Textstelle der F59, S. 11 auf S. $32 f$. der Arbeit). 
festigen, mechanisch ihre Erfahrungen von den Armeeoperationen auf uns übertragen. Die Fähigkeit, die Uberlegenheit der Streitkräf te im geeigneten Augenblick und am rechten Ort herzustellen, das ist der Schlüssel zur Kriegskunst. Manche glauben jedoch voller Einfalt, dab sie das auf arithmetischem Wege, durch die einfache Addition der Bajonette, Schnellfeuerwaffen und Geschiitzrohre erreichen können. [...] Mit einem Fort, ich bin für den Gebrauch der Algebra im Kriege, habe jedoch etwas gegen die Leute, die ihre Arithmetik engstirnif betreiben. Die arithmetischen Veranlagungen einiger haben uns eine Menge Blut gekostet." (UF46, 7, S. 54)

5. Die Idealisierung des Partisanenbilies

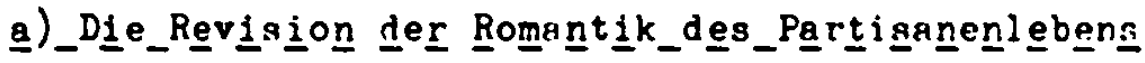

Im Zuge der Umarbeitung des Romans nach den Richtlinien der Partei, speziell der Ausrichtung auf die jetzt geforderte Betonung der organisatorischen Rolle der Partel beim Partisanenkampf und der weitsichtif geplanten Koordination von Partisanenbewegung und hoter frmee, wird Veršigora offensichtlich auch genötigt, die in der UFA5/46 zu wahrheitspetreue Schilderung des Partisanenlebens zu revidieren. Wie schon kurz zuvor angedeutet, wird der sich in vielen literarischen Werken der Kriegsjahre äuBernde Patriotismus vaterländischer Prägung von den Organen der Partei geduldet und gefördert. Auch die sich zur petriotischen Einstellung gesellende romantische Grundhaltung - eine besondere Eigenart der Partisanenliteratur - stößt auf keine offizielle Kritik.

Diesen Sachverhalt bestätigt A.Werth indirekt wie folgt: "Im Sommer 1942 wurde in Moskau ein 430 Seiten starkes Taschenbuch mit dem Titel 'Partisanenfürer' verkauft, das angeblich in einer Auflage von 50000 Stijck gedruckt worden war. [...] Auf den ersten Blick konnte man bei der Lektüre den Eindruck gewinnen, rissische Partisanen seien eine Art ruhmreicher Pfadfinder; es sei zwar immerhin schwierig. 'in Schnee zu leben', und kein besonderes Vergniigen, in Notfällen Moos und Rinden zu essen, doch sei trotz allem das Partisanendasein ein herrliches Leben."1

Als die Partei 1946/47 firr sich in Anspruch nimmt, "Inspirator" und "Organisator" der Partisanenbewegung gewesen zu sein, pabt der aus russischnationa:istischen und romantisch gefärbten Gefühlen kämpfende Partisan nicht mehr ins ideologische Konzept. Der Verteidiger der Heimat hat nun ein Kämp̧er von hohem politischen BewuBtsein zu sein, der sich, einfedenk seines Mlassenstandpunktes, unter der faschistisch-imperialistischen

A. Wer:h, ea0. S. $52 \Delta \mathrm{f}$. 
Herrschaft zum Befreiungskampf erhoben hat und gewillt ist, sein Leben nicht aus Abenteverlust zu riskieren, sondern für seine sozialistische Heimat und die Ehre der Kommunistischen Partei zu opfern. Gemessen an dif sen Vorstellungen vom Partisanen verwundert es nicht, dab eine Reihe von Textstellen dem Zensor miBfallen und folglich in der Passung von 1959 nicht mehr enthalten sind.

Offensichtlich greift man auch in diesem Punkt auf Lenins Partisanenkonzeption von 1906 zurijck, in der es heibt: "Partisanenaktionen sind keine Racheakte, sondern militärische Operationen. Sie gleicher ebensowenig einem Abenteuer, wie die Streifzuge von Jägerabteilunger im Rücken der feindlichen Armee während einer Kampfpause auf dem Kriegsschauplatz den Morden von Duellanten oder Verschwörern gle1chen." 1

Heibt es in der Urfassung von $1945 / 46$ noch "Unter die Partisanen gingen Freiwillige, darunter Romantiker und solche, die zufällig zu den Partisa nen stieBen"? , so finden sich zur Verteidigung der Heimat 1959 nur noch "Freiwlllige und solche, die zufällig zu den Partisanen stieben" 3 ein. Auch die Vermutung Versigoras, daB den die Abtellung inspizierenden Genos sen Dem'jan (vermutlich der Deckname Chruševs) die Romantik des Partisanenlebens beeindruckt, wird ersatzlos gestrichen. ${ }^{4}$ In dieser Weise verfährt der Zensor auch mit Textpassagen, die nur einen indirekten SchluB auf eine vorhandene Romantik zulassen. So fehlen die von Verligora gegebenen Hinweise, daB die Abteilung Kovpaks eine "flotte" Truppe sei ("Verregenes Volk ist versammelt" " "Wir fühlten uns als die Herren dieses Ge. bietes. Die Leute führten sich unbekümmert und wüst auf." ${ }^{6}$ ), die einen "abenteuerreichen $W \mathrm{eg} 7$ vor sich habe ebenso wie die Beschreibung rusti-

21t. nach: Sow jetsystem und demokratische Gesellschaft. Band II (1968) s. v. Guerillakrieg. Spalte 1128 .

2 UF45, S. 46 .

3 F59, S. 36 .

4 UF46, 7, S. 38: "Mir schien, daB ihn schon der Reiz des romantischen Partisanenlebens zu packen begann."

5 UF46, 5/6, S. 28 .

6 UF46, 5/6, S. 29. (V UF46, 4, S. 52 .

7 of 45,8, S. 108 . 
kaler Scherze durch Angehörige der Einheit.

"Wenn sich die Leute der Abteilung besonders langweilten, machten sie einen alten Scherz, den sie den 'Velas verheiraten' nannten. Sie machten irgendeire Alte ausfindig und beteuerten Veles, dab sie in inn verliebt sei. Halb im Scherz, halb im Ernst, spielte er immer gern mit und bemühte sich ernsthaft und beharrlich um Liebesbeweise. Häufig endete die Sache damit, daB Velas mit einem blauen Fleck unter dem Auge oder mit einem zerkratzten Gesicht zurückkehrte." (UF46, 4, S. 47)

Zei tgemäB sind auch die Szenen nicht mehr, bedingt durch die Angleichung des Status der Partisaneneinheiten an den militärischen Duktus der Roten Armee, die offenkundig werden lassen, daB zwischen den Partisanen der "ersten" Stunde und den später aus dem Hinterland eingeflogenen Angehörigen der regulären Armee Differenzen bestehen. In diesem Zusammenhang ist die farbenprächtige Episode, in der ein Kapitän der Roten Armee durch den Partisanenfihrer Lenkin wegen Unterlassurg des militärischen GruBes gemabregelt wird, in der Fassung von 1959 nicht mehr vorhanden.'

"- Genosse Kapitän, warum grüßen sie nicht?- fragte er streng. $[. . . ?$ Der Kapitän schaute verwirrt auf den unbekannten Vorgesetzten. Die Uniform, der imponierende Schnurrbart, das schöne Pferd und die Hauptsache, zwei erbeutete Pistolen im Gürtel und der neue deutsche Sattel - alles sehr seltene Trophäen für die wenig kämpfenden, unbereglichen 'kald'-Abteilungen - schienen inm eine Bestätigung der hohen Vollmachten des Unbekannten zu sein.

-Ich bitte um Verzeihur.g, Genosse Vorgesetzter... - murmelte er verwirt.

-Zu wenig an Entschuldigung, treten Sie zurück... schneller, schneller. Jetzt Marsch... - kommendierte der Cefreite Lenkin den auBer Fassung geratenen Kapitän. Dieser kam an ihm mit strammen Schritten vorbei. Nachdem er noch einige Bemerkungen darüber gemacht hatte, wie die Brust herauszustrecken sei, der Bauch einzuziehen und in welcher Höhe der Ellenbogen sich ziemlichst zu befinden habe und er den bleich gewordenen Kapitän noch ein wenif. zur Eile angetrieben hatte, sprenfte er im Calopp davon." (UF46, 4, S. 51f.)

Durch die rigorose Beschneidung des Textes seitens der Zensur verliert der Roman viel von seiner ursprünglichen Authentizität, zumal die von Verłigora in der Urfassung noch lebendig und relativ wirklichkeitsnah gezeichneten Figuren, wie auch das folpende Kapitel zeigen wird, nachträglich zu positiven Helden hochstilisiert worden sind.

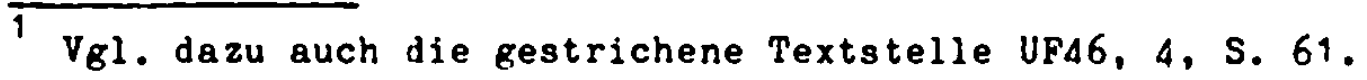




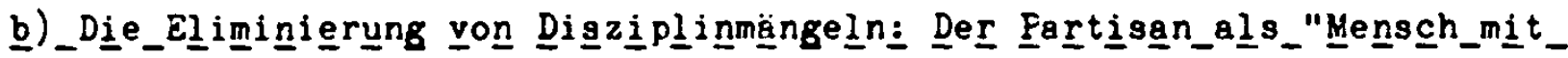
reinem_Gewis.sen"

Nachdem in den vorhergehenden Kapiteln der Arbeit die Diskussion der innerhalb der Forschung strittigen Frugen zlim Fartisanenkrieg (Von welchem Zeitpunkt an darf von einer Partisanenbewegung gesprochen werden?, Helche Rolle spielt die Kommuristische Partei hierbei?, In welcrem Umfang kann die Partisanenbewegunp als ein militärisch hedeutsamer Faktor im Gesamtkonzept der sowjetischen Verteidigungs- und Angriffsstrategie angesehen werden?) theoretisch geklärt und praktisch on den unterschiedlichen Fassungen vor Verłigoras "Ljudi s $\ell_{i s t o j}$ sovest'ju" erläutert worden sind, bleibt noch die nur flüchtig angeschnittene Frage nach den den Partisaner krieg auslösenden Momenten offen.

Nach den Ergebnissen der westlich orientierten historischen Forschung, Hie die sowjetische Lesart eindeutig widerlegen, sind in den ersten Kriegsmonaten keine nennenswerten Partisanenaktionen zu verzeichnen. Die Bevölkerung der westlichen Gebiete der Sowjetunion braucht geraume Zeit, um sich von der Uberraschung des deutschen Vormarsches und der schnellen Besetzung weiter Landesteile zu erholen. AuBerdem empfinden die meisten Bewohner der Baltischen Länder den Einmarsch der deutschen Truppen als Eefreiunf von ter ortrovierter. Sowjetherrschaft, während sich die Einwohner der llkraine und Heiśsußlands abwartend verhalten.' Mit dem Einricken der SS- und SD-Einsatzgruppen, die einzelne spontane tberfälle auf deutsche Hehrmachtangehörige hart uhnden, ändert sich die Situation.

"Die schändliche Wirksamkeit dieser Sicherheitsgruppe und die unmenschliche Ausführung der iusrottungsbefehle sind allgemein bekannt. [...] Sie bestanden zunächst in der Ausrottung und dauernden Bekämpfung kommunistischer Organisationen und ihrer Anhänger, der Erfassung von bmipranten und Feinden des nationalsozialistischen Staates, in der Untersuchung und Bekämpfung aller deutschfeindlicher Bestrebunken und allgemein der Vernichtung aller potentiellen Gegner des Nationalsozialismus. Die letzte huftragsgruppe enthielt die Grundlage des Mordauftrages am jüdischen Bevölkerungstail der Sowjetunion." $i$

\footnotetext{
1 E.Hesse, 8a0. S. 39.

2 aao. S. 35 .
} 
Während sich die Bewohner von Dörfern und Städten unter dem Eindruck der deutscher Besatzungspolitik punktuell zum sporadischen Widerstand entschließer. ' formieren sich versprengte Soldaten und Offiziere der Roten Armee sowie aus der Kriegsgefangenschaft Geflohene hinter den schnell vorrückenden deutschen Armeen zu Partisaneneinheiten; zum einen, weil sie erfahren, daB die deutsche Organisation den in unerwartet hoher Zahl auftretenden tberläufern und Kriegsgefangenen vorsorgungstechnisch nicht gewachsen ist, zum anderen, weil sie nach einem erfolgreichen Durchbruch zu den eigenen Linien fürchten müssen, als Deserteure behandelt zu werden.

Sucht man nach den oben belegten Tatsachen in offiziellen sowjetischen Darstellungen verreblich, so fehlen auch jegliche Hinweise über die unzureichende Versorgung und mangelnde Bewaffnung der Partisaneneinheiten der ersten Stunde (vgl. dazu die in der UF45, 8, S. 42 und UF45, 8, S. 34 enthaltenen Textstellen, die in der F59 fehlen). Entsprechend dem Dosma, daB der Widerstandskampf von der Partei gelenkt wird und die Partisaneneinheiten der Ordnung und dem Befehlsgefüge der regulären Armee untergeordnet sind, muB nun auch zwangsläufig die Eigengesetzlichkeit des Partisanenkampfes negiert werden. Da die einzelnen, isoliert kämpfenden Partisanenabteilungen der Jahre 1941/42 weder über eine hierarchische Befehlsstruktur noch ein militärisch genormtes strategisches Konzept verfügen,

1 G.von Rauch (aa0. S. 363) gibt zu diesem Komplex folgende Daten an, die als Eckpfeiler bei der Entwicklune der Partisanenbewegung gelten können: "Schon die Verordnunf vom 13. Mai 1941 befahl, gefangene Kommissare ohne Cerichtsverfahren zu liquidieren. Der sogenannte 'Kommunistenerla $B^{\prime}$ vom 16 . Septemher sah vor, daB für einen im besetzten Gebiet getöteten deutschen Soldaten 50 bis 100 Kommunisten zu erschieBen seien, der 'GeiselerlaB' vom 1.Oktober gab die Möglichkeit, Geiseln auch aus nichtkommunistischen Bevölkerungsschichten zu entnehmen. Der 'Nacht-und-NebelErlab' vom 7. Dezember sah vor, daB bei Terror- und Sabotageakten die Zivilbevölkerung möglichst unbemerkt vom sogenannten Sicherheitsdienst abtransportiert werden sollte, um in der deutschen Rústungsindustrie eingesetzt $z$ werden. Ein ErlaB vom 18. Dezember sah Repressalien gegen Angehörige von Saboteuren vor, und der 'Bandenerlab' vom 16. Dezember 1942 erlaubte dem 'Chef der Bandenbekämpfung', mit drastischen Mitteln gegen Partisanen vorzugehen."

"Laut Dienstvorschrift von 1936 muBte jeder Sowjetsoldat, der in Gefangenschaft geraten war, vor ein Kriegsgericht gestellt werden." (B.Telpuchovsikij, aaO. S. 594; Fubnote von den Herausgebern A.H1llgruber und H. -A.Jacobsen). 
geschweige denn ein an Beraffnung und Uniform einheitliches Erscheinungsbild aufreisen, sind Disziplinmängel an der Tagesordnung.

Diese können jedoch, wie schon die Reviston der im Partisanenleben vortandenen Romantik verdeutlicht, nach dem bestehenden Dogma nicht zugegeben werien. Gemïi dem Grundsatz, daB Erscheinungen und Vorkommnisse, die dem von der Partei festgelegten Idealbild vom Partisanen widersprechen, nicht existent sind, erfährt der Roman Versigoras durch die Zensur eine einschlägige Bearheitung.

Sämtliche Textstellen, aus denen für den Leser ersichtlich wird, dab eine lockere Disziflin zum Status der Partisanenabteilung Kovpaks gehört, sird in der Fassung von 1959 nicht mehr vertreten. So werden die bei der Verteilung des Beutegutes entstehenden Spannungen, guf deren Höhepunkt Karpenko droht, den Kommissar "um die Ecke zu bringen" ", von der Zensur durch entsprechende Streichungen entschärft, und die Textstelle ( 1,5 Seiten), die AufschluB über die Disziplin und die Kampfmoral einer einzelnen Abteilung it. Gesamtverband Kovpaks gibt, vollständig entfernt.

"Den Ruf der sietten Kompanie pfiffen bei uns die Spatzen vom Dach. Hier hatten sich Leute zusammengefunden, die träge waren, ohne Initiative und feife.[...] Ḧenn es zum Kampf kommt, so läBt die siebte Kompanie entweder die Stellungen im Stich oder verliert beim angriff den Kopf und peht bei Ende des Kampfes auf die eigenen Leute los. Sie haben in ihrem Leben weder ein deutsches noch ein ungarisches Maschinergewehr geseher. Wie kann man auch ea auch sehen, wenn man vor thm wegläuft, ohne sich umzudrehen. Auf dem Rücken hat man keine Augen." (UF46, 4, S. A19.)

MiBfallen dem Zensor schon die von Verşigora im "Rejd za Dnepr" geschilderten Disziplinlosigkeiten und werden dementsprechend eliminiert:

"An allem war abzulesen, daß die Burschen ausgerechnet die nepativen. Seiten des Partisanerlebens angenommen hatten: das ungezügelte Benermen und den Mangel an Disziplin." (LF45, 8, S. 79),

wird die einheitliche Linie auch im "Karpatskij rejd" weiter durchgehalten. So ist die von der Zensur verscront gebliebene Texistelle, aus der hervorgeht, tab der Mangel an Disziplin zum Teil eine Folgeorscheinung der unzureichenden Versorgune ist (1943!), in der Fassung von 1959 nicht

TF45, 8, S. 80 (VRl. dazu auch die Streichung der Textstelle UF45, 8, S. 81). 
nehr enthalten.

"Es war notwendig, die Zügel zu straffen, denn die Abwesenheit von Kovpak und Rudnev hatte sich bei allen rumgesprochen. Zwar lobten die Kämpfer ihre Kommandeure, die die Abteliung von der Front abgezogen hatten, um ihr eine Ruhepause zu gönnen, aber an Mykola und Vasja wurde deutlich, dab die Disziplin zu wünschen übrie lieB: So schlummerte der Wachhabende auf seinem Posten ein oder die Angehörigen der Abteilung gingen ohne Erlaubnis ins Dorf, um etwas EBbares zu suchen. Naturlich konnte man deswegen keine strengen Strafen verhëngen, zumal wir in den Bergen operierten und der Hunger uns würgte." (UF50, 5, S. 21)

Ein in die Passung von 1959 eingefügtes Kapitel soll dafür am Beispiel der Partisanin Gan'ka exemplarisch belegen, welche Konsequenzen für den einzelnen Kämpfer aus der auf individuellen Neigungen beruhenden Disziplinlosigkeit erwachsen. Nachdem der Einheitsführer auf Grund ihrer Alleingänge droht: "Ich nehme sie bei Aufklärungsgängen nicht mehr mit! Sie ist zu undiszipliniert!" (F59, S. 119), ordnet sie sich, wenn auch widerwillib, ins Kollektiv ein.

MuB in einem Dokumentarroman uber den Partisanenkrieg schon der einfache Kämpfer als ein integrer Repräsentant des Sozialismus gestaltet sein, gilt das im besonderen MaBe für die die Einheiten führenden Kommandeure, zumal diesen in den Jahren 1943/44 teilweise militärische Ränge der Roten Armee verliehen werden. Infolgedessen streicht die Zensurbehörde alle die Textstellen, die über die Moral und die Disziplin der Einheitsfïhrer negativen AufschluB geben. Schlieblich wird das von der historischen Forschung eretellte Idealbild vom Partisanengeneral und Helden der sU, Kovpak, empfindlich gestört, wenn der Leser von Veršigoras "Ljudi s cistoj sovest 'ju" erfährt, daB bei strategischen Meinungsverschiedenheiten ein Faustkampf entscheidet, wer von den Kommandeuren Recht bzw. Unrecht hat. 1 Auch darf ein Leiter der Aufklärungsabteilung in Range eines Generalmajors (Verłigora) weder seine Waffe verlegen ${ }^{2}$, noch während einer Einsatzbesprechung vor tbermidung einschlafen ${ }^{3}$ oder sich gar nach dem Gefecht der Ausrüstungsgegenstände des gefallenen Gegners bemächtigen:

\footnotetext{
UF46, 7, S. 27. (ebenso UF46, 7, S. 50).

2 JF45, 8, S. 95f. (vgl. dazu UF45, 8, S. 100).

3 OF45, 8, S. 101.
} 
"Onsere Leute waren über die Deutschen hergefallen und mich ergriff von neuem eine Art kämpferischer Extase.[...] Obwohl ich selbst nicht genau wubte, wozu ich das nötig hatte, lief ich zu ihm hin, $20 g$ inm die Stiefel aus und begann, mich seiner Ausrüstung zu bemächtigen. Als ich diese 'Operation' beendet hatte, hörte ich, daB der Deutsche noch röchelte. Eine Salve war quer durch seine Brust gegangen, nahe dem Hals. Er röchelte, als ob er etwas sagen wollte. Volodja Lapin hatte eine ähnliche Operation bei weitem schneller beendet als ich." (OF45, 8, S. 70)

Einen eigenständigen Bereich innerhalb dieses Kapitels bilden die von der Zensur ausgemerzten Stellen, die zum Problemkreis "Alkohol" gehören. Obwohl die von Verłigora genannten Grunde deutlich machen, daB nicht allein der Mangel an Disziplin, sondern auch die besonderen Unstände der Kriegführung für den GenuB von geistigen Getränken durch Angehörige der Aufklärungseinheit verantwortlich sind ${ }^{1}$ - nicht einmal der Kommandostab hält entsprechende Verbote für nötig - passen diese Vorkommnisse nicht zum Blld einer nach dem militärischen Status der Roten armee geformten und von der Partei gelenkten Widerstandsorganisation.

"Freilich, wie in der dritten Kompanie, so gab es auch in der Aufklërungsabteilung Leute aller Schattierungen, eigensinnige und launenhafte. Die Aufklärungsarbeit drickte diesen Leuten einen besonderen Stempel auf. Der Aufklärer steht dem Tod immer Auge in Auge gegenuber. Ond so ist es nicht verwunderlich, dab viele von ihnen einen hang zum Alkohol hatten. Die Wahrheit ist, daB es das ungeschriebene Gesetzt gab, während eines Einsatzes niemals zu trinken. Es wurde tadellos erfullt und in Falle einer ohnehin seltenen tbertretung rechneten die Aufklärer mit dem Schuldigen unter sich ab. Trotzdem kehrten selbst einsichtsvolle und kühne Leute häufig mit einem Vorrat 'Selbstgebranntem' von der Aufklärung zurick. Nachdem sie den Vollzug des Auftrages gemeldet hatten, verbarrikadierten sie die Onterkinfte. Obwohl wir dies nicht besonders gerne sahen, hinderten wir sie nicht daran. Womit hätten wir unseren aufopferungsvollen und furchtlosen Leuten für ihre unschätzbare Arbeit auch danken sollen?!" (UF46, 4, S. 52f.)

Wird schon die oben zitierte Textstelle von der Zensur eliminiert, so

1 Eine Reihe von Erlebnisberichten und Dokumentarromanen der Kriegsliteratur legt die Vermutung nahe, da $B$ auch in regulären Truppenteilen der GenuB von Alkohol zur Gewohnheit gehört und dies nicht nur in der sowjetischen Armee. So zitiert Kühnrich (aa0.S. 241) auszugweise den Brief eines deutschen Soldaten aus dem Sommer des Jahres 1943, dessen Einheit zur Bekämpfung des Partisanenverbandes Kovpaks eingesetzt ist. Der Gefreite Rolf Friedrich berichtet: "Es gibt reichlich russischen Wodka. Wenn du dich besäufst, zum Teufel, vergiBt du alles auf der Welt, mit Ausnahme der Partisanen." 
sind erst recht alle Passagen, aus denen hervorgeht, daB uber die erwähnte Abmachung hinaus auch während der Kampfhandlungen getrunken wird, in der FS9 nicht mehr vorhanden. ' So fehlt die Schilderung Veršizoras, der zu entnehmen ist, daB ein Kommandounternehmen auf Grund der benebelten Köpfe der Partisanen scheitert ${ }^{2}$ ebenso wie der Hinweis, daB ein Flieger einer Transportmaschine seine Nerven mit Alkohol beruhigt. ${ }^{3}$ Abgesehen von den oben genannten Gründen widerspricht ein Partisan, der die ständige Todesgefahr durch Trinken von Alkohol zu bewältizen versucht, eindeutig den Richtlinien des Sozialistischen Realismus, speziell der Forderung nach dem positiven Helden, dessen literarische Gestaltung "[...J der Partei bei der Erziehung des neuen Menschen, bei der Formung seines geistigen und sittlichen Charakters[...] aktiv Hilfe zu leisten hat."4

Da hier nicht der Ort für eine eingehende theoretische Darstellung der Figur des positiven Helden in seiner je nach literaturpolitischer Lage unterschiedlichen Schattierung sein kann, soll nur einer der Kernsätze zu diesem Heldentypus aus dem Essay A.Sinjavskjjs stellvertretend für viele andere Deutungen zitiert werden: "Der positive Held ist nicht einfach ein guter Mensch, er ist ein Held, den das Licht des idealsten Ideals verklärt, ein nachahmenswürdiges Vorbild für alle.C... D Die Eigenschaften des positiven Helden sind kaum alle aufzuzählen: ideologische Pestigkeit, Mut, Verstand, Willenskraft, Patriotismus, Ehrfurcht vor der Frau, Opferbereitschaft usw... Die Klarheit und Bestimmtheit, mit der er das Ziel sieht und anstrebt, sind seine wichtigsten Tugenden. Daher die erstaunliche Sicherheit in allen seinen Taten, in seinem Geschmack, in seinen Gedanken, Gefühlen und Urteilen. Er weiB genau, wa gut ist und was schlecht ist, er sagt nur 'ja' oder 'nein', er verwechselt nicht schwarz mit weiB, er kennt keine inneren $\mathrm{Zweifel,} \mathrm{keire} \mathrm{Unsicherheit,} \mathrm{keine} \mathrm{unlösbaren}$ Probleme und keine unergrindlichen Geheimnisse und findet selbst in der verworrensten Situation muhelos einen Ausweg - er geht geradewegs auf das Ziel zu." 5

\footnotetext{
1 Als einziger Hinweis zu diesem Problenkreis bleibt die Textstelle in der UF50, 4, S. 12 erhalten, da der Alkoholgenuß nach Verłigoras Darstellung vom Kommissar der Abteilung nach Köglichkeit unterbunden wird. 
Abstrahiert man die ironische Polemik und vergegenwärtigt sich das Ergebnis der durch die Eingriffe der Zensur entstandenen Verschiebungen ${ }^{1}$, so wird deutlich, daB die grundlegende Beobachtung Sinjavskijs auch für den positiven helden der Kriegsliteratur des Jahres 1959 zutrifft. Sind die von Versigora 1945/46 im "Rejd za Dnepr" dargestellten Figuren, obwohl auch hier schon nach den Richtlinien des Sozialistischen Realismus gezeichnet, noch relativ ursprünglich und lebendi 8 , figurieren sie in der Auflage von 1959 nur noch als Schatten ihrer selbst.

G.Struve, dem bei der Beurteilung von Vergigoras Roman die Urfassung vorliegt - und nur auf diese darf die im folgenden zitierte AuBerung bezogen werden - schrefbt dazu: "Der gröBte Teil des Buches[...] besteht aus einem interessanten und offenkundig wahrheitsgetreuen Bericht der therfälle, die die berühmte Fartisanenarmee von Sidor Kovpak, der sich Versigore im Jahre 1942 anschloB, hinter den feindlichen Linien machte." 2

Durch eine Reihe von Streichungen b2T. Neukonzipierungen der angeblich ne. gativen Züge der Partisanen lassen sich eine Zahl markanter Anderungen fixieren. Der positive Held im Partisanenroman des Jahres 1959 besitzt, gemesgen an dem der Jahre 1945/46, folgende "nachteilige" Elgenschaften nicht mehr:

1. Er ist nicht durch die Zufälligkeit des Kriegsverlaufes, aus persönlichen Rachemotiven oder auf Grund romantischer Uberlegungen erst geraume Zeit nach Kriegabeginn Partisan gevorden, sondern al. lein sein hohes politisches Verantwortungsbewubtsein labt ihn sofort bei Kriegseintritt zur Waffe greifen.

2. Er übt weder an den Operationen der Roten Armee ${ }^{3}$ noch am Organisa. tionsgefüge der Partisanenbewegung Kritik.

1 Der Vergleich der beiden Urfassungen "Rejd 28 Dnepr" und "Karpatskij rejd" mit der Fassung von 1959 ergab insgesamt ca. 670 Abweichungen: 449 Streichungen und 221 Neukonzipierungen. 306 Streichungen und 137 Neukonzipierungen entfielen dabel auf den "Rejd za Dnepr", während nur 143 Streichungen und 93 Neukonzipierungen innerhalb des "Karpatskif rej. fixiert werden konnten.

2 G.Struve, Geschichte der Sowjetliteratur (0. J.) S. 404 .

3 Nach offizieller Diktion werden bis 1953 Niederlagen der Roten Armee al "aktive Verteldigung" ausgegeben. Nach Stalins Tod gesteht man die personelle und materielle tberlegenheit des Gegners ein, die mangelnde Wac samkeit auf sowjetischer Seite (verantwortlich Stalin und Zukov) und de unfertigen Ausbildungs- und Rüstungsstand (verantwortlich Berija). 
Folgende positive Züge zeichnen inn Ende der 50er Jahre dafür aus:

1. Er ist ein einsatzfreudiger, mutiger und disziplinierter Kämpfer, der sein Leben für sein sozialistisches Vaterland und die unsterbliche Sache Lenins und seiner Partei opfert."

2. Er bleibt trotz der dem Partisanenkrieg eigenen Gesetzlichkeit moralisch und physisch sauber.2

Parallel zur Verbesserung des Partisanenimages durch Abbau "untypischer" Eigenschaften, läBt sich die Tendenz zur Idealisierung des Rotarmisten feststellen. Sucht man in Verłigoras "Ljudi s Elstoj sovest'ju" zwar verpeblich nach Hinweisen auf die katastrophalen Niederlagen an der regulären Front, so ermöglichen einige wenige Andeutungen jedoch indirekte Schlüsse auf die Kampfmoral der Roten Armee. Auch an dieser Stelle greift die Zensur korrigierend ein, indem sie die der offiziellen Darstellung widersprechenden Passagen streicht bzw. vom Autor ändern läßt.

Wurde schon an den vorherigen Revidierungen deutlich, daB die mangelnde Kriegsvorbereitung und die Onerfahrenheit der Kommandeure zu den unerwünschten Themenbereichen gehören, so darf auch das Verhalten der kämpfenden Truppe weder wahrheitsgetreu noch kritisch verklausuliert geschildert werden. Die Aussage, daB unter den gezielten Schlägen des Gegners auch die Autorität des Kommandeurs die Absetzbewegungen der sowjetischen Soldaten nicht verhindern $\mathrm{kann}^{3}$, ist in der Fassung von 1959 nicht mehr vertreten. Ebenso fehlt das Eingeständnis, daB die Materialüberlegenheit des Gegners zur Demoralisierung führt ${ }^{4}$ und nur die einsetzende Schlammeriode die eigenen Kräfte vor der vollständigen Zerrüttung be-

1 "Alle Sowjetbürger haben in Großen Vaterländischen Krieg für ihre Lebensweise, für die kommanistischen Ideale und für das 'sozialistische Vaterland' mit unvergleichlichem Sorjetpatriotismus gekämpft. Der Krieg wurde für die Rettung der Weltzivilisation gefürt, zur Verteidigung des gesellschaftlichen Fortschritts." (B.S.Telpuchovskij, 880. S. 67E.).

Was unter physischer Sauberkeit zu verstehen ist, zeigt die eliminierte Textstelle in der UF46, 7, S. 25: "Nachdem er das Hosenbein hochgekrempelt hatte, beschäftigte er sich mit dem Fang des Flohs. -He du, Fallschirmspringer! Beende die Jagd! -schrie Michail Kuz'mic. Ohne seine Aufmerksamkeit auf Mischa zu wenden, suchte der Phlegmatiker meiter."

UF45, 8, S. 28, "Und hier spürte ich plötzlich, daB die Autorität des Kommandeurs keinen Eindruck auf meine Kämpfer mehr macht. tillerie gelegen hatte, konnte man fast den Verstand verlieren." 
wahrt.' In ähnlicher Form schreitet die Zensur auch hinsichtlich der bei Veršigora ohnehin nur vereinzelten hufschlüse uber die in deutsche Kriegsrefangenschaft geratenen Rotarmisten ein. Kann der Autor 1946 noch zupeben, daB die sorjetischen Soldaten den Verlockungen der deutschen Herber (600 Gramm Brot für den bintritt in einen Freiw1lligenverbend der deutschen Armee) häufig nicht widerstehen können ("Die Faschisten erreichten oft ihr Ziel." ${ }^{2}$ ), so ist er 1959 gezwungen, durch den fustausch eines einzifen Wortes dem Satz einen neuen Sinn unterzuschieben:

"Die Faschisten erreichten manchmal ihr Ziel." (F59, S. 195)

Durch den euferlich unscheinbaren Eingriff gelingt es Vers̆igora, den Inhalt der strittigen Textpassage dem Dogma anzugleichen, nach dem "weder die schweren materiellen Entbehrungen noch die körperlichen Leiden, wie auch der Tod selbst, [...]den mächtigen Ceist der uberwiegenden Nehrheit der Sowjetmenschen in ter Hitlergefangenschaft brechen [konnten]." 3

DaB Tel puchovskijs Satz nur einen Bruchteil der tahrheit enthalt tatsächlich werden die aus der deutschen Kriegsgefangenschaft zurilckehrenden Soldaten, auch wenn der Verdacht der Kollaboration zu Unrecht besteht, in Uberprüfungs- und Filtrationslagern festgesetzt und gröBtenteils verurteilt 4 - enthüllt A.Solienicyns "Archi-

1UF45, 8, S. 37: "Der Schlamm, die Regenfälle und die Kegelosigkeit machten den Zeitvorteil der Deutschen zunichte. Der russische Hertst blieb an den eisenbeschlagenen deutschen Stiefeln, den Zahnrëdern der deutscher Kraftfahrzeuge haften und hinderte sie em Vormarsch. Die russische Erde gewährte uns einen Zeitgexinn, damit wir unsere von dem plötzlichen tberfall des Feindes zerrüteten Kräfte umgruppieren konnten."

2 yF46, 4, S. 44 .

${ }^{3}$ B.S.Tel puchovskij, aa0. S. 549. Uber die Tatsache, daB nicht nur deutsche, sondern auch russische inwerher in den Kriegsgefangenenlagern tätib sind, Ribt Solženicyn Auskunft: "Nanchmal aher kamen Werber ganz anderer Art - Russen, gewöhnlich von den ehemaligen roten Yolitruks, Hei \&kardisten gaben sich für diese nirbeit nicht her. Die Werber hielten im Lager eine Versammlung ab, beschimpften die Sowjetmacht und riefen zum Eirtritt in tie Spionageschulen und ir. die Vlassovtrupper auf." (Archipelag Gulag (1973) S. 251).

${ }^{4}$ Nach Solženicyns Darstellung (a80. S. 72) werden die ehemaligen Kriegsgefangenen, im. Bestreben, die üherflüssigen Zeufen schmachvoller Niederlagen $z$ u beseitigen, nach Artikel 58,1 b (Landesverrat) des sorjetischen Strafgesetzbuches verurteilt: "GemäB diesen Purkten ist eire auf die Schwächung des Kriegspotentials der UdSSR abzielende Handlung rit Erschießen zu bestrafen $(1-b)$, nur bei milderen Imständen und nur bei $z i v i l p e r s o n e n$ $(1-a)$ mit zehn Jahren Haft." 
pelag Gulag: "Jenes Frujahr 1945 war in unseren Gefängnissen vornehmlich ein Frühjahr der russischen Kriegsgefangenen. Sie zogen durch die Gefängnisse der Union wie ein unübersehbarer dichter grauer Strom, wie ein Heringszug im Ozean." 1

In ähnlicher Weise wie den Kriegsgefangenen scheint es auch denjenigen zu ergehen, die wie Veršigora im Rücken des Feindes während des Krieges tätig sind. ${ }^{2}$ Da Hinweise dieser Art von sowjetischer Seite jedoch nicht geduldet werden, sucht man nach der folgenden Textstelle in der Fassung von 1959 vergeblich:

"Später traf ich sehr häufig mit unnachsichtigen Leuten zusammen, die fij die Tatsache des Verbleibs im feindlichen Hinterland strenge und unbarmherzige Strafen aussprachen. Es kam vor, daB gerade die, die unbarmherzip zu arderen waren, sich als Feiglinge und manchmal sogar als Verräter erwiesen, wenn sie in eine ähnliche Situation gerieten." (UF46, 4, S. 45)

Nachdem Verłigora im AnschluB an die eben zitierte Textstelle zu bedenken gibt, das "nicht die Tatsache des Verbleibs im feindlichen Hinterland, sondern die Frage, wie hast du dich dort verhaltenc.... ${ }^{3}$, MaBstab der Beurteilung sein sollte, wird von der Zensurhehörde auch der kritisch-ironische Vorschlag Restrichen, der eine Gerichtsvorladung an diejenigen Sowjetbürger vorsieht, die sich, obrohl sie nach Kriegsende als Anklëger auftreten, angesichts der deutschen Truppen in den Osten des Landes abgesetzt haben.

"Sollen die Kriegsgefangenen, die klüchtlinge, die Kämpfer und Arbeiter des Urals sowie die Gesundzebliebenen und die groBmäuligen Leute, die bis Aktjubinsk und bis Taschkent Geflüchteten sowie die Helden, die unter freiem Himmel bei schneidendem Frost Panzer montiert haben zum Volkseericht kommen.

Sollen sie kommen und die Frage beantrorten: 'Was hast du, besonders du, für den Sieg getan? Steckt dein Gedanke, dein Werk und dein Blut

im dornigen Kranz?'
Sollen sie die Antwort auf diese Frage vor ihrem Gewissen geben." 4

A.Solženicyn, Archipelag Gulag (1973) S. 243. Siehe dazu auch: N.Betell, Poslednjaja tajna. In: Kontinent 1975.4. 5.6.7.

Vgl. dazu Kapitel B 3, S. 12 der Arbeit (Nekrolog von P.Voron'ko).

3 UF46, 4, S. 45 .

4

UF46, 4, S. 45 . 
Trotz der zahlreichen schwerwiegenden Eingriffe der Zensur, die vor der Fälschung historisch eindeutiger Sachverhalte nicht zurückschreckt, ist mit der Streichung der zuletzt zitierten Textpassage die wohl gravierendste Manipulation innerhalb des vorliegenden Dokumentarromens feststellbar Mit der Eliminierung der für Veršigora entscheidenden Frage "lias hast du, besonders du, für den Sieg getan?", deren Beantwortung den Mabstab für die Entscheidung bildet, ob die an Krieg Beteiligten als "Menschen mit reinem Gewissen" gelten können, wird der Roman seiner $z$ e $n t r a t ~ n$ Fra g e s t e 1 l u $n g$ beraubt. ${ }^{1}$ Die intwort auf die in der Fassung von 1959 ohnehin nicht mehr existierende Frage wird nun nicht mehr durch das Gewissen des einzelnen gegeben, sondern stellvertretend für ihn, entsprechend dem momentan favorisiertem Dogma, von der Kommunistischen Partei und ihren wortfuhrenden Organer. DaB alle Vorkommnisse und Erscheinungen, die nicht ins offizielle Bild passen, exemplarisch totgeschwiegen oder durch entsprechende Manipulationen dem jeweiligen politisch-ideologi schen Standpunkt angepabt werden müssen, klingt auch in dem von Versłgora im Nachwort des "Karpatskij rejd" 1950 niedergeschrlebenen Satz an:

"Die Sowjetmenschen besitzen ein Gewissen - das Gewissen der gesamte Menschheit - die Partei der Bolschewiken... die weise, moralisch sau bere, lebensspendende Kraft der Geschichte. Sie ubt den Nörglern und den Kleinflüubigen gegenüber keine Nachsicht, sie verzeiht nicht den Schwätzern. Sie inspiriert Millionen fortschrittlicher Nenschen und erzieht die Zurückgebliebenen um." (UF50, 5, S. 66)

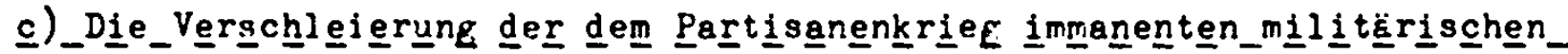

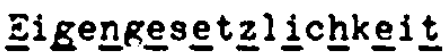

Ein besonders schwieriges Problem für die ohne festen Standort operierenden Partisaneneinheiten bilden die im Kampf verwundeten Partisanen. Zwar besitzt in den letzten Kriegsjahren ein Teil der beweglichen Verbände hrz te oder Krankenschwestern, doch können Schwerverletzte durch das Fehlen von Medikarenten und speziellen medizinischen Einrichtungen weder effekti versorgt noch ihrer Verletzung entsprechend transportiert werden. So musssen Schwerverletzte, da nur selten die Möglichkeit der Unterbringung in

1 Diese Fragestellung Veršigoras und ihre (in der Urfassung) eindeutige Beantwortung veranlaBt P.Voron'ko seinen Nekrolog mit dem Titel "Mensch mit reinem Gewissen" zu überschreiben. (VGl. S. 12 der Arbeit). 
feindfreien Ortschaften besteht, oft zwangsläufig ihrem Schicksal ïberlassen werden.

Obwohl die oben anfedeutete Tatsache von Veršifora ("In einer beweglicher. Abtellunp bilden die Verwundeten wohl immer ein besonders schwieriges Problem." UF45, 8, S. 104) nicht bestätigt wird, miBfallen dem Zensor offensichtlich die Beweggründe, die das Zurücklassen der Verwundeten verhindern. Da weder humanitäre Utberlegungen noch ein sozialistisches Kollektivbewubtsein die Argumentation des Einheitsführers Versigora bestimmen, werden zwei Textpassagen gestrichen:

"Die Verwundeten ihrem Schicksal zu überlassen, erschien uns unzuläsig. Das konnte der Organisation selbst schaden und die Kampfdisziplin untergraben.C...J Die Verwundeten selbst baten, man solle sie erschieBen, weil sie sahen, welche Last sie für die Genossen darstellten." (UF45, 8, S. 104)

In Anbetracht der Schwierigkeiten, mit denen eine ohne eigenes Hinterland - perierende Partisaneneinheit allein bei der Betreuung Verwundeter zu kämpfen hat, beantwortet sich die Frage, wie mit im Gefecht Gefangengenommenen bzw. mit den speziell zur Informationsbeschaffung bei Erkundungsgängen festgesetzten Personen verfahren wird, fast von selbst. Aus Verłigoras Roman geht hervor, daB Rudnev, der Politkommissar im Verband Kovpaks, für derartige Entscheidungen zuständig ist, ehe Versigora selbst die Leitung der Aufklärungsabteilung ibernimmt. Obwohl dies nicht dem Reglement entspricht ("Meine neue PFicht bestand darin, die Aufklärurgsabteilung zu leiten, was ungewöhnlich war und nicht den vorhandenen Regeln entsprach." UF46, 4, S. 49), wird an anderer Stelle deutlich, warum der Kommissar die Abteilung an Versigora abtritt und damit die Verantwortung abwälzt:

"Ich erinnere mich, daB mir Rudnev, als er einst die Verhörungsprotokolle und Anklageschriften verschiedener Leute unterschrieb, sagte: -Die Hand ist mijde geworden. Ich kanr. nicht mehr. HeiBt du - wir vertrauen dir die Sache an. Komm mir nicht mehr mit diesen Angelegenheiten. Entscheide selbst. Nur wenn es irgendein verzwicktes oder schwieriges Problem gibt, dann gib es mir oder dem Kommandeur. Kovpak stimmte der Absicht des Kommissars zu. Diese Entscheidung bürdete mir eine schwere Last an Verantwortung auf und kostete mich viele Stunden angestrengten Nachdenkens. Ich muB eingestehen, dab ich auf diese Tätigkeit in meinem bisherigen Leben nicht vorbereitet worden bin." (UF46, 4, S. 69)

Obgleich die zitierte Textstelle noch keinen direkten Beweis für die ErschieBung von Gefangenen, Verrätern oder von mit ihrem Wissen ein Sicherheitsrisiko für die Partisanen bijdenden Personen liefert, ist sie in der 
F59 nicht mehr enthalten.' Eine weitere, allerdings nur indirekte Bestätigung ergibt sich aus einer in die Fassung von 1948 im AnschluB an die eben genannte Textstelle eingeschobenen Passage, die dann in der Neuauflage von 1959 wieder fehlt.

"Irgendwann werde ich über diese Arbeit ausführlicher erzählen. Es ist nicht immer einfach, die Erde von allem möglichen Schmutz zu rei nigen. Im Moment weiB ich nur eines: Kein gewöhnlicher Mensch könr.te mit solcher Arbeit fertigwerden. Sie forderte ein scharfes Auge, und was die Hauptsache ist, die Fähigkeit, sich in den Leuten auszukennen. Ich habe Bäume gefällt, es flogen Späne dabei, aber mein Gewissen vor dem Volk ist rein geblieben. Der einzige MaBstab war die Frage: Was hast du getan und womit kannst du helfen, Bürger, in der Zeit des groBen Kummers? Welchen Weg hat dein Schiff im Meer der Pri: fungen und menschlichen Leiden genommen? Nicht mit forten, sondern mit Taten antworte mir. Ich habe das Recht und die Macht, dich danach zu fragen, weil ich ein Soldat meines Volkes bin." (F48, S. 24:

DaB in diesem Zusammenhang dann die einzige Textstelle von der Zensur gestrichen wird, die einen direkten AufschluB über Verłigoras Tätigkeit gibt, stellt nur eine logische Folge der vorherigen Revidierungen dar.

"AuBerdem war es ausgeschlossen, daB ich mich an meine neue Pflicht, die Unterzeichnung der ErschieBungsbefehle, gewöhnte." (UF46, 5/6, S. 66)

Angesichts der von Verłigora geschilderten Maßnahmen ist es verständlich, daB die Bevölkerung der Ortschaften, in die der Verband Kovpaks einrückt, mit gemischten Gefühlen reagiert. Gibt Versigoras "Ljudi s Cistoj sorest' ju" auch keine wesentlichen Aufschlüsse über eine ablehnende Einstellung der Bevölkerung, so lassen zumindest zwei Textstellen ahnen, daB keine einheitlich positive $\mathrm{Haltung}$ vorhanden ist.

"Jetzt konnte man sich an die Erkundung des Dorfes machen. Einige GroBmitter schauten durch die Gardinen. Hinter ihnen kamen vorsichtig drei bis vier Bauern hervor: ein Greis, die ubrigen warer junge Burschen. In kurzer Zeit hatte sich an der StraBenkreuzung eir kleiner Kreis versammelt. Schweigend und neugierig schauten sie auf die Kolonne. Die GroBnitter seufzen und flüstern über irgend etwas. Die Bauern schweigen und drücken mit keirem hort weder ihre Gefüle noch ihre Gedanken aus." (UF50, 3, S. 23)

"Aber es gab auch solche, die untereinander sagten: Wenn Kovpak

1 A.Fierth, aa0. S. 531, schreibt dazu: "Sie [die Partisanen] hatten ständig auf Verräter zu achten, und sofern sie solche ergriffen, muBten sit diese - of aus realer Notwendigkeit, manchmal aber aus psychologischer Grinden - töten, etwa die Staroste, die Bürgermeister und die in deutschen Diensten stehenden Polizisten." 
in unserem Bezirk nicht wäre, gäbe es auch keine Deutschen hier. Immer zieht er einen Schwanz Vergeltungskommandos hinter sich her. Und was passiert inm? Er windet sich heraus und uns jagt man... Auf ihre Art hatten sie recht." (UF46, 4, S. 23)

Mit der Streichung dieser beiden Textpassagen erreicht der Zensor, daB keine dem Dogma zuwiderlautenden Außerungen ir. der Fassurig von 1959 enthalten sind, nach dem

"überall in den Dörfern und Siedlungen die Partisanen-Agitatoren von der Bevölkerung freudig aufgenommen wurden. Auf Versammlungen, Meetings und in Gesprächen wollte jeder dabeisein, vom Jüngsten bis zum Altesten. Die Kunde dariber, daB Partisanen-Agitatoren ins Dorf gekommen waren, verbreitete sich schnell unter den Bewohnern. Jeder Sowjetmensch, der unter dem Stiefel der Okkupanten litt, war begierig, das wahrhafte, bolschewistische Wort zu hören."1

Vor dem Rotstift des Zensors bleibt schlieblich auch die Textstelle nicht verschont, die AufschluB über die Tatsache gibt, daB die Partisaneneinheiten eine hohe Zahl von Verrätern beseitigen müssen ${ }^{2}$, un an die deutschen Kerntruppen zu gelangen.

"Die Faschisten bemüten sich, die Sache so zu handhaben, daß die Partisanen gezwungen waren, zehn Russen zu töten, um an einen Deutschen zu gelangen." (UF46, 4, S. 44)

Da einer erheblichen Anzahl von Episoden zu entnehmen ist, daB sich der Verband Kovpaks mit russischen Polizeigarnisonen und Schutzmannschaften militärisch auseinandersetzt - ihre Streichung wïrde den Roman um mehr als ein Drittel seines Umfangs reduzieren - dient ein in die Fassung von 1959 aufgenommener Abschnitt dazu, die das Dogma widerlegenden Erscheinungen als therreste einer vergangenen Zeit einstufen, wobei einmal mehr die "Lumpen der Konterrevolution und die Kulaken" 3 als Erklärurg dienen.

Istorija. Band III (1961) S. 454; ähnliche Formulierungen sind auch in Band IV enthalten.

2 Als Verräter gelten alle Sowjetbürger, die in deutschen Diensten standen bzw. in deutschen Freiwilligenverbänden këmpften.

3

P59, S. 399. 


\section{Die Revidierung antisorjetischer Partisanenaktionen}

Da die in Veršigoras Roman enthaltenen Hinweise iber Aktionen von Gegenpertisanen nur schwer durchschaubar sind, mïssen im Rahmen dieses Kapitel die komplizierten politisches Verhéltnisse kurz umrissen werden. Nachdem dle Autonomie der Ukrainischen Volksrepublik (gegruindet 1918 auf der Grundlage des Friedensvertrages von Brest-Litowsk) schon nach zwei Ja ren durch die Umwandlung in die Ukrainische Sozialistische Sorjetrepublik beendet ist - 1940 werden nach entsprechendem militärischen Druck auch di Baltischen Länder Litauen, Lettland und Estland zu Unionsrepubliken ernannt - brechen nach der Besetzung dieser Gebiete durch die deutschen Tru pen starke antisowjetische Tendenzen durch. Unter den verschledenartigen Kräften, die während des 2weiten Weltkrieges auf dem Territorium der Okraine politisch wirksam werden, nimmt neben der Ukrainischen Nationalrada (UNR) - ihre Anhänger erklären sich als die einzigen legitimen Nachfolger der Petljura-Regierung - des ukrainischen Freikoprs "Poliska Sitsch" und der Organisation "Freie Kosaken" die OUN (Organisation ukrainischer Natio nalisten) die bedeutendste Stellung ein. Den Vertretern der deutschen Ost politik pabt die nationale ukrainische Bewegung, obwohl sie bald in die gemäBigte Melnik-Gruppe (OUN/M) und die radikale Bandera-Gruppe (OUN/B) zerfällt, eut ins Konzept, zumal schon vor Kriegsausbruch im Auftrage der deutschen Abwehr Angehörige der OUN hinter den polnischen Linien Sabotage und Diversionsakte ausführen. 'Bald nach Einmarsch der deutschen Wehrmach kommt es jedoch zu Mibstimmigkeiten, da der Versuch der OUN/B, einen eige ständigen ukreinischen Staat zu proklamieren, von den deutschen Regierung stellen wit der Verhaftung Banderas und seiner engsten Mitarbeiter unterbunden wird. 1941 vertiefen sich durch die Ubernahme Galiziens ins Genere Gouvernement und die tbergabe eines beträchtlichen Teils der Okraine an Rumänien die Spannungen, in deren Folge nationale Partisanengruppen entst hen. Ihre Aktionen sind jedoch nicht gegen die deutsche Wehrmacht gericht sondern sollen nur die vorhandenen Werte vor dem Zugriff deutscher Stelle sichern. AuBerdem wid von den Organen der OUN der Kader für ein ukraini. sches Nationalheer geschaffen, das in der Folgezeit sowohl gegen die sowjetischen Partisanenverbände kämpft, wie auch gegen die dem Reichskommis-

E.Hesse, 880. S. 154 . 
sar Koch unterstehenden Verwaltungsorgane, deren rücksichtslose Verwaltungspraxis sowie das rigoros durchgefürte Arbeitskräftebeschaffungsprogramm auf entschiedenen Widerstand stoBen. Erst im Jahre 1944, unter den Auswirkungen des schnellen sowjetischen Vormarsches, stellen sich nach der Entlassung Banderas aus einem deutschen Konzentrationslager die Kräfte der UPA (Ukraínska Powstanska Armija) geschlossen an die Seite der deutschen Truppen, ohne daB ihre Operationen hinter den sowjetischen Linien weder die Angriffskraft der Sowjetarmee noch die Effizienz der Partisaneneinheiten nennenswert schwächen zu können.

Da in allen sowjetischen Kriegsdarstellungen das Vorhandensein von nationalen Selbstverwaltungsbestrebungen nur am Rande erwähnt wird - die Existenz von antisowjetischen Partisanen wird generell verschwiegen schreitet die Zensur gegenüber den in Versigoras Roman enthaltenen Hinweisen korriglerend ein, ohne jedoch ein festes Prinzip erkennen zu lassen.

DaB Ver 1 igoras Beobachtungen in der Orfassung von 1945/46 veroffentlicht werden können, scheint an der Tatsache zu liegen, daB die Darstellung dieses historischen Sachverhalts zu diesem Zeitpunkt noch nicht auf der Indexliste steht, wie die Verlautbarung Chruscevs als Parteiführer zeigt, der 1944 "[...] in der C̈ffentlichkeit uber antisowjetische Partisanenaktionen berichtete ("Pravda", 16.März 1944)." 1

Zwar wird die Existenz von nationalen Unabhängigkeitsbestrebungen nicht gänzlich geleugnet - nur etwa die Hälfte der betreffenden Textstellen wird von der Zensur entfernt - doch fällt, gemessen an der Fassung von $1945 / 46$ besonders die geänderte Diktion der F59 auf. Werden die Träger des nationalen Ideengutes in der Urfassung unter Nennung ihrer nationalen Herkunft noch relativ sachlich und objektiv beschrieben, unterliegt ihre Darstellung in der Fassung von 1959 eindeutig den Gesetzen eines Parteilichkeitsgrundsatzes, der nur noch negative Kriterien bei der Beschreibung des politischen Gegners zuläBt, wobei die nationale Zugehörigkeit bewuBt unkenntlich gemacht wird. Stellvertretend für diesen Vorgang steht die Revidierung der Passage " C...Jpolnische und deutsch-ukrainische Nationalisten" (UF46, 4, S. 74) in "[...] faschistisch-nationalistische Banditen" (F59, S. 229). Vergleicht man die Darstellung

1 w.Leonhard, Kreml ohne Stalin (1959) S. 89. 
des historischen Tatbestandes durch das Verfasserkollepium der "Istorija".

"Nach dem beliebten Prinzip der Kolonialherren 'Teile und Herrsche' handelnd, versuchten die Faschisten, nationale Feindschaft zu entfachen und die Freundschaft der Sonjetbürger zu untergraben. Aber im besetzten, Gebiet gelank es ihnen nicht, nationale zwietracht zu provozieren:" 1

mit dem 1946 von Versigora glaubhaft gemachten Sachverhalt, so wird auf Grund der Widersprüchlichkeit ersichtlich, warum der letzte Satz der folgenden Passage von der Zensur eliminiert wird:

"Wie es bei der Gestapo die Regel war, begannen sie gegen die bedroh lich anwachsende Partisanenbewegung mit der Methode der Provokation und der Inszenierung nationaler Konflikte zu kämpfen. Ond das gelang ihnen von infang an." (UF46, 4, S. 74)

Neken der Textpassage, die einen indirekten AufschluB über die Zahl der vorhandenen Vationalisten $g$ ibt und auBerdem nichts von einem unversöhnlichen $\mathrm{HaB}$ des sowjetischen Partisanen Veršigora spüren läBt ("Von den Hunderten ukrainischen und polnischen Nationelisten, mit denen ich zusammentreffen, sprechen und diskutieren muBte [...]"; UFA6, 5/6, S. 31), eliminiert die Zensur auch die Textstellen, in denen die gegnerischen Vertreter nicht negativ eenug gestaltet sind:

"Wir forderten, daB die Kette der Nationalisten den Weg freimacht und uns beim Vormarsch nicht stört. Sie bestanden darauf, daB wir unsere Marschroute änderten. Mucha hatte offensichtlich schon viel über uns gehört und war, wie mir schien, nicht feindlich eingestellt.[...] Die Rede von Mucha war freimütig und überzeugend und ir gend etwas an diesem Burschen, dessen Augen haBerfüllt glänzten, bestach." (UP46, 5/6, S. 25f.)

AuBerdem stimmt auch in diesem Punkt die Darstellung Versiforas, da von einer Bekämpfung der nationalistischen Kräfte generell keine Rede sein kann, mit der offiziellen Festlegung nicht uberein.

"Eine andere Aufgabe bestand darin, die deutsch-ukrainischen Nationalisten verstärkt $z$ bekämpfen und die politische Zersetzungsarbeit unter den Regnerischen Truppen, vor allem den Satellitenarmeen, zu verbessern." 2

Die Betrachtung der vom Autor fïr die Fassung von 1959 neukonzipierten Textabschnitte zeipt, daB es dem Zensor, neben der Ausschaltung der der.

\footnotetext{
Istorija. Band III (1961) S. 438.

2 880. Band IV (1962) S. 470.
} 
Dogwa widersprechenden Sachverhalte, um eine Angleichung an die offizielle Diktion geht, die in ihrer Prägung keinen zreifel für den sowjetischen Leser mehr aufkomnen läBt, daB es sich hinsichtlich der nationalen Unabhängigkeitsbestrebungen eindeutig um verbrecherische und damit bestrafenswerte Aktionen handelt. So ist Verłigora genötigt, in der Neuauflage von 1959 die Vertreter der nationalen Befreiungsberegung als "Lakaien des Faschismus" (F59, S. 385), al s "Nachkömmlinge des Halsabschneiders Petljura" (F59, S. 388) und als "Kreaturen des Klassenfeindes" (F59, S. 389) zu bezeichnen, die "der Zorn des Volkes hinwegfegen rird" (F59, S. 385). Er folgt damit sowohl inhaltich we stilistisch der von den Verfassern der "Istorija" gewählten Darstellungsform:

"Das Volk strafte alle Abtrünnigen und Verräter, alle Spione und schmutzigen Abenteurer mit unerbittlicher Verachtung." 1

\section{Der Rückgriff ouf die Tradition des Partisanenkrieges}

Hit dem siegreichen Vordringen der deutschen Truppen in den Kriegsjahren 1941 und 1942 und der daraus erwachsenden Gefahr für den sozlalistischen Staat, sind die Sorjetorgane genötigt, neben den militärischen auch alle geistigen Widerstandskräfte des Volkes zu mobilisieren. Dabei wird die Tendenz zu einem russisch-nationalistisch gefärbten Patriotismus geduldet und schlieblich sogar gefördert, denn der zuerst proklamierte sowjetische Unionspatriotismus erweist sich als blutleeres und kinstliches Gebilde. Den sowjetischen Schriftstellern ist es nun sogar erlaubt, an die traditionellen Einrichtungen und Gebräuche der vorrevolutionären Vergangenhelt anzuknüpfen, da sich die Schaffung eines wirksamen Patriotismus und Nationalismus aus einem historisch-politischem Vakuum als unmöglich zeigt.

Welche Konsequenzen aus dieser Einsicht für die Rote Armee erwachsen, dokumentiert G. von Rauch: "Schon zu Beginn des Jahres [1943] waren neue Rangabzeichen geschaffen worden; die von der Oktoberrevolution als Sinnbild der Konterrevolution und eines reaktionären Kastengeistes beseitigten goldenen Schulterstücke wurden wieder eingeführt. Neue Auszeichnungen, wie der Kutuzov- und Suvorovorden, knüpften an die tberlieferung der Zarenzeit an. Kosakenformationen, einst berüchtigte Werkzeuge zaristischer Unterdrückung und als bedeutsame Träger des gegenrevolutionären Widerstandes im Bürgerkrieg, lebten neu auf." 2

Erstaunlicherweise sind in den Urfassungen von Verłigoras Partisanenromen

\footnotetext{
1 2

Istorija. Band III (1961) S. 439.

G. von Rauch, a80. S. 381 .
} 
weder verstärkte Anzeichen einer patriotischen Gesinnung noch eines histo. risch-traditionellen BewuBtsein feststellbar. Im Gegensatz zum Verfasserkollegium der "Istorija", das die patriotische Einstellung des sonjetischen Volkes schlechthin als Ursache des Partisanenkampfes lokalisiert, "Die Erfahrung des Krieges zeigte, daB ohne den Patriotismus des kan zen Sowjetvolkes und ohne die kluge Fihrung der Kommunistischen Partei ein erfolgreicher Partisanenkampf unmöglich gewesen wäre." 1 ,

gibt Versigora eine wesentlich differenziertere und ehrlichere Einschät-

zung dieses Phänomens (von der Zensur gestrichen):

"Der Patriotismus ist vielgestaltiger Natur: alle sind bestrebt, den Feind zu vernichten, aber die Motive bei der Erlangung des Sieges sind bei jedem anders: der eine ist auf den Sieg deshalb aus, welle sich als besser und tapferer als andere erweisen will; der andere. well er sich die Brust mit einem überflussigen Orden schmücken will; viele deshalb, weil das Gefühl der Pflicht und der Disziplin ihren Charakter prägt und innen zur zweiten Natur geworden ist." (UF46, $5 / 6$, S. 40)

Hie schon oben angedeutet, läBt sich dem Urtext keine direkte Verbindung zur Partisanentradition entnehmen, sieht man von dem mehrfach zitierten Grundsatz der Partisanenkriegfïhrung "Man muB so handeln, wie das Volk es will", der von Lenin konzipiert wurde ${ }^{2}$, und einigen wenigen Einsprengselr. ab. Uber die Vermutung hinaus, dab sich Versigora als nicht in dieser Tra dition stehend empfindet, muB angenommen werden, daB die sich im Untergrundkampf äuBernde konspirative Gesinnung sowie die Beherrschung der den Partisanenkrieg für jedes miBliebige Staatsgebilde gefährlich werdenden Strategien und Taktiken den Machthabern im Kreml wenig willkommen sind un daher auf höhere Weisung ein kijckgriff auf die Tradition der Partisanenbe wegung zu unterbleiben hat. Diese These, die an weiteren Werken der Farti sanenliteratur iberprüft werden miBbte, wird indirekt durch eine kußerune von Verłigora im "Karpatskij rejd" - sie ist in der Fassung von 1959 nich mehr vertreten - gestützt:

Istorija. Bend VI (1965) S. 282 .

2 Der ober. 2 itierte Grundsatz stellt eine der Hauptlosungen des Verbandsfihrers Kovpak dar. Er deckt sich mit der von Lenin aufeestellter. Konzeption für Partisanenaktionen (Punkt 5): "die Partisanenkampfaktionen müssen unter der Kontrolle der Partei durchgeführt werden, und zwar so, daB [...] die Stimmune der breiten Massen berücksichtigt nerden." (21t. nach: Sow jetsystem und demokratische Gesellschaft. Band II (1968) s. v. Guerillakrieg. Spalte 1128 . 
"Die Geringschätzung der Geschichte des Partisanenkrieges kommt teuer zu stehen. Auch die Leute, die sich im Kriegshandwerk auskennen, haben keine Ahnung von ihr und von den Lehrplänen der Kriegrschulen wird er ignoriert." (UF50, 3, S. 30)

Hie unterschiedlich und damit widersprïchlich selbst von parteiamtlicher Seite das Vorhandensein und die Wirkung traditioneller Elemente beurteilt wird, zeigen zwei Verlautbarungen der "Istorija". Einerseits betont sie die Verbundenheit der Partisanenbevegung mit aer Tradition der Bürferkriegspartisanen, anderersei.ts wird das Vorhandensein von Bürgerkriegserfahrungen geleugnet:

"Die reiche Erfahrung aus den vergangenen Freiheitskriegen weitgehend nutzend, insbesondere die Kampftraditionen der Partisanen im Burgerkrieg von 1918 - 1920, entwickelte das sowjetische Volk die vielfältigen Formen und Methoden des Kampfes gegen den Feind." 1

"Durch den Mangel an genügender Erfahrung im Untergrund- und Partisanenkampf entstanden grobe Fehler, die nicht selten groBe Opfer kosteten." 2

DaB die Unsicherheit bei der Beurteilung der Tradition des Partisanenkempfes, zumindest im Bereich der Literatur bis Ende der 50er Jahre weicht, zeigt Versigoras Neuauflage von 1959. Zwar sind in dieser Ausgabe die Textstellen, mit denen ein Bezug zur Tradition herfestellt werden soll nficht funktional integriert und wirken daher "aufgesetzt", doch versucht Veršigora mit einer längeren Passage das bisher "Versäumte" nachzuholen.

"Legten die Taten der Partisanen zu Kutuzovs Zeiten von der ruhmreichen Vergangenheit unseres Volkes Zeugnis $a b$, so verbanden uns mit der von den Partisanen des Bürgerkriegs gesammelten Erfahrungen feste Traditionen und Menschen von Fleisch und Blut. Die von ihnen gewonnenen Erkenntnisse waren in vieler Hinsicht durchaus noch nicht veraltet. In der Regel operierte im ersten Jahr des Großen Vaterländischen Krieges jener Partisanenverband $m i t$ dem besten Erfolg, in dessen Reihen Partisanen aus dem Bürgerkrieg kämpften. Wir hatten in dieser Beziehung Glück. An der Spitze unseres Verbandes stand Kovpak, der bereits 1918 als Partisan gegen die Truppen des deutschen Kaisers und der ukrainischen Hetmane gekämpft hatte. Er entsann sich nicht nur der Heldentaten, sondern auch der Kampfmethoden eires Parchomenko, $X_{a p a e r}$ und Kotorskij. Rudnev wuBte viel vom Kampf der Partisanen des Fernen Ostens. Auch ein Träger des Rotbannerordens aus dem Bürgerkrieg, Michail IvanoviC Pavlovskij, der unter Nikolai Sxors als Partisan gekämpft hatte, war unter uns. Väterchen Frost - Korenev, KuCerjavskij, Kul'baka und viele unserer einfachen Partisanen haben

1 Istorija. Band II (1961) S. 119.

880. Band II (1961) S. 130. 
in roten Partisanenabteilungen sowohl gegen die kaiserlichen Truppen als auch gegen die blauberockten Haidamaken, gegen den Hetman Petljura, gegen Denikin und gegen Machnovs Banden gekämpft.

Oft verwandelt sich ein schlichtes Gespräch am Lagerfeuer zu einer improvisierten Vorlesung, in der das zuindende Wort eines unserer Bürgerkriegspartisanen durch die offenherzige Erklärung der Regeln, Gesetze, Gewohnheiten, Kniffe und Tricks des Partisanenkampfes nur noch unterstrichen wurde. Und dieser kameradschaftliche Ungang mit Menschen, die den legendëren Capaev, Furmanov oder den Tapfersten der Tapferen, Kotovskij, oder den hervorragenden Partisanenhelden Parchomenko so gut kannten, wie wir alle in unserer Abteilung uns untereinander, war zugleich Schule und Stählung des Geistes und mach te uns zuversichtlich in Glauben an unseren Sieg. Diese alten Mitkämpfer von Scors und Zapaev brachten uns die ruhmreiche Vergangenheit des Kampfes um den Sieg der Revolution näher. Sogar denen, die nach dem Bürgerkrieg geboren waren, kam es vor, als ob sie Schulter an Schulter mit Scors, Kotovskił, Capaev und Sergej Lazo kämpften." (F59, S. 413f.)

\section{Der Abbau kosmopolitischer Tendenzen}

Om zu zeigen, welch vielfältige Beurteilungskriterien von der Zensurbehörde an den Dokumentarroman Verł́igoras herantragen werden, muB die einzige Textstelle erwähnt werden, deren Streichung im Zeichen des Kampfes gegen den Kosmopolitismus steht.

"Ein verwundeter älterer Arzt, der mit einer Hand ruderte, begann im Wasser zu versinken. Ich wollte ihm helfen und $20 \mathrm{~g}$ mein FloB näher heran... In dieser Zeit fegte noch eine Maschinenpistolengarbe durch das Wasser, und er, nachdem er aufgehört hatte, Widerstand zu leisten, sich aber noch immer uber Wasser hielt, sagte: Nicht nötif ... Retten sie sich selbst, Kollege... und sang das altertumliche, traditionelle Lied der russischen Studenten

\section{Gaud eamus igitur}

Iuvenes dum sumus...

Der Feldzug gegen den Kosmopolitismus - er wird gegen eine "der Parteilinie nicht entsprechenden, positiven Einstellung gegenüber den geistigen Leistungen des nichtkommunistischen Westens" ${ }^{1}$ gefuhrt und erfabt alle Gebiete des sowjetischen Geisteslebens - gehört zu den Ereignissen, von denen die Werke der Partisanenliteratur nur am Rande betroffen werden.

1 W.Kasack, Lexikon der russischen Literatur ab 1917 (1976) s. v. Kosmopolitismus. 
D VERŠIGORAS "LJUDI S ČISTOJ SOVEST'JU" IM ZEICHEN DER ENTSTALINISIERUAG 1. Der Abbau des Personenkultes in Veršigoras Dokumentarroman

Die vier Telle der Urfassung von Versigoras Fartisanenroman "Rejd za Dnepr" (Teil 1/2) und "Karpatskij rejd" (Teil 3/4) entstehen noch in der Zeit des Stalinkultes. Da die Textausgaben von 1953 und 1955 nicht verfügbar sind, kann im AnschluB an den kurzen allgemeinpolitischen Vorspann der Vergleich mit den Orfassungen nur anhand der vorliegenden Ausgabe von 1959 durchgefüht werden.

Die ersten Anzeichen eines Abbaus des Stalinkultes lassen sich unmittelbar nach Stalins Tod am 5.März 1953 wahrnehmen. Die offizielle Trauerzeit beträgt im Gegensatz zu der bei Lenins Tod (7 Tage) nur drei Tage, wobei kein einziger Sowjetführer - abgesehen von kurzen fürdigungen zweitrangiger Funktionäre und ausländischer Kommunistenfïhrer - öffentlich Stalins Gedenken ehrt. Neben einer Reihe von populären MaBnahmen (Amnestie der unter Stalin Verurteilten ${ }^{1}$, Kritik am Staatssicherheitsdienst, Rehabilitierungs- und Säuberungsaktionen in Georgien, Litauen, Lettland und der Ukraine), die vorderrangig der Einstimmung der Bevölkerung auf den neuer. politischen Kurs dienen, wird das Prinzip der diktatorischen Gewalt eines einzelnen zugunsten der kollektiven Fürung aufgegeben. Zur Reorganisierung gehören neben der personellen Umbesetzung in Präsidium des Ministerrats, im Sekretariat des $Z K$ und der Armeefürung auch die Verringerung der Zahl von Ministerien sowie die Auflösung der Stastskanzlei Stalins. AuBer einer schrittweisen Ersetzung der Führer der Stalinzeit durch jüngere Funktionäre - 1953 wird Berija gestürzt, werden Kiriteenko und Suslov in die Parteifürung berufen - versucht man die Ergebnisse der Politik Stalins punktuell zu korrigieren ${ }^{2}$, ehe zum ersten Mal in einem Grundsatzreferat im Juni 1955 in Sofia vor den anwesenden Funktionären des Parteiaktivs die Person Stalins von Chrušev einer scharfen Kritik unterzogen

1 Ausgenommen von der Amnestie sind die wegen "konterrevolutionärer Verbrechen" Inhaftierten und damit die Mehrzahl der unter Stalin Verurteilten.

2

Dazu gehören u.a.: Die Zurücknahme der 1948 geführten antijugoslawischen Kampagne, das Eingeständnis der Schuld am Kominformkonflikt sowie die kritiklose Duldung der Forderung nach einer Revision der Geschichtsschreibung durch die irmeeführung. 
wird, die eine Reihe von Anklagen aus seinem sogenannten Geheimreferat auf dem $X X$. Parteitag vorwegnimmt.

"Chruschtschow sprach vom Zusammenbruch der 'Leninschen Parteipraxis unter Stalin, vom Terror nach dem XVII. Parteitag 1934, er behandelt Stalins Rolle im Kriege und seine Nachkriegsdiplomatie und beschrieb die innere Situation in der Fuhrung nach Stalins Tod. Er gab bekannt daB die Fälle einiger der von Stalin liquidierten Fihrer auf dem nächsten sowjetischen ParteikongreB rehabilitiert wijden."1

Im Zeitraum zwischen dem Juli-Plenum 1955 und dem XX. Parteitag werden weitere Maßnahmen beschlossen, die die Tendenz der Abkehr von der Stalinära festigen sollen. $\mathrm{Zu}$ ihnen gehören unter anderem:

1. Der ErlaB einer Amnestie für die Sow jetbürger, die während des Krieges mit der deutschen Besatzungsmacht zusammengearbeitet haben.

2. Die offizielle Verurteilung der Prunkarchitektur Stalins.

3. Das Einschwenken auf einen neuen ideologischen Kurs (Kampagne gegen Talmudismus und Buchstabengelehrtheit, Kritik an den Ergebnis sen der spätstalinistischen Geschichtsschreibung, Ankündigung eines neuen Lehrbuchs der Parteigeschichte, Rehabilitierung von bis her verfemten Schriftstellern, Forderung nach einem verstärktem Studium des Kapitalismus und der Warnung vor seiner Simplifizierung).

Auf dem XX. Parteitag im Februar 1956 erfolgt nach den oben erwähnten vor bereitenden MaBnahmen die öffentliche Distanzierung von den Berrachaftsmethoden unter Stalin, die in erster Linie von Malenkov, Suslov und Chruscer getragen wird. Neben der Verurteilung des Prinzips der Alleinherrschaft Stalins werden einerseits die schon vor dem Parteitag gefaBter Beschlüsse bestätigt, zum anderen sollen elne Reihe von weiterführenden EntschlieBungen dle endgültge tberwindung des Stalinkultes anzeigen:

1. Die These vom unterschiedlichen Weg zum Sozialismus (die wirtschaftspolitischen Erfahrungen der SU sollen zukïnftig nicht mehr mechanisch auf die Volksdemokratien ubertragen werden).

2. Die 1deologische Neubegriindung der Koexistenz mit kapitalistische Ländern.

3. Die Rehabilitierung der Opfer Stalins.

4. Die Reform des bürokratischen Staatsapparates (Verwaltung, Staats sicherheitsdienst, Justiz).

5. Verkündung neuer Richtlinien für die Wirtschaft.

6. Die Schaffung neuer Richtlinien für Wissenschaft und Kultur.

Den absoluten Höhepunkt des XX. Parteitages bildet jedoch die interne Sitzung der Parteitagsdelegierten, auf der Chrušev ein dreiundvierzig

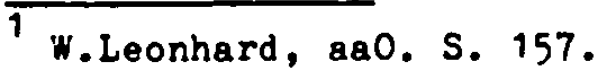


Seiten starkes Manuskript unter dem Titel "Der Personenkult und seine Folgen" vorträgt.

"Chruschtschor tadelte an Stalin den 'groben MiBbrauch der Nacht', sein 'launenhaftes und despotisches Wesen', seine 'Intoleranz', seine 'brutale Willkür', den 'MiBbrauch der sozialistischen Gesetzlichkeit', das 'leichtsinnige Verhalten', die 'MiBachtung bffentlicher Tatsachen', die 'fehlerhafte Führung von Staat und Partel', den 'Eigensinn', den 'GröBenwahn', die 'tberheblichkeit', die 'SelbstverRötterung' und den,'Widerwillen gegen die Anerkennung der Wirklichkeit des Lebens'".

Die Kritik Chruscevs, der sich mit diesen Ausführungen als Vorkämpfer der Entstalinisierung in Szene setzt und damit seine Position festigt, richtet sich jedoch, wie das obige zitat zeift, nur gegen die Person Stalins und entkleidet sie des Nimbus' der Unfehlbarkeit, rührt aber nicht die Grundagen der stalinistischen Gesellschaftsordnung an. Am SchluB des Vortrages ruft Chruscev die Partel auf, den Personenkult aus der Geschichtsschreibung, der Philosophie, der Wirtschaftswissenschaft und Literatur zu eliminieren. Welche Folgen aus dieser Forderung für die in der Stalinära geschriebenen Literatur erwachsen, zeigt auch Versigoras "Ljudi s cistoj sovest'ju" aus dem Jahr 1959.

\section{Die ersatzlose Streichung der die Person Stalins verherrlichenden}

\section{Textstellen}

Im Zuge der Anpessung des vorliegenden Romans an die durch den $X X$. Parteitag geänderte politische Situation werden im Sinne der Aufforderung Chrustevs in den Fassungen von 1945/46 und 1950 in Vergleich zur Ausgabe von $1959 \mathrm{ca} .78$ Textstellen bearbeitet.

Die Uberprüfung der von der Zensur beanstandeten Passagen ergibt jedoch, daB nicht nur die Textstellen, die tatsächlich Auswuchs eines ubersteigerten Personenkultes sind, revidiert werden, sondern auch ein Teil der Stellen im Text eine Bearbeitung erfährt, in denen Stalin in seiner Funktion als oberster Kriegsherr sachlich und ohne glorifizierende Ausschmükkung um der historischen Authentizität willen genannt wird.

Von den 13 Textstellen, die die Leistungen Stalins über Gebühr rühmen und die die magische Ausstrahlung des allmächtigen Führers auf Volk und Armee

W. Leonhard, 880. S. 247 
betonen, sind irsgesamt 1? in der Fassung von 1959 nicht mehr vertreten. $2 u$ ihnen gehören unter anderem ${ }^{1}$ :

"Das gute Gedächtnis des Alten [Kovpak] nahm jedes Wort, jede Geste und jede Pause des Genossen Stalin begierig auf." (UF45, 8, S. 53)

"[...] jeder Partisen wuBte, daB Kovpak den Kamprauftrag von Stalin selbst erhalten hatte und das begeisterte die Leute und steigerte ih. re Energie." (UF45, 8, S. 55)

"[...] der von den Partisanen Kovpaks als Stalin-Feldzug bezeichnet wurde, nach dem Namen des Nannes, der sie für diese ruhmvolle Heldentat befeistert hatte." (UF45, 8, S. 108)

"Genosse Stalin bestimmte scharfsinnig den weiteren Heg der Entwicklung des Partisanenkrieges." (UF50, 3, 3. 33)

"c...] gelenkt durch den Geist des Obersten Führers, des Genossen Stalin." (UF50, 3, S. 34)

"Die weisen Worte des Genossen Stalin, ausgesprochen am 3.Juli 1941, erkriffen das ganze sowjetische Volk und bewirkten im Hinterland des Feindes einen unerbittlichen Partisanenkrieg." (UF50, 3. S. 34f.)

"Als Symbol unserer gerechten Sache kommt uns in den Stunden der töd. lichen Gefahr das Volk mit dem Namen Stalins im Herzen zu Hilfe." (UF50, 5, S. 12)

"Es zeifte sich, daB ein Spezialflugzeug auf den persönlichen Befehl des Genossen Stalin hin zum Cernyjwald flog." (UP50, 5, S. 32)

Aus dem vom Zensor eliminierten Textabschnitt, der 1 1/2 Seiten umfaBt -

Kovpak berichtet den inm ur.terstellten Partisanen zum aiederholten Male von seinem Zusammentreffen mit Stalin im Kreml - sollen nur fün kurze

Passapen den Charakter des Berichts verdeutlichen.

"Ich terichtete dem Genossen Stalin alles: wie wir den Partisanenkrieg begonnen haben, wie wir kimpften, wie wir mit dem Volk Verbindung hielten. Auf alles hatte er eire Antwort. [...] Versteht ihr, vor ihm geriet ich in Errequr.e.[...] Die Partisanen saBen da und hielten die Luft an.[...]'ile konnte er [Stalin] das wissen? - fragte Volodja Sisov vorlaut. -Jeder hr̈tte das nicht wissen können, - antxortete Kovpak Korenev. [...] Was für ein Mensch! Er weiB alles im vor aus...?" (UFAt, 4, S. 63ff.)

Harum von den 12 eliminierten Textstellen nur 4 auf den "Rejd 28 Dnepr" entfallen, dafür jedoch 8 auf den "Karpatskij rejo", liegt offensichtlich in der Tatsache begriindet, daB Verłigora nach der Kritik am "Rejd za Drepr", die ihm den Vorwurf mangelnder Parteilich keit macht, dem Zuge der Zeit folgend, stärker den anteil Stalins er: Partisanenkriep. betont. Nit diesem Schritt entzieht er sich der Kritik am "Karnatskij rejd", zumindest bis zum Jahre 1956.

Ebenso die Textstellen UF50, 3, S. 33; UF50, 4, S. 27 u. UF50, 5, S. 14 
Nur eine einzige Textstelle, die ebenfalls zu diesem Komplex gerechnet werden muß, wird von Veršigora derart geändert, daß sie rudimentär, unter der Ausmerzung der Person Stalins, weiterexistiert.

Die Gründe für dieses Vorgehen sind in einer der theoretischen Grundsatzforderungen des Sozialistischen Realismus zu suchen. Versteht es sich für einen Partisanenführer vom Range und Ansehen Ver\$igoras von selbst, daB er sich im Kampf am leuchtenden Beispiel eines Nannes orientiert, der nach kommunistischer Norm durch seine Qualitäten als positiver Held gelten darf - und die panegyrische Form der Darstellung macht Stalin "zum positiven Helden unter den positiven Helden" - kann diese Eifenschaft des Autors von der Zensur nicht ersatzlos eestrichen werden. So wird an die Stelle Stalins ("Und das leuchtende Beispiel des Genossen Stalin führte uns im Kampf."; UF50, 5, S. 66) die Person des Politkommissars Rudnev eingeschoben, von der der Leser durch die Aussagen Veršigoras inzischen wei $B, d a B$ er den Partisanenabteilungen wie dem Autor selbst ein vorbildhafter Vorgesetzter und Kämpfer ist: "Und die vorbildhafteste Gestalt in meinem Leben, der Kommissar Semen Rudnev, führte uns im Kampf." (UF59, S. 675).

\section{Die Ersetzung Stalins durch paraphrasierende Begriffe}

Die bisher angeführten Textstellen konnten von der Zensur ohne groBe Schwierigkeiten gestrichen werden, weil ihre Bedeutung für den Roman über die Funktion der ornamentalen iusschmückune kaum hinausreicht. Problematischer in dieser Hinsicht sind die Passagen, in denen eine ersatzlose Streichung eine vom Leser erkennbare Lücke hinterlieBe, da das generelle Verschweigen von Stalins Namen auch die Unterschlagung bestimmter Befehle und Aktionen zur Folge hätte. Heil auf diese Weise der dokumentarische Wert des Romans erheblich gemindert wüde, ersetzt der Autor bzw. der Korrektor "Stalin" an den entsprechenden Textpassagen punktuell durch einen paraphrasierenden Begriff.

Zu dieser Form der Revidierung gehört die von Kovpak gewählte Einsatzbenennung "Stalinskij rejd", die in der Fassung von 1959 nur noch unter der Bezeichnung "Rejd za Dnepr" existiert. Drei von inspesamt zweiundzwanzig Beispielen sollen in diesem Zusammenhang den Sachverhalt inhaltlich ver- 
deutlichen. 1

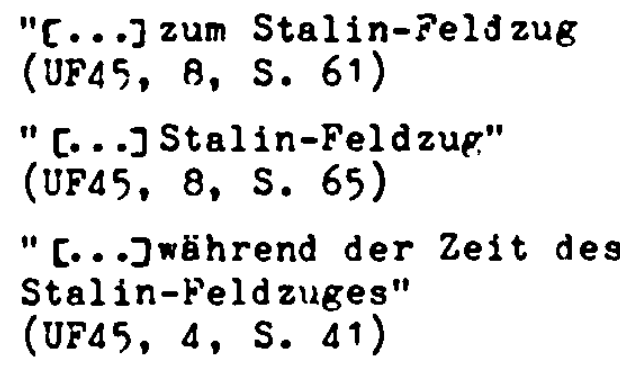

$$
\begin{aligned}
& \text { - "[...]zum Feldzug über das rechte } \\
& \text { Ufer des Dnepr hinweg" (F59, S. 59) } \\
& \text { - "r...]Feldzug" (F59, S. 63) } \\
& \text { - "[...]während der Zeit des Rejd } \\
& \text { za Dnepr" (F59, S. 193) }
\end{aligned}
$$

In ähnlicher lieise reht der Zensor auch gegen die Textstellen vor, in denen die von Stalin en die Partisaneneinheiten ausgegebenen Kampfaufträge bzw. Befehle cenannt werden. LäBt es ter Kontext zu, wird die gesamte Fas. sace eliminiert ("[...]stalinscher Auftrag", UF45, 8, S. 67; "[...]laut Befehl des Genossen Stalin", UF50, 3, S. 61) ${ }^{2}$ und durch keinen reuen Einschub ersetzt. Ist dies inhaltlich oder syntaktisch nicht möglich, wird das jeweilige Attribut oder Nomen pestrichen (" $C . . J$ laut stalinscher hufgabe", UF45, B, S. 54; "[...] der Befehl des Genossen Stalin", UF46, 5/6, S. 46 ; "[...]das stalinsche $2 K "$, UF50, 3, S. 6) ${ }^{3}$ oder durch elnen neuen Begriff abgevanielt. Auch in dipsem Zusammenhang muB das methodische Vorgehen der Zensurbehörde als Fälschung, bezeichnet werden, da die vorgenommenen Korrektiren den Eindruck erwecken, als hahe es nie eine Alleinherrschaft Stalins gefeben bzw. sei das Prinzip der kollektiven Fuhrung, von dem erst seft der Reorganisierung, des Staatsapparates nach Stalins Tod gesprochen werden kann, von jeher Bestandteil des sowjetischen Führungsgrundsatzes gewesen.

"Laut Aufrabe des Genossen - "Laut Aufgabe des HauptquartieStalin [...." $($ ijp50, 3, 3. 3) res [....]" (F59, S. 351)

$1 \mathrm{~V}_{\mathrm{gl}}$. dazu die restlichen Beispiele:

UF45,8,S.72/F59,S.72; UF45,8,S.73/F59,S.73; UF45,8,S.104/F59, S.134; UF46,4,S.4/F59, S.150; UF46,4,S.26/;59, S.175; UF46,4,S.29/F59, S.179; UF45,4,S.40/:59, S.191; UH45,4, S.6.3/F59, S.196;UF46,5/6, S.35/F59, S.246; UF46,5/6, S.A7; 559, S.254;UH46,5/6,S.44/F59, S.257;UF46,7, S.52/F59, S. 348; "F50,3,S.7/F59, S.357; UF50,3,S.12/F59, S.366; UF50, 3, S.20/F59, S.381; UF50,3,S.4?/F59, S.437; UT50,3, S.47/F59, S.437; UF50,4,S.38/F59, S.515; UP50,5,S.59/F59,S.664.

2. VFl. dazu die Textstellen UFA5,8,S.65; UF 45,8,S.73; UF50,3,S.4; UF50,3,S.5; UF50,3,S.6; U.550,4,S.62.

3 Dazu gehört auch die Passage der UF50,3,S.35/F59,S.417. 


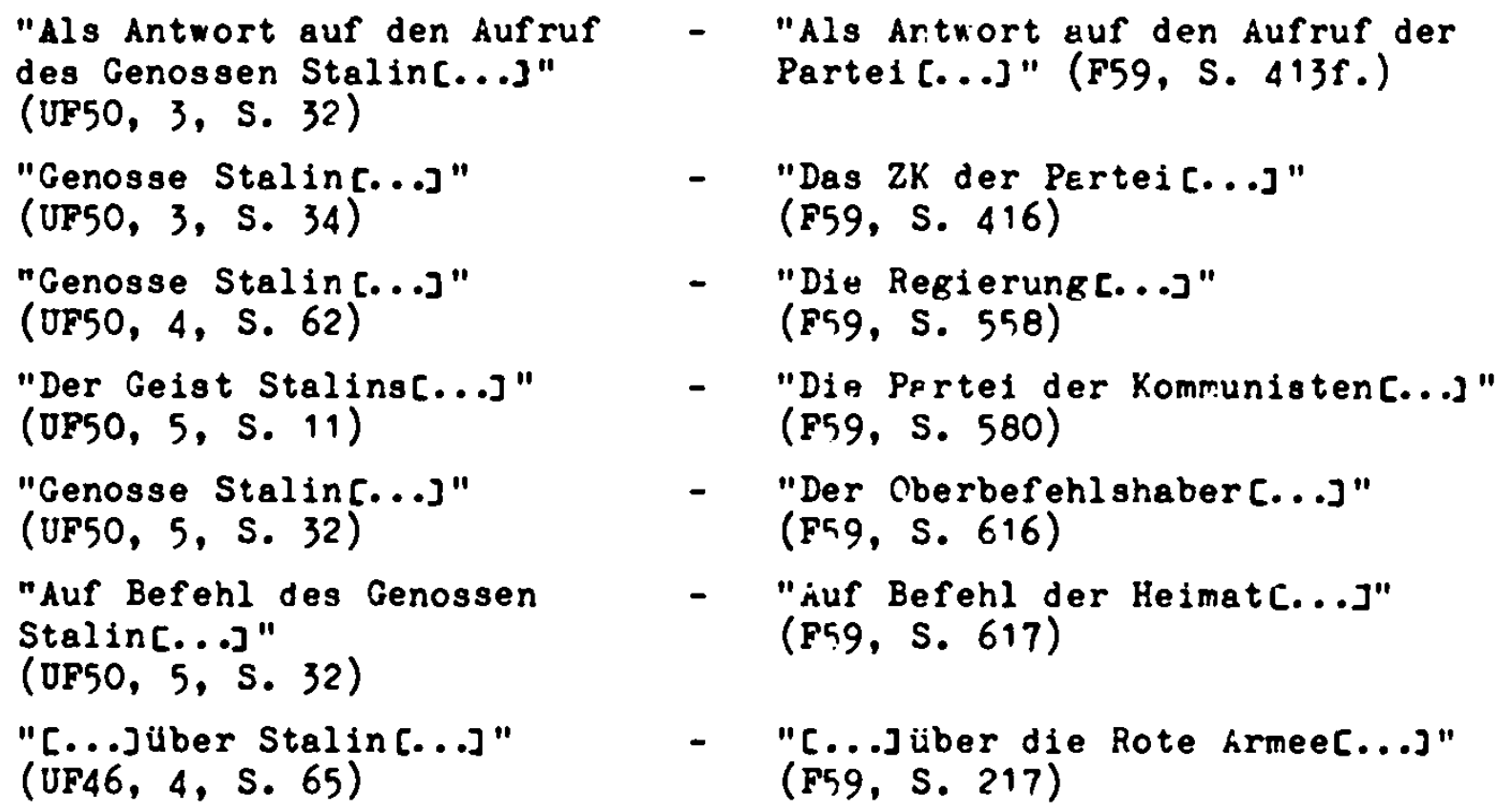

Im Zuge der Umbenennung werden auch gleichzeitig die Truppenteile und Weffengattungen neu benannt, die indirekt oder direkt in den Urfassungen in einem Atemzuge mit Stalin Erwähnung finden.'

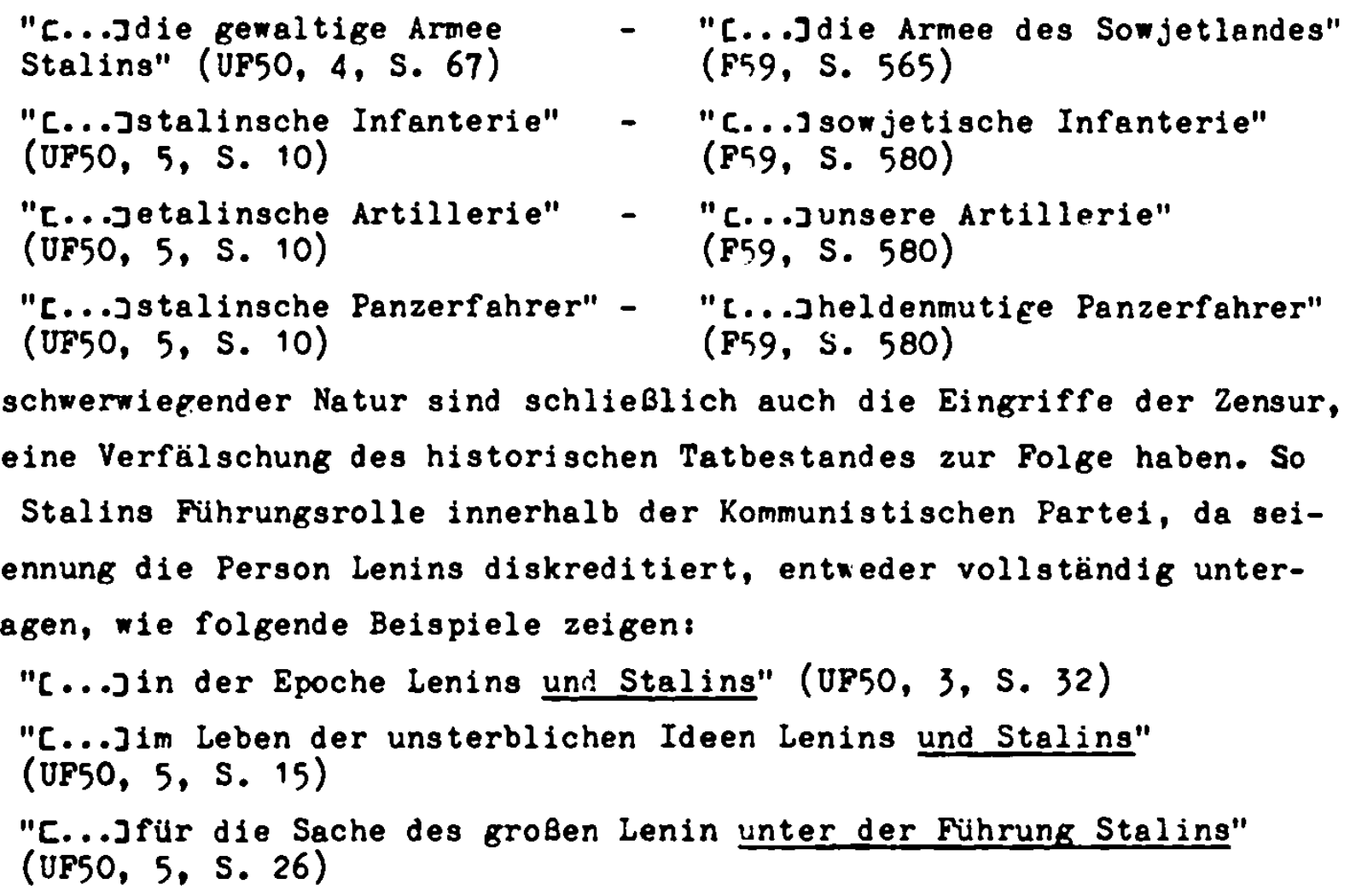

$V_{\text {gl. }}$ dazu auch die Textstellen in der UF50,5,S.32/F59,S.616 und UP50, 5, S.32/F59, S.616. 
"[...Jder Marxismus we Lenin ihn lehrte und wie ihn uns Genosse Stalin lehrt." (UF50, 5, S. 59)

oder durch einen entsprechenden Ersatz umgedeutet:

"Schon im Bürgerkrieg von 1917 - 1920 war die von Lenin und Stalin

gelenkte Partisanenbewegung C...J" (UF50, 3, S. 32)

"Schon Im Bürgerkrieg von 1917 - 1920 war die von der Partel gelenkte Partisanenberegung C...J" (UF59, S. 413)

In ähnlicher Weise verfährt der Zensor mit den historischen Belegen der Tätigkelt Stalins im Zweiten Weltkrieg im Rahmen der Organisation der Par tisanenberegung ${ }^{1}$, wobei besonders Stalins Rundfunkrede vom 3.Juli 1941 in ihrer wörtlichen Wiedergabe wie in ihrer indirekten Erwähnung kompromiBlos ausgemerzt wird.

"Die einzige Richtlinie war die Rede des Genossen Stalin vom 3.Juli des Jahres 1941. Und diese leitete sie den ganzen Krieg. Wie nach einer Magnetnadel, die dem Schiff den Weg zeigt, hielten sle Kurs auf die erbarmungslose Zerstörung des Feindes." (UF46, 4, S. 21)

"[...]um von den Mitgliedern des Partisanenstabes elnige interessante Details zu erfahren, und was die Hauptsache war, um mit den histo rischen Befehlen des Genossen Stalin, der die Ziele und Aufgaben der Partisanenbewegung des sowjetischen Volkes festsetzte, bekanntzuwerden." (UF50, 3, S. 30)

"In seiner historischen Rede vom 3.Juli 1941 sagte der Genosse Stalin: 'In den vom Feind okkupierten Gebieten müsen Partisanenabteilungen $z u$ Pferd und $z u$ Fu $B$ gebildet und Diversionsgruppen geschaffer werden zum Kampf gegen die Truppenteile der feindlichen Armee, zur Entfachung des Partisanenkrieges überall und allerorts, zur Sprenpung von Bricken und Straßen, zur Zerstörung der Telefon- und Telegrafenverbindungen, zur Niederbrennung der Wälder, der Versorgungslager und der Trains. In den okkupierten Gebieten müssen für den Feind und alle seine Helfeshelfer unerträgliche Verhältnisse geschaffen werden, sie müssen auf Schritt und Tritt verfolgt und vernichtet und alle ihre MaBnahmen müssen vereitelt werden." (OF50, 3 , S. 32)

Neben der Tatsache, daB die in der UF5O noch auszugweise zitierte Rundfunkrede Stalin als geistigen Urheber der Partisanenbewegung erkennen läBt - die Tendenz der Entstalinisierungskampagne läuft letzlich derauf hinaus, ihm, dem man zuvor alle erdenklichen Fähigkeiten bescheinigt, nur uber die angedichteten Eigenschaften hinaus auch die real vorhandenen abzusprechen - trëgt die hier vertretende "Taktik der verbrannten Erde" zuJ

Zu diesem Komplex gehört auch die von der Zensur gestrichene Textstell€ UF50, 6, s. 60 . 
Eliminierung bei. Da man nach offiziellem Sprachgebrauch die eigenen militärischen Aktivitäten als gerechten Verteidigungskrieg definiert, die des Gegners jedoch - dem man die Anwendung der von Stalin einwandfrei zuerst befohlenen Vernichtungsstrategie auf seiner Riickzugsbeweging zur Last legt - als ungerechten Raubkricg tituliert, muB die historische Rede vom 3.Juli 1941 in der Fassung von 1959 verschwiegen werden.

Interessant im Rahmen des Kapitels ist euch die Textstelle in der UF50, in der gleichzeitig neben Stalins Verdiensten an der Partisanenkrieffihrung die von Chruǧtev, Ždanov und Voroß̆ilov erwähnt werden. Entgeren der Annahme, daB allein Stalins Anteil vom Zensor einschlägif becrheitet wid, ist jedoch die gesamte Textpassage in der F59 nicht mehr vorhanden.

"Deswegen unterstehen die Partisanen auch dem persönlichen Befehl Befehl des Genossen Stalin. Er ist Parteiführer, oberster Krieesherr und der Führer des Volkes. So einfach ist die ganze Sache aufgebaut. In der Ukraine werden die Partisanen von Nikita Serfeevid befehligt, in Leningrad von Genossen Zdanov. Genosse Vorosilov aber ist der Oberfehlshaber der Partisanen." (UF50, 5, S. 60)

Der wohl einzige stichhaltige Grund, der diesen Sachverhalt erk] ̈̈rt, liegt in der Rangfolge der Aufzählung begrïndet, die einerseits Stalin den größten Verdienst zusichert, zum anderen die entscheidener. Fürer der nachstalinistischen Ära - abgesehen von Zianov, der schon 1948 atirbt als Vasallen Stalins erscheinen läBt und in eine gefährliche vähe der Mitverantwortlichen des Personenkultes als stille Dulder zieht.

E DIE REAKTION AUF DIE KANPAGNE GEGEN DEN PERSONENKULT UND DIE AUFWERTUNG STALINS

Die Reaktion der sowjetischen Öffentlichkeit auf das von Chruscev auf der internen Sitzung gehaltene Referat - es wird in gekürter form in den Hochschulen, auf Partei- und Komsomolversammlungen verlesen ${ }^{1}$ - ist unterschiedlich und reicht vom (seltenen) Treuebekenntnis ${ }^{2}$ bis zur systenkritischen AuBerung. Um die in Gang kommende Diskussion zu kanalisieren, veröffentlicht die "Pravda" am 28.März und am 5.April zwei richtungreisende Artikel. Während ersterer ("Poßemu kul't ličnosti cuzd duchu marksiz-

\footnotetext{
1 W. Leonhard, as0. S. 272.

2

Besonders in Stalins Geburtsland Georgien.
} 
ma-leninizma?"), neben der Erwähnung von Staling Verdiensten, die MiBstände der Stalinära verurtellt, llegt der Schwerpunkt des zweiten ("Kom. munisticeskaja partija pobezdala i pobezdaet vernost'ju leninizma") auf der Verkündung von MaBnahmen zur therwindung des Personenkultes, wobel gleichzeltig die Vertreter der Richtung gewarnt werden, "[...] die in de Entstalinisierung weitergehen woll[t]en, als es der nachstalinistischen Fuhrung genehm [ist]."

Im Gegensatz zur Sorjetunion, in der sich die Beseitigung des Personenkultes in den von Chrusicev abgesteckten Bahnen vollzieht - den Höhepunkt der Kampagne bildet in Juni 1956 die Absetzung der prostalinistischen Finhungskräfte Molotov und Kaganovid - drohen die Ereignisge in den osteuropäischen Satellitenstaaten diesen Rahmen zu sprengen. Während die Re aktion der Fihrungsschichten in der DDR und in Albanien konservativer Na tur sind, müssen die Partelführungen Rumäniens, Bulgariens und der Tsche choslowakei unter dem Druck der Cffentlichkeit politische Konzessicnen machen. Am weltesten in der Entstalinisierung von allen Blockländern geh Polen. Hier, und damit deckt sich weitgehend die Auffassung mit der der kommunistischen Parteien Westeuropes (Italien, Frankreich, GroB-Britannien), werden die Stalin zur Last gelegten Verbrechen nicht als Summe vo Charakterfehlern, sondern als systemimmanente Erscheinungen begriffen. I Sommer 1956, bedingt durch die innenpolitische Entwicklung (Ausufern der Reformtendenzen auf dem Sektor von Kunst und Literatur) ${ }^{2}$ sowie die auBen politischen Ereignisse in Polen (die Streikbewegung in Posen weitet sich zum Aufstand aus), sind erste Anzeichen einer Abkehr von der Entstalinisierune erkennbar, die sich mit der Resolution des $\mathrm{ZK}$ der KPdSO vom 30.J ni 1956 und den "Pravda"-Artikeln vom 6. und $24 . J u l 1$ noch veratärken. Mi der blutigen Niederschlagung des Volksaufstandes Anfang November in Onga durch sowjetische Truppen kommt der Abbau des Personenkultes zum Stillstand. Die 1deologischen Thesen des XX.Parteltages werden mit der gleicr. zeitigen Rehabilitierung von Molotov und Kaganovid abgeschwächt, die Fer

W.Leonhard, 8a0. S. 277 .

2 Der Umschlag auf diesem Sektor wird u.a. durch die Herausgabe der Samu lung von Chruscevs Reden unter dem Titel "Za tesnyj ovjaz' literatury iskusstva 8 zizn'ju naroda" eingeleitet, die "eine modernisierte Version der Theorien der Zdanovära darstellen."(M.Slonim, s80. S. 377). 
ler Stalins nur noch selten erwähnt, dafiir jedoch seine Verdienste bei der Oktoberrevolution, beim sozialistischen Aufbau sowie beim Kampf gegen die Peinde der Arbeiterklasse nachdrücklich betont.

Die Phase der stürmischen Entstalinislerung, wie die folgende Verhärtung des innenpolitischen Kurses anzeigt, ist im Januar 1957 endgulltig abgeschlossen, die oben schon sichtbar werdende neostalinistische Tendenz wird zum traditionelien Neujahrsempfang im Kreml am 31.Dezember 1956 und am 17.Januar 1957 beim Empfang in der chinesischen Botschaft von Chrušcev selbst gebilligt. Er führt bei diesen Anlëssen aus:

"Die Imperialisten bezeichnen uns als 'Stalinisten'. Wenn es um den Kampf gegen den Imperialismus geht, dann können wir versichern, daB wir tatsächlich alle Stalinisten sind."1

1. Die Auswirkungen der Aufwertung Stalins in Veršlgoras "Ljudi \& Eistoj sovest'ju"

In der vorliegenden Ausgabe von 1959 ist die in Kapitel $E$ der Arbeit skizzierte Kehrtwendung bereits spürbar. ${ }^{2}$ So sind insgesamt ca. 14 Textstellen, die nach den Prinzipien der Entstalinisierung überhaupt nicht mehr oder nur in stark modifizierter Form in der F59 auftreten durften, in vollem Umfange erhalten. GemäB der Erkenntnis, daß Stalins Kampf gegen die Feinde der sozialistischen Gesellscheftsordnung und des Marxismus-Leninismus als Verdienst zu werten sei - der siegreiche Ausgang des GroBen Vaterländischen Krieges gehört nach offizieller sowjetischer Diktion, trotz der zuvor geübten Kritik, seit $1955^{3}$ zweifellos dazu - bleibt ein gerinfer Prozentsatz der Textpassagen, in denen Stalin erwähnt wird, vom Zensor unangetastet. Dies gilt besonders für die Textabschnitte, die einen positiven Schluß auf Stalins Anteil bei der Lenkung des Partisanenkrieges zulassen, wie folgende Beispiele beweisen:

B.Meissner, Das Ende des Stalinmythos (1956) S. 11.

2 Ob die in Veršlgoras Roman vorhandenen Textstellen, die die Person Stalins berühren, nach 1953 oder 1955 erfolgter Eliminierung in die Ausgabe von 1959 wieder aufgenommen wurden, oder ob sie der Zensor bei der Bearbeitung dieser Ausgabe, schon in Kenntnis der politischen Entwicklung bewuBt nicht angetastet hat, war leider nicht zu klären, da die Werkausgaben von 1953 und 1955 nicht vorlagen.

B.Meissner, aa 0. S. 12 . 
"Auf Vorschlag des Vorgesetzten des Zentralstabes der Partisanenberepung im Hauptquartier des Oberbefehlshabers Cenosse Stalin wurden am 31.August 1942 die Leiter der Partisanen eingeladenc...." (F59, S. 46)

"Matveev hatte den vollständigen Text der Befehle und Vorträge des Genossen Stalin in das Partisanengebiet mitgebracht." (F59, S. 48)

"Mit seirem Befehl zum 1.Nai stellte uns Stalin, die Fartisanen, mit den Kämpfern der Roten Armee auf eine Stufe." (F59, S. 48$)^{1}$

Die Ursachen fij diese widersprüchlichen Maßnahmen der Zensur lassen sich zum Teil auch aus der schwieripen Situation ableiten, in der sich der Zensor befindet. Die Streichunp aller Stalin betreffender Textstellen wïrde bedeuten, daß das von Versigora vertretene Parteilichkeitsprinzif, da Stal in die Partei schlechthin verkörpert, in er heblichem $\mathrm{NaBe}$ pemindert wïrde, zumel eine Ersetzung durch paraphrasierende Begriffe bei Renauer Datierung des historischen Vorgangs nicht immer möglich ist.

Neben der Erwähnung vom Zusammentreffen der Fartisanenführer mit Stalin im Kreml, hzw. der Passagen, die in enfem Zusammenhank mit diesem Treffen stehen, bleihen auch ein Teil der Textabschnitte erhalten, in denen Verłigora die zweite Konferenz vom September 1942 reflektiert. 2

$Z$ ieht man die Beobachtung von $\%$.Leonhard hinzu, aus der hervorpeht, da $B$ schon im September ein Teil der Werke Stalins von parteiamtlicher Seite rehabilitiert werden,

- "Die Redaktion der Parteizeitachrift 'Kommunist' (Nr.14, Septemher 1956) teilte mit, sie habe eine Vielzahl von Briefan erhalten mit der Anfrage, 'ob man beim Studium der marxistisch-leninistischen Theorie und der Geschichte der KFdSU die Schriften Stalins benutzen darf, und wenn ja, welche'. Andere fragten, 'ob man sich nicht überhaupt von den Schriften Stalins lossager. sollte'. Dies sei natirlich 'völlig falsch'. Stalin sei ein 'großer marxistischer Theoretiker' gewesen; seine Schriften bis zum Jahre 1934, vor allem 'Die GrundlaEen des Leninismus' (1924), 'Protleme des Lenirismus' (1926) und 'ther die Industrialisierur.g und die rechte Abweichung der KPdSU' (1928), sollten im Rahmen der Parteischulung unbedinet studiert werden." 3 -

so erklärt sich die Erwähnuny der Schriften Stalins, zumal aus dem Kontex hervorgeht, wie folgende beispiele zeifen, dab es sich nur um sein Frühwerk handeln kann. In diesem Zusammenhenp nimmt der Zensor euch die Nor-

\footnotetext{
1 Vel. dazu die übrigen fassagen F59,S.49; F59,S.616; F59,S.668.

2 F59,S.415.

3 w.Leonhard, aaO. S. 319.
} 
nung Stalins in Verbindung mit Lenin in Kauf, obwohl die in Kapitel $D 3$ der Arbeit belegten Streichungen in klarem widerspruch $z$ den noch vorhandenen Textstellen stehen:

"Ein Buch war immer der ständige Begleiter von Rudnev. Lenin und Stalin, Turgenev und Tolstoj, Gogol' und Gor'kij - mit ihm kam der Kommisaar zur Roten Flotte. Von Februar 1932 an war Rudnev Kommissar und Vorgesetzter der Propagandaabteilung des Dekastrinschen Festungsbezirkes im Fernen Osten." (UF50, 5, S. 17/ F59, S. 590)

"Ich machte mich an die Werke von Lenin und Stalin." (UF50, 5, S. 44/ F59, S. 638)

Lassen die bisher zitierten Textstellen die komplizierte Situation bei der Besorgung der $F 59$ deutlich werden, obwohl trotz der widersprüchlichen Ergebnisse die Gründe für das Vorgehen des Zensors sichtbar gemacht werden konnten, ist die Erhaltung der folgenden Passage nur erklärhar, wenn man sie als Ausdruck der parteitaktisch gegenlëufigen Tendenzen innerhalb der Entstalinisierung wertet. So bleibt in Versigoras Partisanenroman des Jahres 1959 der Name "stalinsches Traktorenwerk" (F59, S. 530), im Gegensatz zu den vorherigen Korrekturen, ebenso erhalten wie die Stadtbezeichnung "Stalingrad" ". Selbst eine Textstelle, die eindeutig im Zeichen des Personenkultes steht, wird vom Zensor nicht revidiert. ${ }^{2}$

"Oft lëutete das Telefon und die Stimme des Genossen Stalin war zu hören: Berichten sie, wo sich Kovpak hefindet! Wie steht seine Sache? Was giht es neues uber das Schicksal von Rudnev?" (UF50, 5, S. 32/ F59, S. 616)

\section{Die ersten Anzeichen eines neuen Fürerkultes}

Die ersten sichtbaren Indizien in Verigoras "Ljudi s cistoj sovest'ju", die für den Aufbau eines neuen Führerkultes sprechen - sie betreffen die Person Chrußcevs - sind, gemessen an denen des Stalinkultes, von nicht gravierender Natur. Während der Zensor aus der von Ver Beschreibung Chruscevs die Passage eliminiert, die dessen Physiognomie wie folgt beschreibt: "Zum ersten Mal sah ich den allen im Sorjetland bekannten Menschen. Ein erschöpftes, müdes Gesicht... rosige Wangen.... kräftige Hände. Einen nachdenklichen Blick aus ibbermüdeten Augen. "? di ent

1 F59,S.548/UF50,4,S.57. Da die Umbenennung von Stalingrad in Volpograd erst am 27. Januar 1959 auf dem XXI.ParteikongreB beschlossen wird, konnte sie vom Zensor wahrscheinlich nicht berücksichtigt werden.

2

3

$V_{\text {gl }}$. dazu auch F59,S.49/UF45,8,S.53.

UF50,5, S.61. 
ein in die Fassung von 1959 eingeschobenes Kapitel dazu, neben den in der Urfassunf schon zum Ausdruck kommenden Verdiensten bei der Leitung des Partisanenkrieges in der Ukraine, Chruskevs menschliche Art und organisatorische Fähifkeiten zu unterstreichen. So wird er von Versigora als ein Vorgesetzter gezeichnet, der trotz wichtiger strategischer Entscheidungen noch die Zeit findet, sich persönlich für die Beschaffung eines Funkgerätes für die Abteilung Kovpaks einzusetzen, wobei er selbst eine langwierige Diskussion mit dem Verbindungsmann der Einheit, Kornienko, nicht scheut. 'Bedenkt man, daB dieser Textabschnitt für die Fassung von 1959 extra konzipiert wird und vergleicht einen der letzten Sätze mit der Passage, die aus der UP5O auf Grund des zum Ausdruck kommenden Stalinkultes weichen muBte, so wird die Absicht Verśigoras deutlich:

"Und in dieser Zeit flog am sternenubersäten Himmel der Front, die frostige Luft mit den Propellern zerschneidend, ein von Chrugcev gesandtes Flugzeup zu Kovpak." (F59, S. 105)

"Es zeigte sich, daB ein Spezialflugzeug auf den persönlichen Befehl des Genossen Stalin hin zum Cernyjwald flog." (UF50, 5, S. 33) Hirft man einen Blick auf die politische Szenerie der Jahre zwischen dem $X X$.Perteitag und dem vorfristig einberufenen XXI.Parteikongre $B$ vom Januar 1957, so restätigen die Ereignisse eindelitig die Tendenz zum Chruscevkult. An die Stelle des Prinzips der kollektiven Führung ist die Vormachtstellunf eines einzelnen gerückt, hedinft durch die ständige Machterweiterung Chrustevs, wie die Vorgänge auf dem Parteitag selrst veranschaulichen.

"Auf den XXi.l'arteitag sprach kein einziger prominenter Redner such Chruschtschow selbst nicht - von der kollektiven Führune. Statt dessen strnd iikita Chruschtschow im Nittelpunkt. Sein Rechenschaftsbericht wurde nicht. mehr als 'Bericht des Zentralkomitees' hezeichnet, sondern als die 'Große Rede des Genossen Nikita Sergejewitsch Chruschtschow'. Die Reiner sprachen nicht mekr von der Parteifihrung und dem Zentralkomitee, sondern vom 'ZK mit N.S.Chruschtschow an ter Spitze' $[\ldots]$. 2

Vergegenwärtift man sich die Auswüchse des Stalirkultes sowie die sich in wesentlich pemäBigteren Bahnen bewefenden Formen der Chruscevverehrung, so wird deutlich, in welch hohem $\mathrm{KaBe}$ sich beide Phänomene in der Literatur, in diesem Falle Versigoras "Ljudi s listoj sovest'ju" spiegeln.

\footnotetext{
1 Dieser Textehschnitt konnte auf Grund seiner Länge nicht zitiert werden, siehe deshalb F59, S. 101ff.

2

H. Leonhard, aa0. 3. 498 .
} 
$F$ DIE FEINDBILDVERSCHIEBUNG ALS ERGEBNIS DES WANDELS VON INNEN- UND AUSSENPOLITIK

\section{Statistische Analyse}

In der Orfassung von Versigoras "Ljudi s Eistoj sovest'ju" (Teil 1/2) wird zur Bezeichnung des Gegners der Partisanen fast generell der Nationalitätsbegriff "nemec" oder der im Krieg geläufige Spitzname "fric" verwendet, während der ideologische Begriff "fasist" bzw. "gitlerovec" dagegen kaum auftaucht.

$$
\begin{array}{cc}
\text { "nemec/fric/nemeckif" } & \text { "fasist/fasistskij/eitlerovec/ } \\
\text { ca. } 205 \times & \text { bitlerovskij" }
\end{array}
$$

Dieses Verhältnis bleibt in der Fassung von 1948 voll erhalten.

In dem 1950 erscheinenden Teil 3/4 ist erstralig eine starke Verschiebung in der Benennung erkennbar.

$$
\text { "nemec/fric/nemeckij" } \quad \text { _fasist/fasistskij/gitlerovec/ }
$$

$$
\text { ca. } 205 \times \quad \text { ca. } 90 \times
$$

Der Vergleich der zusammengelegten Telle der Urfassungen (Teile 1-4) mit der Fassung von 1959 ergibt ein erneut verändertes Verhältnis.

$\begin{array}{cc}\text { Teil } 1 / 2 ; 1945 / 46 & \frac{\text { Teil } 1 / 2 ; 1959}{\text { "nemec/fric/nemeckij" }} \\ \text { ca. } 405 \times & \text { "nemec/fric/nemeckij" } \\ \text { "fasist/gitlerovec/fa- } & \text { ca. } 370 \times \\ \text { sistskij/gitlerovkij" } & \text { "fasist/gitlerovec/fa- } \\ \text { ca. } 25 \times & \text { sistskij/gitlerovskj" }\end{array}$

Die Annahme, daB es sich bei dem beobachteten Unterschied zwischen den Fassungen der Teile $1 / 2$ von 1945/46 und 1959 nur um eine spätere Angleichung im Sinne der Urfassung von Teil S/4 aus dem Jahre 1950 hendelt, be- tëtigt sich nicht, wie der Vergleich zwischen der schon entsprechend ausgerichteten Fassung von Teil 3/4 von 1950 und Teil 3/4 von 1959 zeigt:

$\begin{array}{cc}\text { Teil 3/4i } 1950 & \frac{\text { Teil } 3 / 4 i 1959}{\text { "nemec/fric/nemeckij" }} \\ \text { ca. } 205 \times & \text { ca. } 190 \times \\ \text { "fasist/gitlerovec/fa- } & \text { "fasist/gitlerovec/fa- } \\ \text { ristskij/gitlerovskif" } & \text { ristskij/gitlerovskij" } \\ \text { ca. } 90 \times & \text { ca. } 105 \times\end{array}$


Aus der statistischen Analyse gehen damit $z$ e i zeitlich markante Einschnitte hervor:

Während die zuerst beobachtete ideologische Verschiebung mit Sicherheit in den Zeitraum 1949/50 fällt, kann die zweite prägnante anderung zwar durch die Ausgabe von 1959 sichtbar gemacht werden, doch ist eine genaue Datierung auf Grund der statistischen Analyse nicht möglich. Erst mit der Aufdeckung der historischen Ursachen wird deutlich, daB die zweite Verschiebung in den Zeitraum von 1954/55 fällt.

\section{Die historischen Ursachen}

Die Gründe, die letztlich zu der in Kapitel $F 1$ beschriebenen Verschiebung führen, sind in erster Linie in der Entwicklung der Beziehungen zwischen den Siegermächten des Zweiten Weltkrieges zu suchen. Da eine lückenlose Darstellung der einzelnen Phasen des Kalten Krieges, die von außerordentlicher Komplexität und Vielschichtigkeit sind, den Rahmen der Arbeit sprengen würde, können nur die entscheidenen Stationen auszugsweise und in stark vereinfachter Form aufgezeigt werden.

Kontroversen über eine ganze Reihe von Problemen zwischen den USA und England auf der einen Seite und der UdSSR auf der anderen lassen sich schon während des 2weiten Weltkrieges registrieren; Spannungen prägen auch das Bild der Konferenzen von Teheran (1943), Jalta (1945) und Potsdan (1945), die sich jedoch durch die KompromiBbereitschaft der Vertreter Englands und der USA in Grenzen halten. Durch die immer stärker werdenden Expansionsbestrebungen der Sowjetunion, tritt 1945/46 an die Stelle der bis dahin von den Westmächten betriebenen Politik der Kooperation im Blick auf eine gemeinsam zu schaffende Weltfriedensordnung eine Haltung, dfe "Geduld mit Festigkeit" verbindet (auch unter dem Namen "Eindämmungs-Politik" oder "Containment" bekannt). Die Ergebnislosigkeit der Moskauer Konferenz 1947 hinsichtlich einer Reihe von Problemen der Deutschlandfrage (Reparationen), dazu die Auseinandersetzungen im Sicherheitsrat und im AtomkraftausschuB der UNO, die Sowjetisierungstendenzen in Ostmitteleuropa und die Ansprüche der UdSSR auf die Kontrolle der Meerengen nach der Kündigung des abkommens von Montreux führen $z u$ einer Verschärfung der

1 B.Meissner, Russland, die Westmächte und Deutschland. Die sowjetische Deutschlandpolitik 1943 - 1953 (1953) S. 78. 
Gegensätze zwischen Ost und West und lassen die ersten Umrisse einer fester. Blockbildung sichtbar werden. Diese verstärken sich noch, als Źdanov in September 1947 die sogenannte "Zwei-System-Doktrin" verkïndet:

"Die als Folge des Krieges eingetretenen grundlegenden änderungen in der internationalen Lage und in der Lage der einzelnen Länder haben die gesamte politische Weltkarte ungestaltet. Es entstand eine neue Gruppierung politischer Kräfte. Je gröher die Periode ist, die uns vom Kriegsende trennt, desto krasser treten zwei Hauptrichtungen in der internationalen Nachkriegspolitik hervor, die der Teilunf der ir. der Weltarena aktiven politischen Kräfte in znei lauptlager entsprechen:Das imperialistische und antidemokratische Lager einerseits und das antiimperialistische und demokratische Lager andererseits. Die führende Hauptkraft des imperialistischen Lagers stellen die USA dar.[...] Die antiimperialistischen und antifaschistischen krüfte stellen das andere Lager dar. Die Grundlage, dieses Lagers bilden die UdSSR und die Länder der neuer. Demokratie."

Bedingt durch das Scheitern der fünften Tafung der AuBenministerkonferenz in London" das "In erster Linie durch die sowjetische Strategie des 'Kalten Krieges' verursacht wird" 3 , gehen die Hestmächte daran, den Wiederaufbau und die Sicherung der eigenen Welt diesseits des Eisernen Vorhangs zu beschleunigen.

Mit der Sprengung des Allierten Kontrollrates, des oberaten Organs der Vier-Mëchte-Verwaltung Deutschlands im Mërz 1948, durch den Vertreter der Sowjetunion und den Ergebnissen der Brisseler Fünf-Mächte-Konferenz (ZusammenschluB Belgiens, Frankreichs, Luxemburgs, der Niederlande und Englands zu einem Bündnis) verschärft sich die politische Situation zxischen Ost und West weiter, begleitet von einer wachsenden Pressepolemik, und führt 1948 zur Blockade Berlins. Die AuBenministerkonferenz der Ostblockstaaten in Warschau (Juni 1948) benutzt die UdSSR, neben der Machtdemonstration gegenúber den Westmächten, um die einzelren Ostblockländer mit einer angeblichen deutschen Gefahr zu schrecken und nogh enger an sich zu ketten.

Die folgende Phase der Entspennung auf internationaler Ebene, bedirgt

1 2it. nach T.Weingartner, Die AuBenpolitik der Sow jetunion seit 1945 (1973) S. 70f. (Dokument 6 "Shdanovs weltpolitische Analyse, September 1947": Auszug aus dem Referat Żdanovs:"Utber die internationale Lage" auf der Gründungstagung des Kominform).

2

Die Tagung steht im Zeichen heftiper Debatten über die sonjetischen Reparationsforderungen im Rahmen des Deutschlandproblems.

B.Meissner, as0. S. 156. 
durch eine gewisse Verständigungsbereitschaft der Sowjetregierung den Westmächten gegenüber (Anfang 1949), währt nur kurze Zeit. Die Gründung des Comecon, die Komplettierung des osteuropäischen Beistandspaktes und die Gründung der DDR auf der einen Seite sowie der AbschluB des Nordatlantikvertrages und die Konstituierung der Bundesrepublik Deutschland auf der anderen, zementieren die Spaltung Deutschlands und verschärfen die internationale Atmosphäre von neuem.

Während die Westmächte die Staatsbildung der DDR in scharfer Forr verurtellen, bezeichnet Malenkov in seiner Festrede zum $32 . J a h r e s t a g$ der Oktoberrevolution im November 1949 die Gründung der DDR als Wendepunkt in der Geschichte Europas, nachdem Cuikov zuvor erklärt hatte, daB allein die Bildung einer "Marionettenregierung" in Bonn schuld an der Vortiefung der Spaltung Deutschlands sei: "Es versteht sich von selbst, daB sich die Demokratisierung und Entmilitarisierung Deutschlands nicht mit einer Lage vereinbaren läBt, bei der auch nur ein Tell Deutschlands, in die Hände der gestrigen Inspiratoren des Hitlerregimes gerät."

Hinter dem Konzept der sowjetischen Pressepolemik, das W. Erfurt wie folgt analysiert, verbergen sich realpolitische ziele:

"Die Sprache gegenüber dem Westen wurde zusehends härter und ausfallender. Dies ist iumer ein Zeichen dafür, daB die Sowjets ihren Willen nicht durchdrücken konnten. Stets wird dann der ganze, zeitwei118 zurückgehaltene Wortreichtum, den der Marxismus für seine 'Feinde' bereithält, über den Widersacher ausgeschüttet. Damit soll der Gegenseite die alleinfge Schuld am Scheitern einer Verständigung zugeschoben werden. Zugleich soll aber eine 'moralische' Plattform für eine heftige Reaktion und Gegenreaktion des Kreml geschaffen werden. Deshalb wird das Verhalten des Gegenspielers weit dusterer geschildert als es auch in den Augen der Sow jets tatsächlich 1st, und die Gefahren, die das gegnerische Verhalten angeblich heraufbeschwört, werden in dramatischer Weise überhöht."

Mit der These vom "Wiedererstehen des deutschen Imperialismus" hoffen die sonjetischen Politiker einerseits die Spannungen innerhalb des Westblocks erhöhen und die Bundesrepublik auBenpolitisch 1solieren zu können, während auf der anderen Seite die damit verbundene Erstellung eires neuen Feindbildes die Bindung der Satellitenstaaten an Moskau verstärken soll und gleichzeitig als Rechtfertigung der enormen Rüstungskosten dient, die dem sow jetischen Volk neben der Wiederaufbauarbeit und der Industrialisierung des Landes zusätzlich aufgebürdet werden.

\footnotetext{
Z1t. nach B.Meissner, aso. S. 220 .

2 w.Erfurt, Die sowjetrussische Deutschland-Politik (1959) S. 33.
} 
Viahrend die in Verłigoras "Karpatskij rejd" von 1950 beobachtete verstärkte Ideologisierung aus der oben skizzierten politischen Situation der Jahre 1945 - 1949/50 erwächst, resultiert der in der Fassung von 1959 erneut registrierte Wandel, wie die im folgenden beschriebene politische Entricklung zeigen wird, aus den internationalen Vorgängen der Jahre $1950-1954 / 55 .^{1}$

Durch die agkressive Politik des Kreml in Korea 1950 beginnt die westliche Welt, ihre politischen, wirtschaftlichen und militärischen Bemühungen um die Sicherung der eigenen Welt erneut zu verstärken, wobei jetzt besonders die Frage der deutschen Aufristung im Vordergrund steht. duf die Uberlefungen der westlichen AuBenminister in New York im September 1950, die Bundesrepublik an der Verteidigunesgemeinschaft zu beteiligen, reagieren die in Prag tagenden Vertreter der Osttlockstarten mit scharfem. Protest und bezeichnen die geplante Aufstellung deutscher Kontinfente in der Europëischen Verteidifungsgemeinschaft als Bruch des Potsdamer Abkommens und als offenen tbergang zur Aggressionspolitik. Als die Bundesrepublik dem Pleven-Plan zustimmt und die AuBenminister der drei Viestmächte in Brijssel (Dez. 1950) die Bildung, eir.er Europäischen Streitmacht (EVC) billiken, sehen sich die Tellnehmer der kommunistischen "Fieltfriedensbewepung" in Warschau genötigt, im "Wanifest an die Völker"der Felt" gegen eine "erneute Entfachung des Kriegsbrandherdes in Deutschland eufzurufen" ${ }^{2}$. Da das Jahr 1951 ebenfalls ir. Zeichen starker Differenzen steht die USA kündigen das amerikanisch-sowjetische Handelsabkommen von 1937 , die Bundesrepublik wird Mitglied des Europarates und unterzeichnet den EGKS-Vertrag - hält die Sowjetunion am Konfrontationskurs fest. So erklärt Berija anläBlich des 34 .Jahrestages der Oktoberrevolution im Septerber 1951: "In letzter Zeit wird die Remilitarisierung hestdeutschlands unter Hinzuziehung Hitlerscher Kriegsvertrecher in beschleuniften Tempo durchgeführt." 3 , während die Vertreter der kommunistisch gesteuerten

1 Nit an Sicherheit grenzender Viahracheinlichkeit müBte die in der Ausgabe von 1959 registrierte Verschiebung schon in der nicht vorliependen Fassung von 1955 zu finden sein.

2

B.Meissner, aa0. S. 220.

3 Zit. nach B.Meissner, aa0. S. 276. 
Neltfriedensbewegung i November 1951 in Wien folgenden Passus in ihre Resolution "ther das deutsche Problem" aufnehmen:

"Die Hiedererweckun des Nazismus in Hestdeutschland und vor allem die Rolle, die men ehemalige Nazigenerale spielen läBt, indem men sie an die Spitze der neven deutschen firmee stellt, bedeuten eine ernste Gefahr für die ganze Welt und insbesondere für das deutsche Volk und seine Nachbarn."1

Ungeachtet der groBangelegten Proparanda-Aktionen gegen die westliche Integration von sowjetischer Seite, schliebt die Bonner Regierung im Mai 1952 mit den Hestmächten den Deutschlandvertrag ab, der die Aufhebung des Besatzungsstatutes und die Wierierherstellung der auBenpolitischen Handlungs freiheit kedeutet, und unterzeichnet in Paris den EVG-Vertrar. Im April tesaelben Jahres benutzt Wilhelm Pieck anläßlich der 1.-Mai-Feier in OstBerlin diese Ereignisse dazu, die faktisch längst vollzogene Aufrüstung der DDR zu fordern. Auch hierbei dienen die "imperialistischen Kriefstreiher" als Rechtfertigungsgrund.

Der sowjetische Historiker E.Tarle kommentiert die Unterzeichnung des Generalvertrages und des EVG-Vertrages wie folgt:

"Die Ruhrmonoriolisten, die hinter der Bonner Regierung stehen, und die mit heiler Haut davongekommenen Nazimilitaristen, deren Dienste Washington so sehr braucht, erhalten jetzt für den Verrat, den sie an den Lebensinteressen des deutschen Volkes begehen, die Möglichkeit, die faschistische Wehrmacht wiederaufzustellen, und können damit Hoffnung schöpfen auf Revanche, auf einen neuen Feldzug nach Osten mit voller Unterstützung der amerikanischen Imperialisten."2

Nachdem die USA 1952 ihr Konzept der "Eindz̈mmungspolitik" ("Containment") zugunsten der "Zurïckdämmungspolitik" ("Roll-back") ändern, die Bundesrepublik die Einheziehung in die Natc auf der Grundlage der Fariser Verträge billigt (1954) und die UdSSR die DER als souveränen Staat anerkennt, beginnt "die Zejt der 'Zwei-Stasten-Theorie', der 'Anerkennung der Realitäten'." 3 Obfleich die "Zwei-Lafer-Theorie" von der "Koexistenz-Theorie" abgelöst wird, peht der systemetische kufhau des Feindbildes einer revanchistischen Bundesrepublik unverändert weiter, da sie 1955 Mitglied der Nato wird.

1 Zit. nech B.Meissner, aa0. S. 280.

2 Zit. nach B.Weissner, aa0. S. 306.

3 P.Noack, Deutsche Außenpolitik seit 1945 (1972) S. 44. 
DaB 2 wischen diesen beiden unterschiedlichen Taktiken nach sowjetischer Auffassung nicht unbedingt ein widerspruch bestehen muB, zeigt der Artikel der "Pravda" vom 26. Dezember 1956, in dem der Zeitschrift "Voprosy fllosofii" vorkeworfen wird, "die auBerordentliche These der Partei daruber, daB die friedliche Koexistenz zweier Systeme nicht den Verzicht auf den Kampf gegen die bourfeoise Ideologie bedeute" 1 , nicht aufgedeckt zu haben.

Die Antwort der SU ist die Gründung des Warschauer Paktes im Mai 1955 und die Kündigung der während des 2 weiten Weltkrieges mit Grobhritannien und Frankreich geschlossenen Bündnis- und Beistandsverträge. Als Erklärung führt sle an, "die Regierungen Frankreichs und Grobbritanniens hätten die 'Pariser Verträge', die die Remilitarisierung Westdeutschlands und seine Einbeziehung in die militärische, gegen die Sowjetunion gerichtete Gruppierungen vorsehen, gebilligt."

An Form und Inhalt der sowjetischen Propaganda-Aktionen ändert sich auch in den folgenden Jahren nicht viel; nur hinsichtlich der Dauer und Intensität bestehen graduelle Unterschiede. So werien bei fast allen Konflikten zwischen den Westmächten und der UdSSR sowie bei Spannungen innerhalb des sozialistischen Lagers die Schuldursachen auf die "reaktionären Kräfte des westlichen Lafers" abgeschoben (Aufstand in Polen, Volkserhebung in Ungarn, "Prager Frühling" ${ }^{3}$ ), wobei für die politischen Verhältnisse im gespaltenen Deutschland und in Berlin permanent die "westdeutschen Imperialisten faschistischer Provenienz" verantwortlich gemacht werden. Zudem können auf Grund dieser Argumentationsführung die eigenen politischen Maßnahmen [Eingliederung der NVA in die Streitkräfte des Viarschauer Paktes, Verkündung des Republikflucht-Gesetzes, Errichtung der Mauer ("Friedensgrenze") in Berlin] als Schritte der "Friedenssicherung" ausgegeben werden.

Obwohl der absolute Höhepunkt der propagandistischen Kampagne 1954/55

Zit. nach B.Meissner, RuBland unter Chruschtschow (1960) S. 10.

2

E. Deuerlein, Deutschland nach dem Zweiten Weltkrieg 1945-1955 (1964)

S. 212 .

3 Schon der Aufstand in Ost-Berlin am 17.6.1953 wurde von W. Ulbricht in der oben angedeuteten Weise interpretiert: "Die Provokation am 17.Juni hat die Partei iberrascht. Viele Genossen erkannten nicht sofort den faschistischen Charakter [... " (21t. nach E.Deuerlein, aaO. S. 232). 
überschritten ist, hält die Zensurhehörde offensichtlich auf höhere Weisung am einmal geschaffenen Feindbild fest, wie Versigoras "Ljudi s listoj sovest' ju" aus dem Jahre 1959 beweist, da es sich in seiner Anwendbar. keit als äuBerst vielfältig zeigt.

\section{Einige inmerkungen zur ideologischen Komponente der Feindbild-} verschiebung

Neben den schon in Knpitel $F 2$ genannten Gründen, die zur Feindbildverschiebung führen, muB eine weitere wichtige Komponente der Umbenennung von "nemec/fric" in "gitlerovec/fasist" genannt werden. Durch die Ideolofiaierung des ehemaligen Kriegsgegners verlagert sich der Ideengehalt auf eine politisch-weltanschaulichn Ehene: der Kriegsgegner wird zum Klassenkontrahenten. Deutet sich diese Verschiebur.R schon während des Krieges an und wird im Februar 1946 von Stalin bestätigt -

"Unser sieg bedeutet vor allem, daB unsere sowjetische Gesellschafts. ordnung gesieft hat, das die sowjetische Gesellschaftsordnung die Feluerprobe des Kriefes mit Erfolk bestanden und ihre volle Lebensfähikkeit bewiesen hat [....]"1.

weirhalten dio in Kapitel F 1 beschriebenen Vorfänge lediflich eine Konplettierung der Doktrin. ${ }^{2}$ Aus dem bewaffneten Konflikt zweier Völker bzk. Nationen - Deutschland fegen RuBland - wird ein Veltanschauungskrieg Sozialismus regen Faschismus. Cleichzeitig mit dieser Unpolung ändert sich auch eines der Grundaxiome, das bisher der Nobilisierung des russischen Volkes diente: an die Stelle des iationalhasses tritt der KlassenhaB (vorher nur intriebskraft innenpolitischer Auseinandersetzungen).

Im zuletzt. Renannten Punkt. scheint eir. bewuBter Rïckgriff auf die in Lenins Revolutionslehre gesammelten Erfahrungen vorzuliegen, die nun auch auf auBenpolitische Konflikte ubertrager. vierden. Hatte schon Clausewitz ir. seinem Kerk "Vom Kriege" betont, "daB im Krieg 'dem einzelnenc...jkein feindseliges Gefihl gegen den einzelnen beizuwohnen' pfleft, vielmehr der Vationalhaf die individuelle Feindschaft ersetze, und - wo auch dieser $\mathrm{HaB}$ anfangs fehle - 'sich das feind-

2it. nach T.Heingartner, aa0. S. 63 (Dokument 2: "Stalin uher den Charakter und die Bedeutung des Zweiten Weltkrieges").

2

Betrachtet men die Propaganda des Dritten Reiches, so wird deutlich, da hier der Krieg von vornherein auch unter ideologischen Gesichtspunkten konzipiert war (Vernichtung des Bolschewismus). 
selige Gefühl an dem Kampfe selbst' entzünde, steht die Erweckung

'feindseliger Gefühle' zur Konstituierung des Klassenkrmpfes [...] am Anfang der Leninschen Revolutionsanweisungen." 1

Welch hohe Bedeutung die sowjetischen Ideologen und Historiker dem ideologischen Faktor bei der Begründung des sowjetischen Sieges über Deutschland zumessen, zeigen, neben der nachträglichen Umarbeitung von Verłigoras Partisanenroman", zwei Sätze der "Istorija":

"Die Ideologie des Marxismus-Leninismus war einer der wichtigsten Faktoren für die Erringung des Sieges über Hitler-Deutschland." 3

"Die gegenwärtige Epoche, die gewachsenen MaBstäbe, die Kompliziertheit und die Wichtigkeit der neuen politischen Aufgaben, die durch den Gang der historischen Entwicklung vor uns gestellt wurden, einschlieklich der weiteren Festipung der Verteidigungsbereitschaft des Landes, erfordern die ständige Schärfung der ideologischen Kaffen, das ständige Bemühen um die Erhöhung der politischen Kachsamkeit der Sow jetmenschen und den unermüdlichen Kampf gegen die reaktionären Ideen der kapitalistischen Gesellschaft." 4

\section{G $\triangle U$ USBLICK}

Rekapituliert man die Ergebnisse der Arbeit, so wird ersichtlich, daB sich die bis zum heutigen Zeitpunkt erschienene Partisanenliteratur in drei Hauptphasen aliedert.

Zur ersten Phase gehören die in Kapitel B 2 genannten Werke, die im Zeitraum von 1944 bis 1946/47 entstehen. Sie sind noch durch das freizügige KLima der gelenkten Liberalität der Kriegsjahre geprägt. Zu den Werken der zweiten Phase gehören die revidierten Ausgaben der schon im erstgenannten Zeitraum vertretenen Romane und die Erscheinungen, die im Zeichen der starr dogmatisch gehandhabten Parteilichkeit geschrieben werden. Sie kennzeichnet in erster Linie die Betonung des hohen Anteils der Partei und ihrer Mitglieder am Partisanenkampf sowie der über-

W.E.Schmitt, Krieg in Deutschland. Strategie und Taktik der sonjetischen Deutschlandpolitik seit 1945 (1961) S. 101.

2

Ob sämtliche Werke der Kriegsliteratur in dieser Wieise ungearbeitet wurden, konnte im Rahmen der Arbeit nicht überprüf werden, doch liegt die Vermutung nahe.

3 Istorija. Band VI (1965) S. 181.

4 8.0. S. 183. 
national-weltanschauliche Zug, der aus der nachträglichen Ideologisierung des Partisanenkrieges erwächst (1947 bis 1953/54). Hierzu gehören M.Naumovs "Chinelskie pochody" (1953) und N.Saburovs "Za liniej fronta" (1953).

Zur dritten und letzten Phase miissen schlieblich die Werke der vorhergehenden Ceneration gerechnet werden, die entsprechend dem Entotalinisierungsauftrage Chruscevs umgearbeitet worden sind sowie diejenigen, die nach Beendiaung der Nivellierungskampagne des Personenkultes entstehen: D.Medvedevs "Na beregach juźnogo Buga" (1957), P.P.Verłigores "Rejd na San 1 Vislu" (1959), J.Kozlovs "Ljudi osobogo sklada" (1959), V. Ijaß̌lenkovs "Karajułčij gorod" (1961), M. Naumovs "Stepnoj rejd" (1961), A.Judenkovs "V ofmennom kolce" (1962) und M.Naumovs "Zapednyj rejd" (1969).

Vor dem reichen Hintergrund der dreifach gegliederten Partisanenliteratur kann die vorliegende Arbeit notwendigerweise nur ausschnitthaften und in Vorausschau möglicher weiterer Schwankungen der Generallinie- vorläufigen Charakter haben, da sie mit Ver\$igoras "Ljudi s cistoj sovest'ju" nur ein einzelnes Werk exemplarisch herausgreift.

Doch auch aus einer derart begrenzten Analyse läBt sich auf Grundsätzliches der marxistischen Wertung schlieBen. Bedenkt man die aus der unterschiedlichen Handhabung des Parteilichkeitgrundsatzes erwachsenden Folgen für die Partisanenliteratur und ihre Autoren, so gerät der Objektivitätsanspruch der marxistischen Wissenschaft, wie er einer Grundsatzformulierung der Zeitschrift "Kommunist" zu entnehmen 1st, in ein zweifelhaftes Licht:

"Die marxiatischen Historiker vertreten den Standpunkt der Arbeiterklasse, deren Interessen voll und ganz mit dem objektiven Verlauf des gesellschaftlichen Entwicklung zusammenfallen. Sie bedürfen keinerlej vorgefabter Schemata, sie brauchen die Tatsachen nicht zu entstellen. Die Parteilichkeit der marxistischen Wissenschaft, ihre militante Unversöhnlichkeit gegenüber den bürgerlichen Verzerrungen und reformistischen Theorien sind nicht möglich, ohne die Wiederspiegelung des Wesens und der Logik des historischen Prozesses. Die proletarische

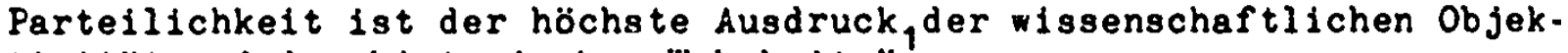
tivität und der historischen Wahrheit."

Mit einer solchen Definition führt sich, zumindest nach westlichem Verständnis, die marxistische historische Wissenschaft der fünfiger Jahre - miBt man den obigen Satz an den Ergebnissen der Arbeit - selbst ad absurdum.

Tit. nach B.S.Tel puchovskij, a80. S. $88 \mathrm{E}$. 


\section{ABKCRZUNGSVEKZEICHNIS}

Veršigoras "Ljudi s listoj sovest'ju" erschien, abpesehen von einzelnen Auszügen in "Literaturnaja gazeta", "Vozaty", "Vokrug sveta" urd "Stalinskij sokol", in vier Teilen.

Teil 1/2 wurde in der Zejtschrift "znamja" (1945) 8 und (1946) 4, 5/6, 7 und Teil 3/4 in "Zvezda" (1950) 3,4, 5 veröfientlicht.

Zum Vereleich mit den Urfassungen lagen die Ausgaben von 1948 (hier ist naturgemäB nur Teil $1 / 2$ enthalten) und von 1959 (Teil 1-4) vor.'

Um eine raumsparende ïbersichtliche Handhabung beim Zitieren zu gewährleisten, gelten für die vorliegende sirbeit folkende Abkürzunfien:

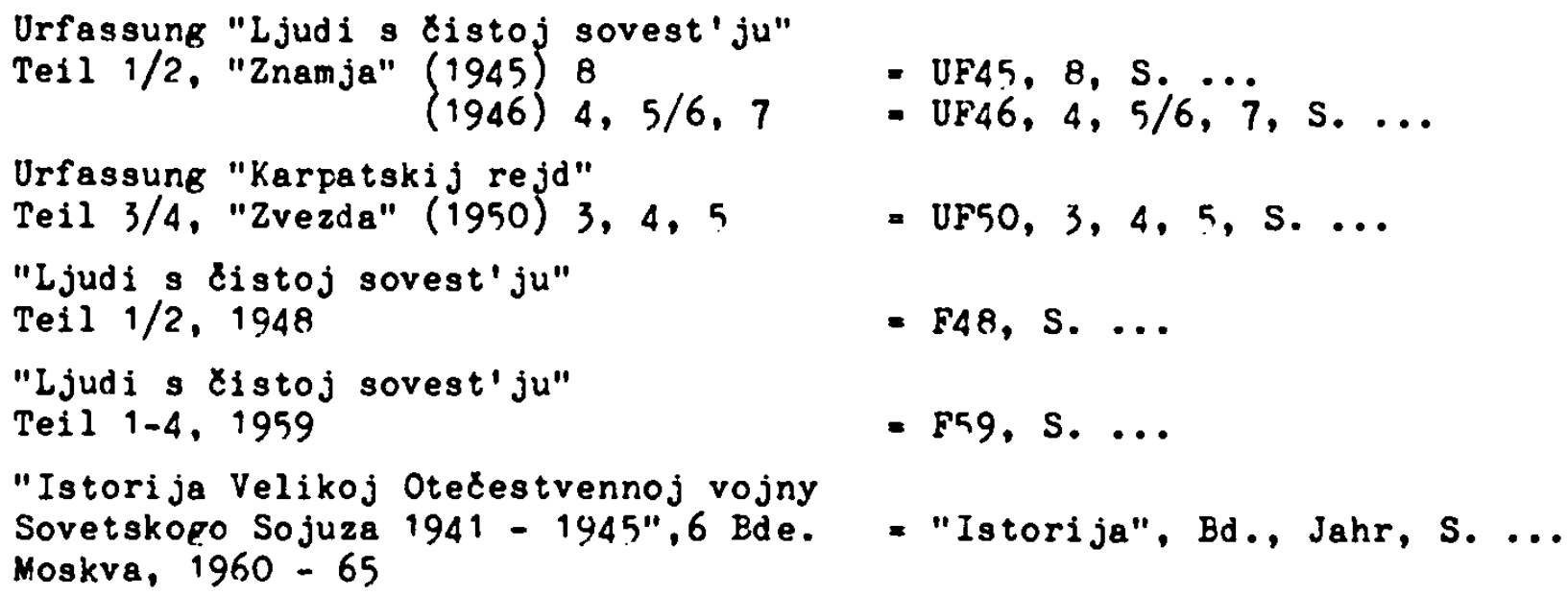

Sind innerhalb eines Zitates aus den Urfassunpen beatimmte Passapen unterstrichen, bedeutet das, daB diese in der Urfassung von 1948 bzw. 1959 der genaue Ort ist jeweils gekennzeichnet - nicht. mehr enthalten sind.

Die aus den vier Fassungen von "Ljudi s listoj sovest'ju" zitierten Textstellen liegen in der Arbeit in einer lbersetzung vor; ihr orifinalwortlaut kann dem Anhang der Arbeit entrommen werden.

1 In diesem Zusammenhang muB erwähnt werden, daB ab 1953 die Teile $1 / 2$ and $3 / 4$ vereint unter dem Titel "Ljudi s ל̇istoj sovest'ju" erscheinen, wobei Teil 1/2 nun den Titel "Rejd $2 a$ Dnepr" trägt, wïhrend Teil $3 / 4$ weiter unter der tberschrift "Karpatskij rejd" rangiert. 
S. 14 "Фашистн часто достигали своей чели."

F 59, S. 195: "Фашистн иногда достигали своей чели."

S. 18 "Приходилось мне встречать таких партизанских руковояителей, которше мнили себя крупными стратегами, а на самом Аеле Просто СУАьба и геоРрафия войны поставила их на Участок, гАе немцам нехватало сил аля его оккупаиии."

S. 19 "Командование Объеяинения, Собственно Говоря, являлось ЛИшь Своеобразн世м ПУнКтом СбОра АОнесенИй, - местом, Че-

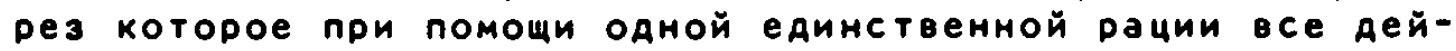
Ствия Партизанских ОтряАов СОобщались на Большуо землю. И Большая земля, по мере возмомности, помогала партизанам ящиком патронов, свежей газетой, комплектом питания. А в остальном все действовали по приниипу: 'Ауй кажднй BO पTO TOPasA'."

"B первне же ани пребнвания в партизанском крае мне приШЛОСЬ ПрИСУТСТВОВать На ОАНОМ Из СОВещанИЙ КОМанАИРОВ районных соединений, но еще Ао начала совещания я узнал от ветеранов партизанского края, что еще зимой 1941-1942 Года леса Брянщине стали базой всех честных советских Лодей, Оставшихся или специально оставленных на охкупированной врагом территории. [...] По признву партии в лесах остались поАпольные группы И организации. [...] Коммунистн, комсомольчн, Передовне рабочие и колхозники, трУАовая Интеллигенция нашей области, так ме как и весь Советский народ, По призыву партии Стали подавать заявления о зачислении их в партизанские отрядн."

"Партизанское движение в некоторых районах приняло характер всенародного восстания против Фашистских захватчиков и проводило в страх и трепет Фашистских заправил и их ставленников. Наши боевне дела тревожат не только немеиких солАат и мандармов. Как Увидите, нашими успехами обеспокоено и внсокое гитлеровское начальство."

S. 20 "В 'несчастливое' число 13 иоля 1942 года я попрощался на азродроме с меной."

"в первне же ани пребнвания в партизанском крае пришлось ПрИСутствовать на ОАном Из СОверщаний КоманАИрОв районных СоеАинений."

"Совещание Аля меня было очень кстати. Пробыв несколько яней на территории, занятой партизанами, я еще не совсем ясно преАставлял себе приниипш организачии и управления

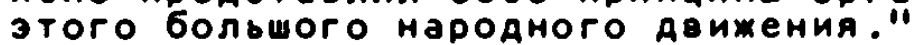

"Уже на 1 мая 1942 года, по неполным данным [...] партизанш области истребили 19845 вражеских солат, 237 офицеров, 1 генерала, 2090 полицейских и предателей. Взято в плен 74 офицера и 172 солдата. Собрано много разведАанных о противнике и его передвижении. Эти сөедения пе- 
DедавалИСь военномУ КОМандОванИо ФрОнта.

Сбито стрелковым оружием, уничтожено в эшелонах и путем налетов на аэродромы 44 вражеских самолета. Пуиено под откос 32 вражеских зшелона, в том иисле 5 эшелонов $c$ техникой врага - танки, самолетн и два бронепоезда. Разрушено 205 километров железнодорожного пути; взорван 41 железнодорожный мост, 84 моста на шоссейных и грунтовнх дорогах. Разгромлено 9 воинских штабов, 8 управлений поличии. Взорвано и сожжено 42 танка и бронемашины, 418 автомашин, 6 иИстерн С ГОрючим, 9 тягачей, 21 склая и база с продовольствием И вооружением.

Взяты трофеИ: 10 танков И бронемашин, 14 оруаий, 154 пулемета, 400 винток, 14 автомашин, 135 пошадей, 146 пово3ок, несколько сот ГОЛОв ПрОАУктивноГО СКОта.

Партизанами были изгнаны немцы и их ставленники из 346 населенных пунктов со 170 тнсячами населения."

S. 21 "Генерал Блочман, со своими солАатами веяущий борьбу с партизанами, в приказе 1 от 15 Февраля 1942 года писал: 'Развеакой Уставлено больше количество Партизан. Партизаны хорошо обуты, одеты, имеот хороших лошадей, Сани, АОстаточно лыж и маскировочных халатов. В русских селах население сочувствует и помогает партизанам. B селах ни полииии, ни старост нет. При расположении на отAux $50 \%$ coлgat cпать не ложатся.'

- Генерал Фон Гриаус в приказе от первого иоля сорок nepвoro rоAa писал:

'Партизаны лучше стреляот, выбирарт лучшие позичии аля Оборон, и напаяения, чем маяьярские солАаты. Партизанам

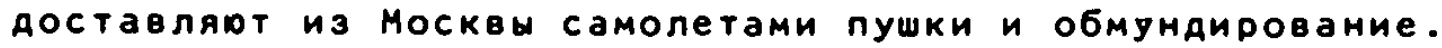
...KогАа крестьянин спрашивает винтовку, не Аавай - может yбитb.

... Нельзя разтоваривать в домах - все будет передано партизанам." "'

S. 22 "Генерал Фашистской главной ставки Фон Браухич в положении 'no борьбе с партизанами' пишет такое: 'Pусские партизаны наносят УАары не только по мелким войсковым чаСТям И СоеАИнениям АействуоциХ войск, НО НарУшают Снабжение войск, разрушарт военнше сооружения в тнловых районах."'

S. 23 "Партизаны - это армия без интенданства, армия, ная которой нет ни определенншх законов, ни их блюстителей, ни ревтрибуналов, ни миличии. Поэтому зАесь легко скатиться К Простому банаитизму, К Употребленио оружия аля легкой, Привольной И САтОЙ жизни."

"Никто не знал, что там тоже действуот партизанские отряАн. ОТРяАН эти бЫли 'АИкими', ТО есть Аействовавшими на свой Собственний рНСК И Страх, не имея ни связи С Большой Землей, ни полномочий, ни утвержденных Инстанциями АИректив. ЕяИнСтвенной Аирективой была речь товарища Сталина от 3 иоля 1941 года. И ее хватило им на всо войну. Как по магнитной стрелке, указыварщей путь кораблю, держали они курс на беспощадное истребление врага." 
S. 23 "в партизаны шли добровольчн, романтики были и случайные люаи $[\ldots]$...

"Оба они были [Ковпак и Руанев] Поставлены районными организациями во главе выделенных райкомом групп коммунистов. Большинство Первых Партизан подбиралось из партийного актива."

S. 24 "Сабуров, Емлотин, Дука, Проковский и Аругие";

"Слушая рассказы Ковпака И Аругих участников зтой знаменательной встречи, Партизаны И командиры БрянскоГо Края И УКраИнСКИХ ОТРЯАОВ КаК-ТО ПОАтянУЛИСЬ, ПОЛИтИчески И морально Повзрослели."

S. 25 "Партизанская война становилась частьо общего плана по разтрому врага."

"По ним [поиказам], как по компасу данному в наши руки партией большевиков, выверяли мы свой боевой путь."

"Ковпак получил от Сталина и Ворошилова боевое задание совершить новый рейА."

S. 26 "Еще в начале рейда [...] в Брянском партизанском крае, Который стал базой Аля мноГИХ ОтряАОв, мы были свидетелями кипучей Аеятельности Иентрального штаба Партизанского Авижения."

"Офицеры связи были почти во всех отрядах, в том иисле и у Kовпака."

"По своему служебному положенио я не мог.тога знать во всех деталях приказ Главкома партизанским двитением, но в общих иертах его знали многие команаиры."

S. 27 "Уже после войны, встречаясь с партизанами - ленинградскими, 5рянскими, белорусскими и крымскими, изучая их Аневники и записи, мне неизменно приходилось сталкиваться с Фактами, показывающими, как руководители партии заботились n помогали $c$ первых шагов заромдению партизан-

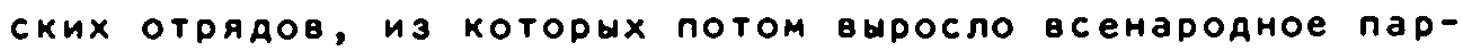
тизанское Авижение. [...] Как неотделимая часть вооруженных сил, в тылу врага Аействовали партизанские отряАн, направляемые Верховным Главнокомандованием по верному пути к победе."

S. 28 "В отряде было восемьсот коммунистов. Из них погибло около четырехсот. [...] И на смену упавши вставали в строй новые и новне коммунисты. Народ питал нашу силу."

"я аумал еще о патронах, пулеметах и о том, как провезти их через Фронт. A партия уmе думает о мире. 0 том, как eго отстоять. Как Украсить нашу родину Авориами, садами... О сиастье народа и его созидательной, мирной мизни."

"Bсе ОнИ тверАО знарт [КОвпакови世], Ито только потому, что партия организовала и повела за собой весь великий советский народ, Аобились ма в борьбе против врага." 
S. 31 "Это было в ночь с 4 на 5 некабря 1942 года. В эту ночь, за полтору тисячи километров на восток от нас, войска Красной Армии под Сталинградом завершали окружение армии Паулюса."

"А 'Сарнский крест' - зто была посильная помощь партизан Ковпака героической Красной Армии, отныне начавшей поворотный путь к великим победам."

"Заяание Правительства, Аанное лично Матвееву, а через

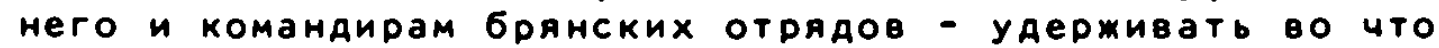
6山 то ни Стало ПарТИзанский Край, УАерживать сейчас Как базу Аля рейдовиков, а в Аальнейшем как крепкий плацАарм Аля наступарщих частей Красной Армии - нужно было выполнить. [...] И этот край станет не только базой Аля многочИсленных разведчиков Красной АрмиИ, но И будет наносИть мощные УАары По врагУ во взаимодействиИ с полками и аивизиями победоносной Красной Армии."

S. 31 f "Скамем Прямо: АО Сталинградской битвы все мы предъявляли счет к Красной Армии. Много Горьких слов било сказано, много ГорьКИХ АУм ПереАумано. ВеАЬ мы Громили немцев по тылам их и шли впереA, а там Ао сих пор только отступали. И зти горькие Аумы как-то выразил наш позт Платон BODOHOKO':

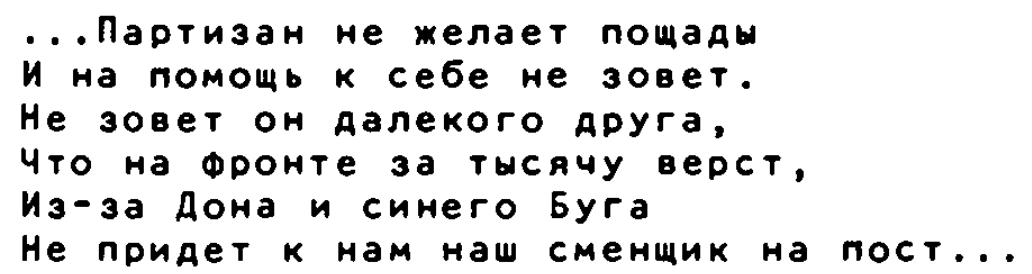

S. 32 "Они оставляли города, села, реки. Оставляли, может быть, и с тяжелым чувством, но все же сзаяи лежала страна, все более наливавшаяся Сталинской волей к победе, и они чувствовали ее. У них был тыл, могучий советский тыл. А мы, - армия без тыла и Флангов, - мы видели лишь горькие результаты отступления, [и знанку его]. Мы видели по-

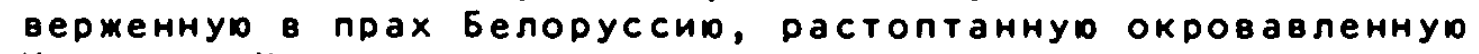
Украину. И еще мы знали мысли И гневные слова одного приказа и больше чем кто-либо Аругой имели право мы, штатские людей, учителя, бухгалтеры, колхозники и музыканты, взявшиеся за оружие, кинуть упрек лодям, отступавшим на восток. Если не все, то многие из нас понимали, что не Своей лихостьо или Особым воИнским талантом мы АобИвались этих частных побед, а тем, что против нас Аействовали самые слабые войска врага, что все свои лучшие силы и ресурсы Гитлер бросил на Краснуо Армио."

"Вот тУт случился со мной большой КОнФуз, который почему-то был расиенен командованием аивизии и Ааже более вшсоким командованием как некое вндамщееся событие, героизм, что ли. Если бы команаир корпуса и начальники политоделов, которые через Аень после зтого случая хвалили нас, понимали по существу, что произошло, им стало бы АСно, पто батальоном Командовал безграмотный в военном Отношении человек, КОтОрнй По своей беспомощности сАелал 
глупость, случайно принесшур временнур удачу. [...] может 6ыть, там томе командовал такой же, как и я, безграмотний офичер."

"Mне, как и многим солаттам, не имевшим тогаa достаточного боевого опнта и плохо знавшим врага, еще непонятая была зта черта тупой немецкой тактики. Через полтора года мы узнали, что '... немиа аккуратны и точны с своих действия, когяа остановка позволяет осушествлять требования устава. В зтом их сила. Немцы становятся беспомонными, когда обстановка усломняется и начинает 'не соответствовать' тому или иному параграфу устава, требуя принятия самостоятельного решения, не предусмотренного уставом. 8 зтом их основная слабосmо."

S. 34 "[... J малодушные командиры, политработники - процент их был не велик, но нам он резал глаза, вонзался острой итлой в сердие, [... j"'

"Потому ли, - повторяо, что 'стратегической смелости' нехватало, или потому, что и в партизанском аеле, неизвестно откуда, завелось местничество и делячество. А нигде так вредно не отражается делячество, как в сельском хозяйстве и партизанской войне."

"Eще и Aругое соображение поиходило в голову. 8озмомно, что посланные на укрепление партизанских штабов военные товарищи механически переносили на наше дело опыт военных армейских операции. Умение создать превосходство сил в нужный момент и в нужном месте - вот ключ военного мастерства. Hо лоди простодушные Аумалт Аоститнуть его арифметическим путем, путем подсчета штыков, автоматов и стволов. [...] Словом, я за алгебру войны и против людей, усколобо подменяриих ее арифметикой. Арифметические наклонности некоторых стоили нам немало крови."

S. 36 "8 партизаны шли добровольчы, романтики были и случайные лоди"

"добровольин и случайные лоди"

"Лихой народ собрался."; "Мы чувствовали себя хозяевами зтого края. Лоди вели себя беспечно и разгульно."

S. 37 "Kогда в отряде лодям бывало особенно скучно, прибегали к старой шутке, которая называлась: 'женить веласа'. Hаходили какую-нибудь старушку и уверяли Веласа, что она в него влоблена. То ли аля смеха, то ли всерьяз, он всег да охотно соглашался и начинал серьезно и настойчиво домогаться взаимности. Чане всего кониалось зто тем, что Bелас ходил с синяком под глазом или с поцарапанным ли4ом."

"- Товарин капитан, почему не приветствуете? - строго спросил он. ...Капитан растерянно посмотрел на неизвестного начальника. Военный Костом, внушительные усы, прекрасная лошадь $и$, самое главное, два трофейных пистолета на поясе и новое немецкое седло - столь редкие трофей в мало воевавших 'лесных' неподвижных отрядах - no- 
казались ему подтверждением высоких полномочий неизвестhoro.

- Прошу прощения, товарищ начальник... - смущенно пробормотал Он.

- Извенения мало, пройдитесь обратно... быстрей, быстрей. Tеперь шагом а-а-рш... - командовал еФрейтор Ленкин оторопевшему капитану. Тот прошел перед ним строевым шагом. Саелав несколько замечаний насиет того, как держать груаь вперед и убирать живот и на каком уровне полагается находиться локто и еще немного погоняв совсем обалдевшето капитана, Ленкин ускакал галопом."

S. 40 "Седьмая рота у нас была притчей во языцех. Народ там собрался какой-то вялый, безинициативный, трусоватый. [...] Что ни бой - так седьмая рота или с обороны убежить, или в наступлении запутается и к кониу боя по своим лупит. [...] В жизни своей ни немецкого, ни мадьярского пулемета не вияели. Аа и то, как его увидишь, когда от нето тикаешь без оглядки. На спине ведь глаз нет."

"По всему было вияно, что хлопиы быстро устаивали именно отрицательные стороны партизанской тизни - өольницу, отсутствие аисииплины."

S. 41 "Нужно было подтянуть вожжи. Отсутствие Ковпака и Руднева сказывалось во всем. Бойцы нахваливали своих командиров, сумевших внеести отряд и дать им передышку, но мы с Мыколой и Васей видели: дисииплина все больше падала то часовой задремал на посту, то бойчн без разрешения уходили в деревно за харчами. За зто нельзя было строго карать в ropax, korá ronoa aушил нас."

"не возьму я ее больше в разведку! Аисииплины не пониMaet!"

S. 42 "Народ наш дорвался до немиев, и здесь меня снова охватил боевой зкстаз. [...] Сам не зная, зачем мне зто нужно, я подбежал к нему, стащил с него сапоги и стал стаскивать амуницио. [...] Koraа я заканиивал зту 'операчио', я услишал, что немец хрипит. Очередь прошла через его груаь, близко от шей. Он хрипел, буато что-то хотел сказать. Володя Лапин закончил подобнуі операцио бистрее и лучше меня."

"Так же, как и в третьей роте, в разведке были люди колоритные, своеобразные и своенравные. Работа разведчика накладывала на зтих людей особые черты. Разведчик всега работает с глазу-натлаз со смертьо. И не уаивительно, что среаи них многие пристрастились к алкоголо. Было, правда, ненаписаное правило - никогда не пить разведке, во өремя выполнения заяания. Виполнялось оно безукоризенно, а за редкие нарушения разведчики разделывались с виновником по-своему и почти без видимого вмешательства командования. Тольковые и лихие разведчики всегда возвращались с разведки с запасом 'ropmuero'. Aoложив о выполнении, дома 'заклаянвали'. Мы хотя и не особенно поощряли зто, но и не мешали им. Ну, чем еще могли мы отблагодарить наших самоотверменных и бесстрашнuх лодей за их неоченимую работу?!" 
S. 45 "Завернув штанию, он занимался повлей блох. - Эй тш, парашотист! Кенчай охоту! - звонко крикнул Михаил Кузьмич. He ебоашая на Мишу внимания, флегматик велал сосреяоточенне cвoе aeno. - Бросай oxоту!"

"И тут я почувствовал, ито авторитет командира не Аействует больше на моих бойцов."

"Побшвав несколько ночей Под метояическим обстрелом артиллерии, можно сойти с ума."

S. 46 "Фашисты часто достигали своей чели."

"Фашистн иногаа Аостигали своей чели."

"Грязь, дожаи и бездорожье вмрывали у немиев Фактор времени. Русская осень цеплялась, липла к кованым немецким сапогам, зубчатым колесам немецких автомашин и мешала им подвигаться вперед. Русская земля давала нам виигрыш времени, чтобн мы могли перегруппировать сөои силы, расстроенные внезапным нападением врага."

S. 47 "Позже приходилось мне встречаться с чересчур строгими Лодьми, Которне за Самнй Факт Пребнвания человека во вражеском тылу взыскивали строго и безжалостно. Случалось, उти беспощадные $K$ аругим лоди сами, Попав в аналогичные условия, оказывались трусами, а иногда и предателями."

"Hе Факт пребшвания в тылу, а то, как ты вел себя там [.... ]"

"Пусть придут на суаилише народа пленные, беженцы, воины и рабочие Урала, пусть придут да бежавшие до АКтобин-

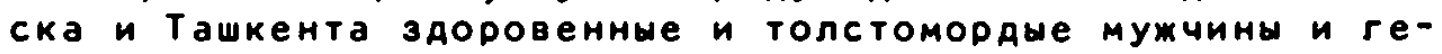
роические лоди, ПоА Открытым небом на морозе делавшие танки.

ПУсть Приаут И ответят на вопрос: 'Что же ты, Именно тU,

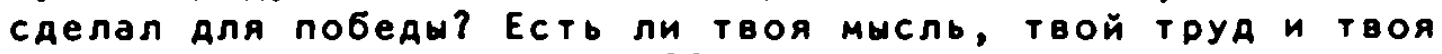

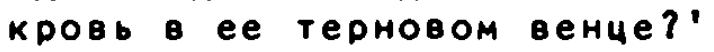

ПУсть Хотя бы ПереА своей совестьо ответят на этот воnpoc."

S. 48 "Что же ты, именно тн, саелал Аля победн"

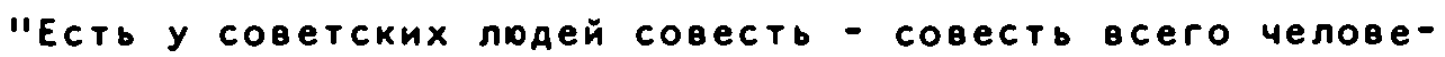
чества - Партия большевиков... Муарая, строгая, Животворящая сила истории. Не дает она поблажек ни нытикам, ни маловерам, не прощает сосокаощих, вдохновляет миллионы передовшх людей и перевоспитывает отсталых."

S. 49 "В рейдовом отряде проблема раненшх всегда является, пожалуй, Самой сложной и труаной проблемой."

"Бросать раненых нам казалось недопустимым. Это могло ПовреАить Самой организации и Повшшенио боевой АИсииплины. [...] Сами раненые просили пристрелить их, так как они өияели, Какой обузой они являотся Аля товарищей."

"g в своей новой должности руководил разведкой, может, нёеб̆чно, не по писанHUM правилам." 
S. 49 "ПОмно, РУАнев, ПОАПИСЫвая ОАнаЖАЫ ПрОтокоЛЫ АОПрОса И Обвинительные закльчения разной публики сказал мне: - Рука устала. Hе могу больше. Знаешь что - мы доверяем тебе. Hе носи больше ко мне зти дела. Решай сам. А если уже Что-нибУАь очень запутанное или сломное, Аавай мне или командиру. Ковпак согласился с мнением комиссара. Это решение взвалило на меня большуо тяжесть ответственности, Оно стоИло мне многИХ часов тяжелого раздумья. Признарсь, к Такой Аеятельности я не был подГотовлен всей своей предыдущей жизньD."

S. 50 "Kогаа-нибуаь \& расскажу об этой работе болеe подробно. Очищать земль от всякой нечисти всегAa не легко. Сейчас я знар одно: никакой следователь обычного типа не мог бы справиться С такой работой. Она требовала острого глаза и, самое главное, умения разбираться в людях. Я рубил лес, летели щепки, НО Совесть моя перея народом ииста. ЕАИнСтвенной мерой бЫло: Что сделал И чем способен

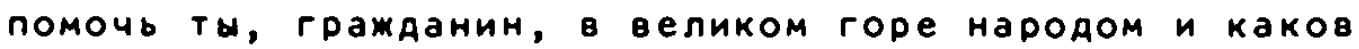
путь твоего корабля в этом море ИСПнтаний И СТраданий человеческих. Не словами, а делами отвечай мне на зтот вопрос. A имею право, имею власть так спрашивать тебя, потому что я солаты своего народа."

"Кроме того, я никак не мог привыкнуть К новой обязанности подписыват бумаги на расстрел лодей."

"Tеперь момно было приступить к изученир села. Несколько баб выглянуло через перелазы. Вслед за ними осторожно вышли три-четыре мужика: ОАИн Старик, оСтальные - молоAне парни. Вскоре перекреста образовалась небольшая толпа. Молча, С жадным Любопытством ГЛядят на Авижение коЛонны. Бабы взАнхают И О чем-то шепчутся. Мужики моЛчат, никакими словами не выражая ни своих чувств, ни своих мнслей."

"[...] но были и такие, что меж собор говорили: Не было 6 Ковпака, не было 6 и немцев в нашем районе. Всега за ним Хвост Карателей тянется. Ему что? Он выкрутится, а нас гонарт, гоняот... Они по-своему были правы."

S. 51 "Немцы старались саелать так, पтоб партизанам нужно было

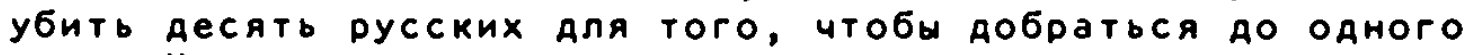
немиа.".

"лохмотья контрреволоции и кулачье"

S. Sl "Как и подобало гестаповцам, они стали бороться против грозно нараставшего ПартизанскоГо Авижения методом Провокачии, разииганием национальных конФликтов. вначале удалось."

"Из сотен украинских и польских начионалистов, С которы-

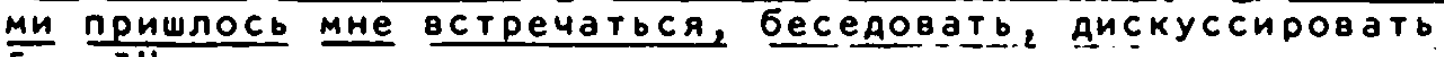
[.... $]^{\prime \prime}$

"Мы требовали, чтобы цепь националистов очистила дорогу и не мешала нам продолжать путь, они настаивали на том, чтобы мы изменили маршрут. Муха, видимо, слышал о нас многое и, как мне показалось, не был враждебно настроен." 
S. 54 "Речь Мухи была откровенной и убедительной, И что-то зтом парне, глаза которого блестели ненавистыр, подкупало."

S. 56 "Патриотизм бнвает разный: все стремятся К уничтоженир

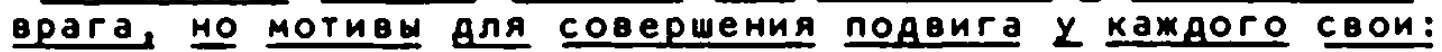

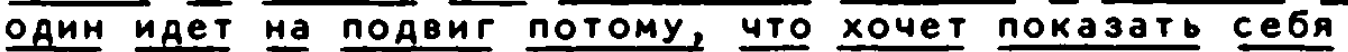

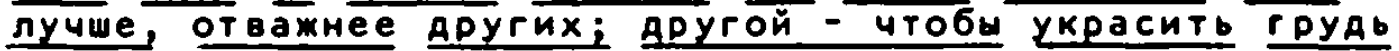
лишним орАеном; многие- Потому Аисииплины впиталось в характер, стало их второй натурой.

"Надо делать так, Как народ хочет"

S. 57 "Пренебрежение к истории партизанских войн Обходится Аорого. Ааже лояи, посвятившие себя военному делу, не знаоr eе, a в програмmах военных школ партизанское дело даwe не упоминается."

"Если дела партизан кутузовских времен были лишь славным Прошлым нашего народа, то с опытом Партизан Гражданской войнн нас связывали крепкие траяиции, живне люди, близкий и во многом еще не устаравший опнт. Как правило, в Перв世й ГОА ОтечественнОЙ ВойнН Успешно воевал тОт Парти-

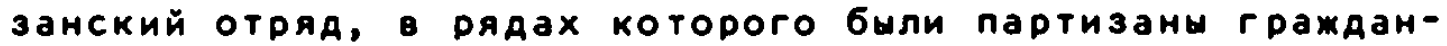
ской войнн. Нам в зтом отношении повезло. Во главе отряда был Ковпак, Партизанивший еще в 1918 году против кайзеровских войск и гетманиев. Ковпак, живо помнивший не только героику, но и способы действий Пархоменко, Чапаева, КотовскоГо. Руанев многое знал о борьбе АальневоСточных Партизан. В нашем отряде Аействовал краснознаменец - военком Гражданской войны Михаил Иванович Павловский, Партизанивший Под командованием Николая Шорса. ДеА Мороз - Коренев, Кучерявский, Кульбака и многие Аругие рядовне Партизан世 Аействовали в КраснопартизанскиХ ОтряAах и против кайзеровских войск, И против синежупанншх гайдамаков, гетмана и Петлорн, и против Аеникина, и против бана Махно.

Часто простая, заяушевная беседа у костра преврашалась в импровизированнуо Лекиио, в которой оГненное слово ветерана Подкреплялось заяушевным объяснением Правил, законов, Обнчаев, Уловок, ХИтростей Партизанской войнн. И зто товарищеское общение с лодьми, которые так же близко, как все мы знаем Аруг Аруга, знали и общались С легенАарным Василием Ивановичем Чапаевым И Аимитрием Анарееөичем Фурмановым, $C$ храбрейшим среди храбрых Григорием Ивановичем Котовским, С выдариимся Героем-партизаном Пархоменко, было и школой и закалкой Ауха и вселяло уверенность в непобедимость нашего дела.

Эти ветераны щорсовцы и чапаевцы сближали нас с славным прошлым 6орьбн за револоцио. И Ааже тем, которне родились Гораздо позже, казалось, Ито они сражартся плечо в плечо в одном стров и с Шорсом, и с Котовским, и c Yanaевым, и с Сергеем Лазо."

S. 58 "Раненый пожилой врач, загребая одной Грушаться в воду. Я хотел ему помочь, рукой, начал поплотник блиме... В это оремя еще одна ПОАТОняя СвОЙ aвtomathas oчepeab 
полоснула nо воде, И Он, бросив сопротивляться, но, Продолжая дершаться на воде, сказал: 'Не надо... Спасайтесь сами, коллега... и запел старинную, традиционную песно pycckих cryaentoв: ..."

S. 62 "цепкая память старика [Kовпака] схватила каждое слово, кажднй жест и паузу товарища Cталина."

"[...] каждый партизан знал, что боевое задание Ковпаку давал сам Сталин, и это воодучшевляло лодей, накаляло их енергией."

"[...] названный партизанами Ковпака сталинским - по имени человека, вдохновившего их на этот славный боевой подаит."

"Товарищ Сталин прозорливо наметил дальнейший путь развития партизанской войны."

"[...] направляем гением Верховного Главнокомандующего товарища Сталина [... ]"

"Вещие слова товарища Сталина, сказанные им 3 иоля 1941 гояа, подхватил весь советский народ, поднявшийся в тылу opara на беспошаднуо войну. И зти слова громом партизан

"Оказывается, это по личному приказу товарища Сталина летел специальный самолет к Черному лесу [...]"

"Как символ нашего правого дела, в часы смертельной onachости народ идет нам на помощь с именем Сталина cepaue."l

"-... Я обо всем доломил товарищу Сталину: как начали партизанить, Как ворем, как с народом связь Аермим. На все вопросы ответили. [...] Понимаете, хлопиы, трохи я перея иим заволновался. [...] Партизны сидели затаив дыхание. [...] Как же он [Сталин] знал зто? - восхищенно спросил володя Шишов. - Такой человек на штоб не знал, ответил Ковпака Коренев. [...] Вот человек! Так наперед все знать..!"'

S. 63 "И светлый пример товарища Сталина водил нас в 6ой."

S. 64 "[...] к сталинскому рейду" - "[...] к рейду на правый

"[...] сталинский рейд

$[\ldots]^{\prime \prime}$

"[...] во время сталинско- - "[...] во время рейда за ro рейаa" Aнепр"

"[...] cranинское задание [...]"; "[...] no nриказу то-

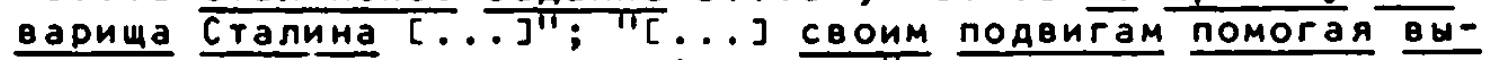
полнять приказы товарища Сталина.

"[...] по сталинскому заяанио"; "[...] своим подвигам помогая вuпонять приказы товарища Сталина."

S. $64 /$ "По заданир товарища Cra65 лина [...]

"в ответ на призыв товарища Сталина [ ]"

"Товарищ Сталин [...]"

"[...] товарияем Сталиным

[...]
- "По заданио Craвки [...]"

- "в orвer на призыв партии [... $]^{\prime \prime}$

- "Центральный комитет партии [...]"

- "[...] npaвnteльством $[\ldots]^{\prime \prime}$ 
"[...] reнием Сталина"

"[... товарищ Сталин

$[\ldots]_{11}$

"... no npukazy товa-

рища Сталина [...]"

"[...] o Cranине [...]"

S. 65

"[...] великой армии Ста лина"

"[...] сталинская пехота

$[\ldots]^{\prime \prime}$

"[...] сталинская артил-

лерия $[\ldots]^{\prime \prime}$

"[...] сталинские танки-

cты $[\ldots . .]^{\prime \prime}$

"[...] в зпоху Ленина и Сталина."

"[...] в жизнь бессмертинх идей Ленина = Сталина."

"[...] за дело великого Ленина под водителиством СталиHa. $" 1$

"Ведь марксизм, как учил Ленин, как учит нас товарищ Cталин."

S. 66 "Еще в гражданской войне 1917 - 1920 годов руководимое Лениным и Сталиным партизанское движение [... $]^{\prime \prime}$

"Ене в гражАанской войне 1917 - 1920 годов руководимое партией партизанское движение [... ]"

"Единственной Аирективой 6ала речь товарища Сталина от 3 иола 1941 года. И ее хватило им всо войну. Как по матнитной стрелке, указнварщей путь Корабло, дершали они курс на беспонадное истребление врата."

"[...], a от работников партизанското штаба узнать некоторые интересные детали и, главное, познакомиться с историческим приказом товарища Сталина, определившим чели и заяачи партизанского движения советского народа."

"в своей исторической речи от 3 иоля 1941 года товарищ Сталин говорил: ' ... В занятых врагом районах нужно созаавать партизанские отряды, конные и пешие, создавать Аиверсионные группы Аля борьбы с частями вражеской армии, Аля разиигания партизанской войны всоду и везАе, Аля взрнва мостов, АОрог, Порчи телефонной и телеграфной связи, пояжога лесов, Склаяов, обозов. В захваченных районах создавать невнносимне условия для врага и всех его пособников, преследовать и уничтожать их на каждом wary, срывать все их мероприятия. '"

S. 67 "Bот почему и партизанами руководит лично товарищ Сталин. Вожаь партии, вожАь войск и вожАь народа. Вот Как построено это дело... На Украине руководит ими Никита Сергеевич, в ленинграде - товарин панов. А товарин Ворошилов - главком партизанский."

S. 70 "По представлених начальника Центрального штаба партизанского движения при Craвке Bерховного Главнокоманду- 
омего товарищем Сталиным 31 августа 1942 года были приняты руководители партизан [... ]"

"Матвеев привез в партизанский край полный текст прика308 И АОкладов товарища Сталина."

"В своем первомайском приказе Сталин приравнял нас, партизан, к воннам Красной Армии."

S. $7 \int$ "Книжка была Постоянным спутником Руанева. Ленин и Сталин, Тургенев и Толстой, ГоГоль И ГОрький - вот с чем приходил комисСар К красноФлотиу. С Февраля 1932 года РуАнев - КомисСар и начальник Политодела Декастринского укрепленного района на Дальнем Востоке."

"я сел за труды Ленина и Сталина."

"Часто раздавался звонок, и голос товарища Сталина слушался в трубке: 'Доложите, гае Kовпак?' 'Как дела Kовпака?'; 'Что нового известно о суавбе Pуанева?'."

"Я впервне вияел зтого, всей советской стране знакомого, человека. Усталое, усталое личо... розовые щеки...

крепкие руки. Задумчивый взгляд давным-Аавно невысыпавшихся глаз."

S. 72 "А в это время в звездном Фронтовом небе, затребая лопаСтями винтов морозный воздУХ, Летел К Ковпаку самолет, посланный Хрущевым."

"Oказывается, это по личному приказу товарища Сталина nетел специальный самолет к 4 ерному лесу..." 
ANHANG
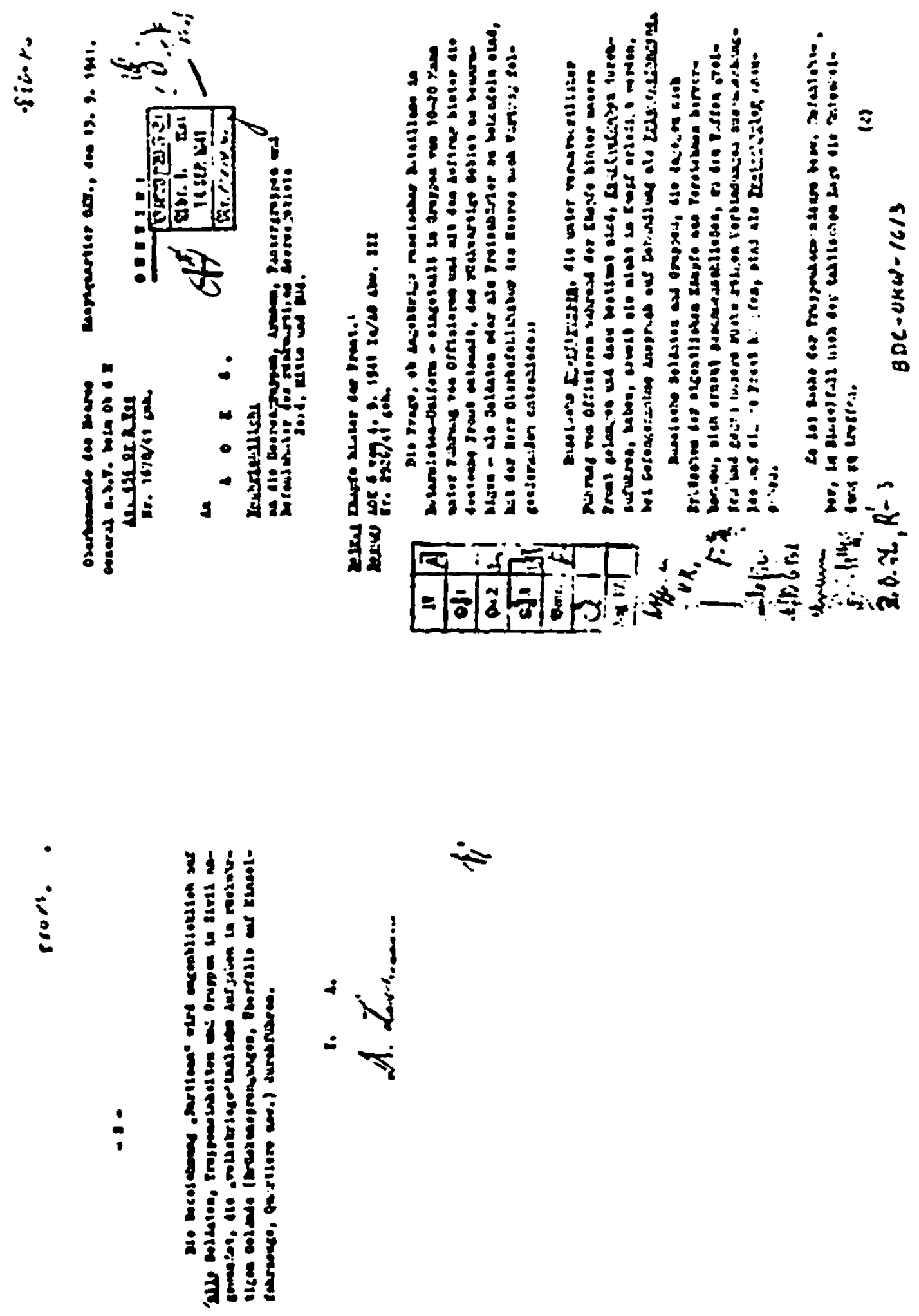


\section{BIBLIOGRAPHIE}

\section{Primärliteratur}

Versigora,P.P. \& Ljudi s listoj sovest'ju. In: Znamja. Moskva 1945. 8. 1946. 4. 5/6. 7 .

- Karpatskij rejd. In: Zvezda. Moskva/Leningrad 1950. 3.

4. 5 .

$$
\begin{aligned}
& \text { - I Ljudi s Eistoj sovest'ju. Moskva } 1948 . \\
& \text { - I Ljudi s Eistoj sovest'ju. Moskva } 1959 .
\end{aligned}
$$

\section{Sekundärliteratur}

\section{Nachachlingswerke}

Bol'saja sovetskaja énciklopedija v 74 tomach. Moskva 1949ff.

Kratkaja literaturnaja enciklopedija v 7 tomach. Moskva 1962 - 1972.

Russkie sovetskie pisateli prozaiki. Blobibliograficeskij ukazatel'.

Moskva/Leningrad $0 . J$.

Sowjetsystem und Demokratische Gesellschaft. Eine vergleichende Enzyklopädie. 6 Bände. Freiburg/Basel/wien 1968 - 1972. Hrsg. C.D.Kernig.

\section{Lit teraturges $\underline{\text { ch }}$ ichten}

Hubner,P. : Literaturpolitik. In: Kulturpolitik der Sonjetunicn. Stutt-

gart 1973. Brsg. O.Anweller, K.-H.Ruffmann.

Kasack,W. : Lexikon der russischen Literatur ab 1917. Stuttgart 1976. Istorija russkoj sovetskoj literatury v 4 tomech 1917 - 1965. Moskva

1967 - 1971. Hrsg. A.G.Dement'ev, L.M.Pol jak, L.I.Timofeev.

Russische sorjetische Literatur im tbertlick. Leipzig 1970. Hrsg. H.Jün-

ger.

Slonim,M. : Die Sowjetliteratur. Eine Einführung. Stuttgart 1972.

Steininger, A. : Literatur und Politik in der Sowjetunion nach Stalins

Tod. Wiesbaden 1965.

Struve,G. : Geschichte der Sowjetliteratur. München 0.J.

Guellien zur Part

Armstrong,J.1. : Soviet partisans in World War II. Madison 1964.

Bydkov,L.N. : Partizanskoe dvizenie v gody Velikoj Oterestvennoj vojny

1941 - 1945. Kratkif ocerk. Moskva 1965. 
Görlitz,W. : Der Zweite Heltkrieg 1939 - 1945. 2 Bände. Stuttgart 1952. Hesse,E. : Der sow jetrussische Partisanenkrieg 1941 - 1944 im Spiegel deutscher Kampanweisungen und Befehle. Göttinger philosophische Dissertation. Zürich/Frankfurt 1969. Erschienen als Studien und Dokumente des Zweiten Weltkrieges. Band 9. Zürich/Frankfurt 1969.

Istorija Velikoj Otedestrennoj vojny Sovetskogo Sojuza v 6 tomach 1941 1945. Moskva 1960 - 1965. Rrsg. Institut Marksizma-Leninizma pri CK KFSS. Otdel istoril Velikoj Otelestvennoj vojny.

Karov,D. : Partizanskoe dvižnie v SSSR v 1941 - 1945 gR. Mjunchen 1954. Kolmsee,P. : Der Partisanenkampf in der Sowjetunion. tber Charakter, Inhalt und Formen des Partisanenkampfes in der UdSSR 1941 - 1945. OstBerlin 1963.

KornejZuk, A. Ukrainskie partizany. In: Slavjane. 1942. 1. Kühnrich, H. Der Partisanenkrieg in Europa 1939 - 1945. Ost-Berlin ${ }^{2} 1968$. Ponomarenko,P. : Partizanskoe dviǩenie v Velikoj Otećestvennoj vojne. In: Bol'ševik. 1943. 13.

Rauch,C. von : Geschichte der Sowjetunion. Stuttgart 1969.

Redelis,V. : Partisanenkrieg. Entstehung und Bekämpfung der Partisanenund Untergrundbewegung im Mittelabschnitt der Ostfront 1941 bis 1943. Heidelberg 1958.

Sovetskie partizany. Iz istorii partizanskogo dviženija $v$ gody Velikoj Otečstrennoj vojny. Moskva 1961.

Stalin,J. : Uber den Großen Vaterländischen Krieg der Sowjetunion. Moskau 1946.

Stalin spricht. Die Kriegsreden vom 3.Juli 1949 bis zum 9.Mai 1945. Stockholm 1945.

Stariśkov, $M$. : Partijnye organizaci $\mathbf{v}$ tylu vraga. In: Propaganda i agitacija. 1943. 10.

Telpuchovskij,B.S. : Die sowjetische Geschichte des GroBen Veterlëndischer Krieges von 1941 - 1945. Frankfurt/M. 1961. Arsg. A.Hillgruber, H.-A. Jacobsen.

Verśigora,P.P. : Brat'ja po oruziju. O narodnych formach voorużennoj bor'. by russkogo i ukrainskogo narodov. In: Oktjabr'. 1954. 3. 4. 5. Werth,A. RuBland im Krieg 1941 - 1945. 2 Bände. München/Zürich 1965. 
Kinkler,K. : Die Partisanenkriegführung. Mainzer juristische Dissertation. Mainz 1953.

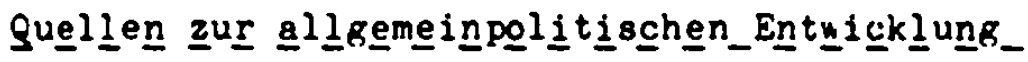

Betell,N. : Poslednjaja tajna. In: Kontirent. 1975. 4. 5. 6. 7. Deuerlein,E. : Deutschland nach dem 2weiten keltkrieg 1945 - 1955. Konstanz 1964 .

Erfurt,W. : Die sowjetische Deutschland-Politik. Eine Studie zur Zeitgeschichte. EBlingen 1959.

Leonhard,W. : Kreml ohne Stalin. Köln 1959.

Meissner,B. : RuBland, die Westmächte und Deutschland. Die sonjetische Deutschlandpolitik 1943 - 1953. Abhandlungen der Forschungsstelle für Völkerrecht und Ausländisches C̈ffentliches Recht der Universitet Hamburg. Band 5. Hamblirg 1953.

- : RuBland unter Chruschtschow. Porschungsinstitut der Deutschen Gesellschaft für Auswärtige Politik e. V. Band 15. Miinchen 1960. - RuBland ir. Umbruch. Der Wandel in der Herrschaftsordnung und sozialen Struktur der Sowjetunion. Dokumente und Rerichte des Europa-Archivs. Band 9. Frankf./M $195 i$.

- Die Kommunistische Partei der Sowjeturion vor und nach dem Tode Stalins. Parteiführung, Parteiorganisation, Parteiideologie. Dokumente und Berichte des Europa-Archivs. Band 12. Frankf./M 1954.

- : Das Ende des Stalin-Mythos. Die Ergehnisse des 20. Parteikongresses der Kommunistischen Partei der Sonjetunion. Parteiführung Parteiorganisation - Parteiideologie. Dokumente und Berichte für Europäische Politik und Wirtschaft. Frankf./M 1956.

Noack,P. : Deutsche suBenpolitik seit 1945. Stuttgart/Berlin/Köln/Mainz 1972.

Sapiro,L. : Kommunističeskaja partija Sovetskogo Sojuza. Firenze ${ }^{2} 1975$. Schmitt,W.E. : Krieg in Deutschland. Strategie urd Taktik der sovjetrussischen Deutschlandpolitik seit 1945. Diisseldorf 1961.

Solzenicyn,A. : Archipelag Gulag. Paris 1973.

Weingartner,T. : Die AuBenpolitik der Sowjetunion seit 1945. Eire Einführung. Studien zur Auswärtigen und Internationalen Politik 8. Disseldorf 1973. 
Sonstige_Quellen

Al'tman,I. : Dramaturgija v 1947 godu. Ins Oktjabr'. 1948. 3.

Bogoljubov,K./Rjakin,M. I Ljudi s Elstoj sovest'ju. In: Literatura $v$

skole. 1947. 4 .

Brovman,G. : Oblik geroja. In: Znamja. 1947. 8.

Bulgakov, M. : Master i Margarita. Frankf./M 1969.

Cakovsk1j,A. : Obidnaja snischoditel'nost'. Ins Novyj mir. 1948. 5.

Doltrieva,C. : Tribuna Xitatelja. In: Znamja. 1947. 4 .

Dmitrevskij,V. \& Petrovid 1 ego kniga. In: Ogonek. 1946. 12.

Fadeev und die Rolle der Partel. In: Ostprobleme. 1953. 8.

Grüner,K. \& Das Problem des positiven Helden in der Sowjetliteratur.

In: Sowjetstudien. Institut zur Erforschung der UdSSR. 1963. 15.

Hubner,P. Zensur in der UdSSR I. Berichte des Bundesinstituts fur ostwissenschaftliche und internationale Studien. Köln 1970/71.

Im Verband der sowjetischen Schriftsteller der UdSSR. Ins Ost-Probleme. 1954. 25.

Karavaeva, A.skniga o Karpatskom rejde. In: Literaturnaja gazeta. 1951. 2. Kaverin,V.A.:Das Ende elner Bande. Aus dem Russ, von M.Wiebe. Mit einem Nachwort von W.Kasack. Frankf./M 1973.

Komissarževskij,V. Celovek na scene. Zametki režlssera. In: Novyj mir. 1952. 10.

Korobov, L. : Soldat svoego naroda. In: Literaturnaja rossija. 1963. 27.

Kosticyn, A. Memuary geroev narodny vojny. In: Pogranienik. 1946. 23/24.

Kuznecov,A. : Babij Jar. Aus dem Russ. von A.Kaempfe. München/Zürich/wier 1970.

Laureaty Stalinskich premif $2 a 1946$ god. In: Znamja. 1947. 8.

Nel'a,S. Idejno-chudozestrennye puti sovetskoj prozy. In: Znamja. 1947. 6.

Prochodov,A.: Pođemu ne ustranjajutsja nedostatki knigi pri ee pereizdanijach. Ins Kul'tura i Zizn'. 1948. 11.

Raddatz,J.F. : Marxismus und Literatur. Eine Dokumentation in drei Bänden. Hamburg 1969.

Ruhle,J. : Literatur und Revolution. Die Schriftsteller und der Kommunismus. Köln/Berlin 1960. 
Savel'ev,P. : Ljudi s distoj sovest'ju (Karpatskij rejd) P.Verłigory.

In: Novyj mir. 1951. 4.

Sinjarskij,A. (Terc,A.) : Cto takoe socialisticeskij realizm. Fantastileskij mir Abrama Terca. 0.0. 1967.

Sinickij,A. : Soldaty armil mira. In: Komsomol'skaja pravda. 1950. 52.

Tarasenkov, A. : Ljudi s cistoj sovest'ju". In: Druzba narodov. 1947. 16.

Tarasenkov, A. : O nekotorych proizvedenijach sovetskoj voennoj prozy. In:

Propagandist 1 agitator. 1948. 5.

Trofimenko,P. : Novoe izdanie chorosej knigi. In: Novyj mir. 1952. 7. Usević,E. : Ljudi s Eistoj sovest'ju. In: Znamja. 1947. 1.

Volkov,S. : Ljudi s distoj sovest'ju. Ins Voennyj vestnik. 1946. 16. Voron'ko,P. : Celovek s čistoj sovest'ju. In: Novyj mir. 1963. 4. 